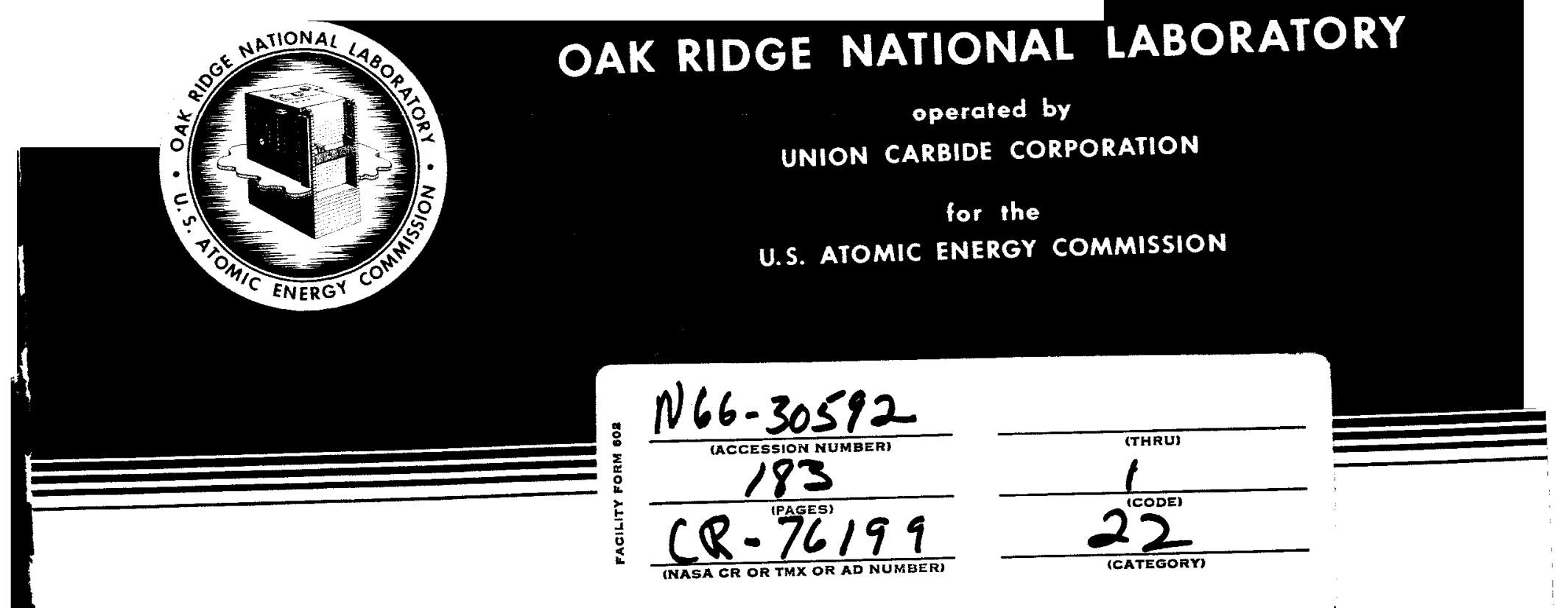

\title{
ABSTRACTS OF DIGITAL COMPUTER CODE PACKAGES ASSEMBLED BY THE RADIATION SHIELDING INFORMATION CENTER
}

\author{
Betty F. Maskewitz
}

Note:
This Work Partially Supported by
NATIONAL AERONAUTICS AND SPACE ADMINISTRATION
under Order R-104
and
DEFENSE ATOMIC SUPPORT AGENCY
under Order EO-804-66

RADIATION SHIELDING INFORMATION CENTER 
This report was prepared as an account of Government sponsored work. Neither the United States,

A. Makes any warranty any person acting on behalf of the Commission:

completeness, or usefulness of the information or implied, with respect to the accuracy, any information, apparatus, method, information contained in this report, or that the use of privately owned rights; or

B. Assumes any liabilitios

any information, apparatus, with respect to the use of, or for damages resulting from the use of As used in the above "person octinged, or process disclosed in this roport.

contractor of the Commission, orting on behalf of the Commission" includes any employee or or contractor of the Commission, employee of such contractor, to the extent that such employee provides access to, any information pursuant to of such contractor prepares, disseminates, or or his employment with such contractor.

Copies of this document are available from

\section{RADIA TION SHIELDING INFORMATION CENTER OAK RIDGE NATIONAL LABORATORY \\ P.O. BoX X \\ Oak Ridge, Tennessee 37830}




\section{ACKNOWLEDGMENTS}

The collection and dissemination of the information contained in this book of abstracts represent the work of many people. We are grateful to the code contributors, without whom there would be no computer code collection; to the report authors, who tried very hard to put into words all the information necessary to the understanding and successful use of a complicated tool; to the USAEC, to NASA, and to DASA, for their encouragement and their financial support in the RSIC programs.

It is a pleasure to acknowledge the contributions of other members of the RSIC staff. The writing of the code package abstracts is a continuing effort. Betty L. McGill assists in every phase of this effort: doing research for material, writing, editing, and proofreading. Hemma E. Francis and Henrietta R. Hendrickson of the Central Data Computing Facility (CDPF) and Nan W. Watts of the ORNL Computer Facility (ORNL-CF) verify the accuracy and completeness of that part of the abstract which describes the hardware, the software, and the contents of the code package. Jewell R. Ellis, in addition to many other duties as RSIC secretary, types and assists in editing, proofreading, and in expediting printing and distribution.

R. G. Alsmiller, Jr., and Frances S. Alsmiller give valuable advice in connection with abstracting the space and accelerator shielding code packages. And, finally, S. K. Penny, RSIC Director, and D. K. Trubey, staff member, are always available for consultation and see to it that I do not go too far astray in describing the nature of the problem solved and the method of solution in the code abstracts.

Betty F. Maskewitz

RSIC Codes Coordinator 
PAGE NO.

Preface ... . . . . . . . . . . . . . . . vii

RSIC Abstract Format . . . . . . . . . . . . . . . . $x i$

Sample Cover . . . . . . . . . . . . . . . . . . $x V$ Alphabetic and Numeric Index xvii Index by Calculational Techniques . . . . . . . . . . . xix Code Package Listing . . . . . . . . . . . . . . . . . xxiii Computer Code Package Abstracts

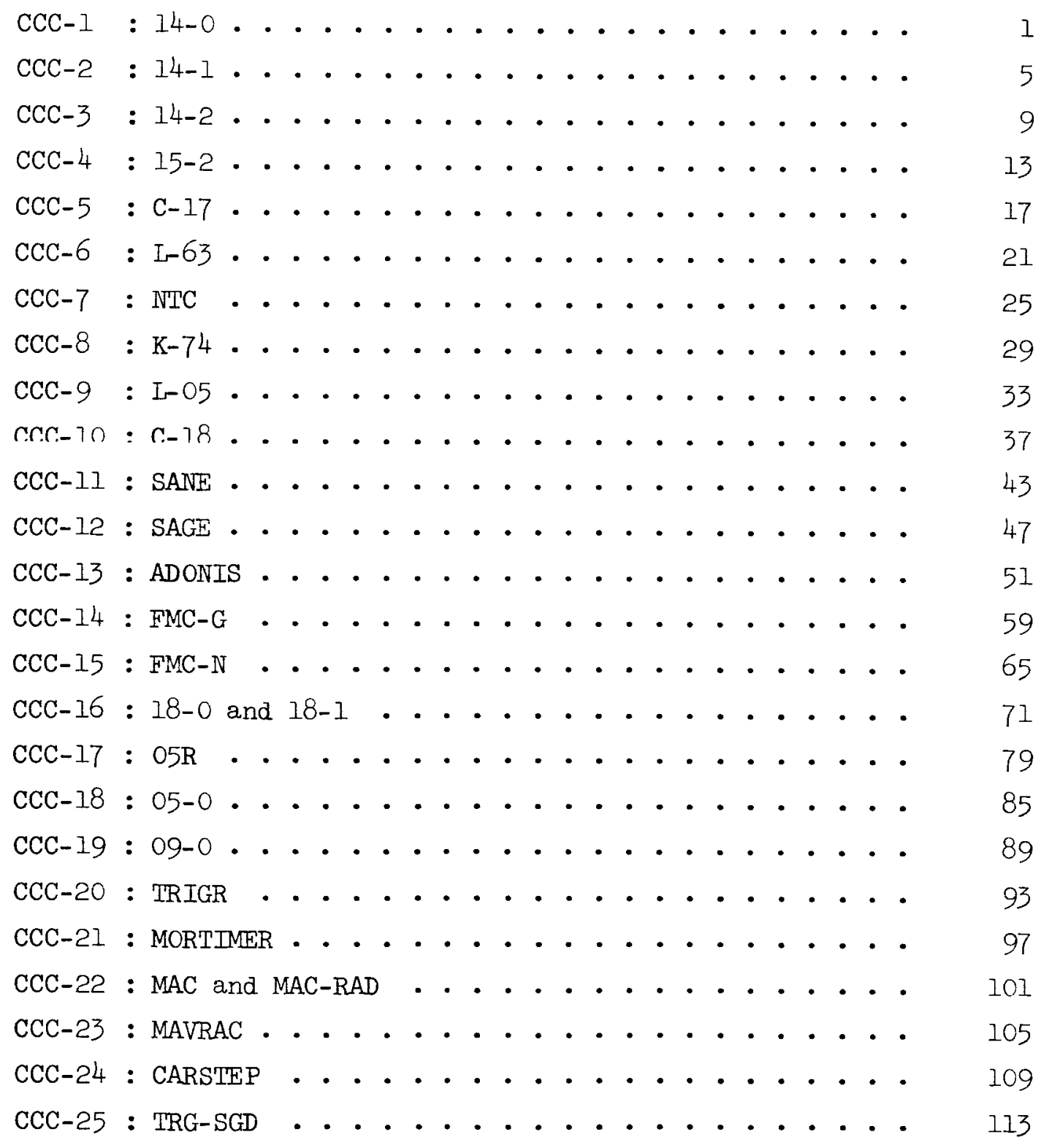


PAGE NO.

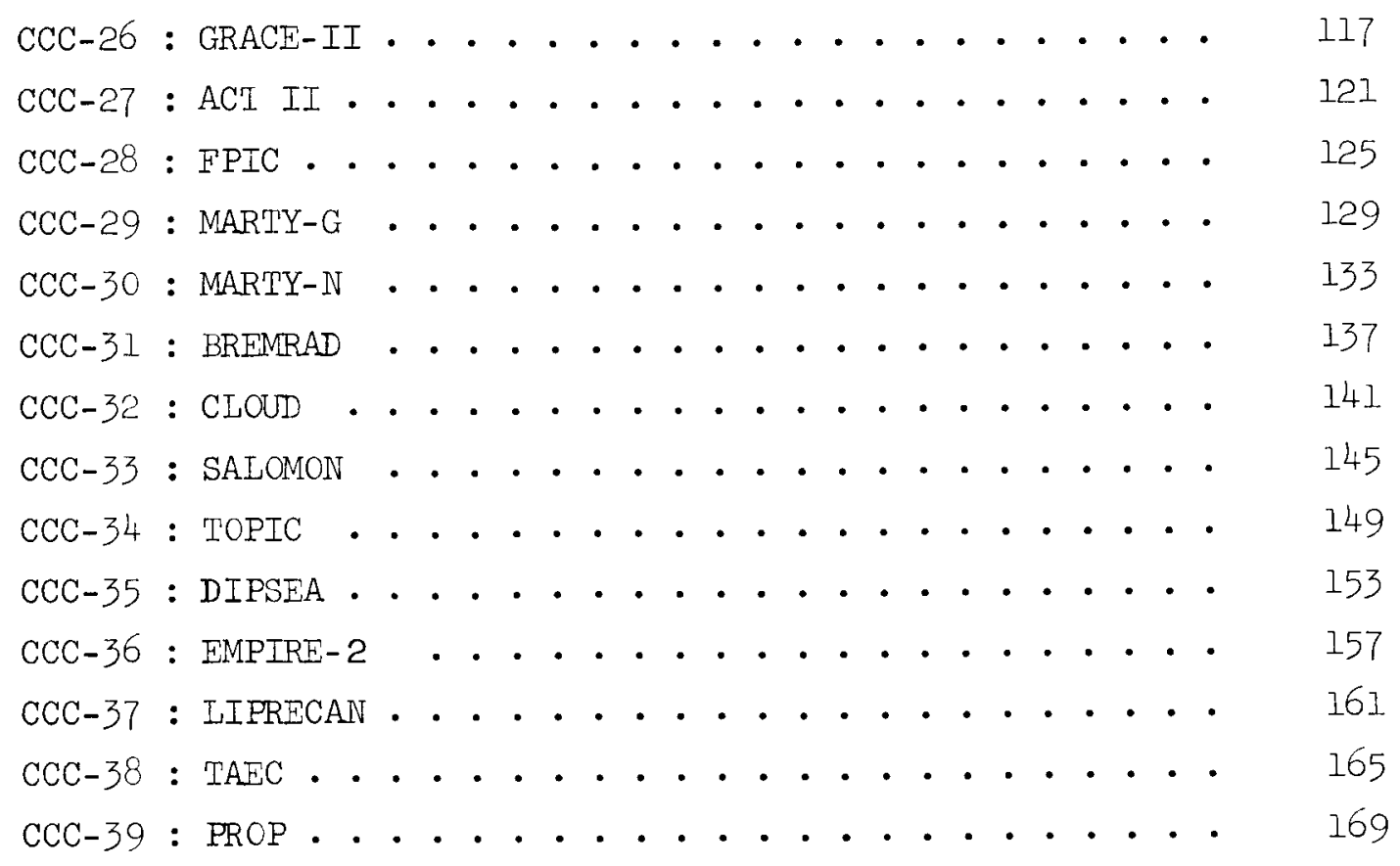




\section{PREFACE}

The term "code package" was coined by RSIC to describe a miscellaneous grouping of materials which, when interpreted and used correctly in connection with a digital computer, enables the scientist-user to solve technical problems in the area for which the material was designed. In general, an RSIC "code package" consists of: (a) written material - reports, instructions, data sheets, listings of data and any other useful material; (b) other materials - IBM card decks, or, more often, a reel of magnetic tape on which the IBM card decks (source and binary), sample problem input, including any available libraries of data, and the BCD output from the sample problem are written. Not only is the main code of interest included in the package, but any auxiliary routine which has been made available to RSIC is also included.

There are many, and varied, opinions in circulation concerning the use of the words "code" and "program." The RSIC definition of each may be helpful in reading the abstracts of the code packages. The word "code" is used to denote the inert set of instructions and data, whether present as cards, or tape, or as a machine listing, which together make a logical design for solving a problem on the computer. The word "program" is used to describe the process of problem-solving. It may be used to denote the overall process of designing a code and the individual doing the work is usually called a "programmer." It may be used in the process of problemsolving to denote the actual processing of data using the code.

The abstract format chosen by RSIC grew out of the need to adequately describe the code package. Care was taken to make the format include all of the information required by the formats of the Argonne Code Center and the ENEA Computer Programme Library.

The main purpose of the abstracts is to give to a potential code user several criteria for deciding whether or not he wishes to use the code. In many cases, there may be significant gaps in the information given. The abstracts will be revised or updated as needed. The reader is urged to bring errors or omissions to our attention.

The abstracts included in the initial distribution were written and edited by members of the RSIC staff. In a few instances, the contributor supplied an abstract which was very useful. Ideally, the abstract should be written by individuals at the contributing installation, leaving only 
the job of editing to the RSIC staff. A copy of the RSIC format is included to be used as a guide for this purpose.

The loose-leaf notebook covers were chosen for practical reasons. From time to time, new abstracts will be issued, and existing ones will be updated, corrected, modified or deleted. The code contributor, or any other volunteer, is invited to write to RSIC suggesting any desired change. Such changes, if coming from any other source, will be cleared with the contributor of the code.

The RSIC staff is particularly anxious to note our contributors properly and to give credit, whenever merited. It is hoped that any lapse will be called to the attention of the Codes Coordinator.

When a code is to be placed in the RSIC collection the contributor is asked to designate an individual familiar with the programming, operation, and data preparation to be available to answer questions. If the code is very complex, or if several codes are being placed in the collection at a given time, RSIC requests that a briefing be given to members of the staff. This is ideally in the form of an informal workshop held at the contributing installation.

When codes are received by RSIC, they are put into the RSIC routine checking process. When fully processed, the codes are packaged, assigned a CCC-number and an abstract is written. The distribution of an abstract indicates that in the code package described the codes are operable, the sample problems having been run by the RSIC staff.

The RSIC collection may include computer codes which, for various reasons, have restricted distribution. The restriction will be explained in item (12) of the RSIC abstract and the code package will be handled in whatever manner required because of the restriction.

The sample cover, pages $\mathrm{xv}$ and $\mathrm{xvi}$, is included in this introduction to the abstracts to call attention to the cover for the written material in the code package and to the legal notice which accompanies each code package that is distributed.

With the encouragement of the USAEC, RSIC cooperates closely with the U. S. Code Center (USCC) at Argonne and the ENEA Computer Programme Library (ENEA-CPL) serving other OECD countries from Ispra, Italy. Nuclear 
codes, not related to shielding, are collected and disseminated from Argonne in the USA. In the event that a code is also packaged by Argonne and/or ENEA-CPI, the abstract number is given in item (I) of the RSIC abstract. The European shielding scientist may find it more expedient to make his request for a code to ENEA-CPJ when it is available there. This cooperative agreement existing between the code centers was brought about in an effort to serve the scientific community more efficiently. It does not eliminate the need for open lines of communication between the individual shielding scientist and the information center. The overall RSIC program requires the stocking of the information store as well as retrieving from it. Members of the RSIC staff are always available for consultation in connection with the shielding code packages. 


\section{RSIC ABSTRACT FORMAT - SHIEIDING COMPUTER CODE PACKAGE}

\section{$\underline{\text { Pagination }}$}

In upper right corner give the number assigned to the package and the page number. Example: the four pages of code package CCC-l would be numbered $1.1,1.2,1.3$, and 1.4 .

Heading

RSIC CODE PACKAGE CCC-xx, where $\mathrm{xx}$ is the number assigned by the Center when the code is packaged and ready for distribution.

Descriptive Headings and Contents: Items 1 through 13

1. NAME AND TITLE OF CODE

a. Name given to main code.

b. Give a descriptive title. This title should tell something of the nature of the code: calculational method, geometry, or any feature that distinguishes this shielding code from another. AUXILIARY ROUTINES

Name and descriptive title of auxiliary codes used in preparing data or in processing output.

Give any useful background information or history of the primary code or the auxiliary codes. Such information should include the name of a code that might have been superseded or extended into this version, establish credit for original work, explain a code name that has been changed, or give a specific meaning if there is one to the name selected.

\section{CONTRIBUTORS}

a. Give name and location of installation where code was developed.

b. If more than one installation is involved in the code development, give name and location of installation with whom credit is to be shared.

c. If an additional contribution is made to the code package by an installation other than that listed in (a) or (b), give name and location of installation and itemize the addition. 
3. CODING IANGUAGE AID COMPUTER

Make a brief statement, as "FORTRAN; CDC 1604."

4. NATURE OF PROBLEM SOLVED

Give a brief description of the physical problem, including any basic physics approximations contained in the problem formulation.

5. METHOD OF SOLUTION

Make a short summary of the mathematical and numerical techniques used in the calculation.

6. RESTRICTIONS OR LIMITATIONS

Include restrictions suggested by storage allocation and implied argument range restrictions due to approximations, etc.

7. TYPICAL RUNNING TIME

Give enough detail to enable the potential user to estimate the running time for a given choice of program parameters.

8. COMPUTER HARDWARE REQUIREMENTS

a. Designed for what machine configuration? Size?

b. Upon what other machines is it operable?

c. What auxiliary storage (such as tapes, discs, drums) is needed?

d. What is the channel configuration?

e. What auxiliary equipment (such as punch, printer, plotter) is needed?

f. Is clock sampled?

9. COMPUTER SOFTWARE REQUIREMENTS

a. Under Programmer Control

If routines included in the package have been coded in mixed languages, indicate extent of each. If a certain class of routines is in assembly rather than compiler language (inputoutput, random number generator, etc.), this should be stated. 
b. Operating System or Monitor

With the operating system or monitor and associated subroutine library distributed by the computer manufacturer defined as "standard," note all deviations from this standard pertinent to the operation of the program. The following questions should be answered.

(1) Monitor or other system?

(2) Is an interpreter or manager or executive routine required?

(3) Are nonstandard library routines used?

(4) Are there variations in channel assignments? Is a special I-O table required?

(5) Are operator decisions or actions required (use of switches, etc.)?

10. RFFERENCES

List (by report number, title, author, and date) documentation available for describing the code and its utilization.

11. CONTENTS OF CODE PACKAGE

Name items in the package, as

a. documentation: listed references and any additional available material,

b. codes, including main program and any auxiliary programs, relating in what form they are being distributed,

c. software being distributed with the code package,

d. sample problem input and output,

e. libraries available for use with the codes.

12. HOW TO OBTATN PACKAGE

a. Where inquiries may be addressed.

b. If transmitted on tape, how many tapes are required?

c. Where are tapes to be sent?

13. DATY OF ABSTRACT 


\title{
OAK RIDGE NATIONAL LABORATORY
}

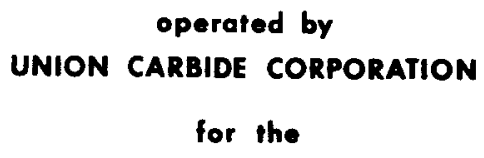

U.S. ATOMIC ENERGY COMMISSION

\section{RSIC COMPUTER CODE COLLECTION}

\author{
FMC-N
}

MONTE CARLO SIMULATION OF NEUTRON LIFE HISTORIES IN A SOURCE-SHIELD CONFIGURATION

\author{
Contributed by \\ General Electric - Cincinnati \\ Nuclear Materials and Propulsion Operation
}

RADIATION SHIELDING INFORMATION CENTER

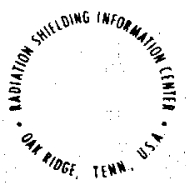




\section{LEGAL NOTICE}

This report was prepared as an account of Government sponsored work and describes a code which is one of a series collected by Rodiation Shielding Information Center. These codes were written by various Government and private organizations who contributed them to RSIC for distribution; they were not originated by RSIC. RSIC is informed that each code has been tested by the contributor and sample problems have been run by RSIC; however, neither the United Stotes, nor the Commission, nor Union Carbide Corporation, Nuclear Civision, nor ony person octing on behalf of the Commission or Corbide:

A. Makes any warranty or representation, express or implied, with respect to the accuracy, completeness, usefulness or functioning of any information, code, program and related material, or that the use of any information may not infringe privotely owned rights; or

B. Assumes any liability with respect to the use of, or for damages resulting from the use of any informotion, code, program and related program material disclosed in this report. 


\section{ALPHABETIC AND NUMERIC INDEX OF CODE PACKAGES}

\begin{tabular}{|c|c|c|c|c|c|}
\hline \multicolumn{2}{|c|}{ Code Package } & \multicolumn{3}{|c|}{ Code Package } & \multirow{2}{*}{$\frac{\text { Page No. }}{25}$} \\
\hline ACT: II & $\mathrm{CCC}-27$ & 121 & NTC & $\mathrm{CCC}-7$ & \\
\hline ADONIS & $\mathrm{CCC}-13$ & 51 & 05R & $\mathrm{CCC}-17$ & 79 \\
\hline BREMRAD & $\mathrm{CCC}-31$ & 137 & PROP & CCC-39 & 169 \\
\hline $\mathrm{C}-17$ & $\mathrm{CCC}-5$ & 17 & SANE & $\mathrm{CCC}-11$ & 43 \\
\hline $\mathrm{C}-18$ & $\mathrm{CCC}-10$ & 37 & SAGE & $\mathrm{CCC}-12$ & 47 \\
\hline CARSTEP & $\mathrm{CCC}-24$ & 109 & SALOMON & $\mathrm{CCC}-33$ & 145 \\
\hline CLOUD & $\mathrm{CCC}-32$ & 141 & TAEC & $\mathrm{CCC}-38$ & 165 \\
\hline DIPSEA & $\mathrm{CCC}-35$ & 153 & TOPIC & $\mathrm{CCC}-34$ & 149 \\
\hline EMPIRE- 2 & $\mathrm{CCC}-36$ & 157 & TRG-SGD & $\mathrm{CCC}-25$ & 113 \\
\hline FMC-G & $\mathrm{CCC}-14$ & 59 & TRIGR & $\mathrm{CCC}-20$ & 93 \\
\hline FMC-N & $\mathrm{CCC}-15$ & 65 & $05-0$ & $\mathrm{CCC}-18$ & 85 \\
\hline FPIC & $\mathrm{CCC}-28$ & 125 & $09-0$ & $\mathrm{CCC}-19$ & 89 \\
\hline GRACE-II & $\mathrm{CCC}-26$ & 117 & $14-0$ & $\mathrm{CCC}-1$ & 1 \\
\hline $\mathrm{K}-74$ & $\mathrm{CCC}-8$ & 29 & $14-1$ & $\mathrm{CCC}-2$ & 5 \\
\hline $\mathrm{L}-05$ & $\mathrm{CCC}-9$ & 33 & $14-2$ & $\mathrm{CCC}-3$ & 9 \\
\hline$I-63$ & $\mathrm{cCC}-6$ & 21 & $15-2$ & $\mathrm{CCC}-4$ & 13 \\
\hline LIPRECAN & $\mathrm{CCC}-37$ & 161 & $18-0$ and $18-1$ & $\mathrm{CCC}-16$ & 71 \\
\hline MAC and MAC-RAD & $\mathrm{CCC}-22$ & 101 & & & \\
\hline MARTY-G & $\mathrm{CCC}-29$ & 129 & & & \\
\hline MARTY-N & $\mathrm{CCC}-3 \mathrm{O}$ & 131 & & & \\
\hline MAVRAC & $\mathrm{CCC}-23$ & 105 & & & \\
\hline MORTIMER & $\mathrm{CCC}-21$ & 97 & & & \\
\hline
\end{tabular}


CODE PACKAGES, CATEGORIZED BY CALCULATIONAL TECHNIQUES

PAGE NC.

MONIE CARLO

CCC-4 : 15-2 (gamma rays, air scattering) ........ 13

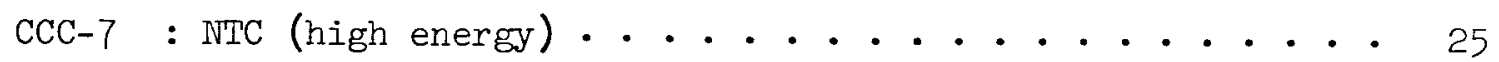

CCC-8 : K-74 (infinite medium, air scattering)....... 29

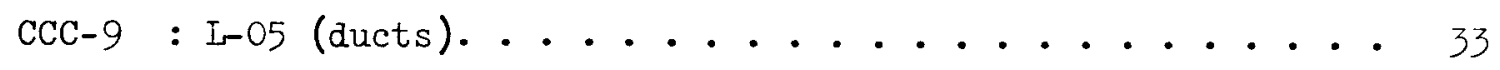

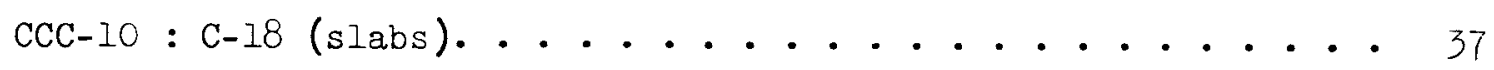

CCC-Il : SANE (neutrons, spherical geometry) ....... 43

CCC-12 : SAGE (gamma rays, spherical geometry) ....... 47

CCC-13 : ADONIS (parallelepiped geometry) ........ 51

CCC-14 : FMC-G (general geometry, garma rays) ....... 59

CCC-15 : FMC-N (general geometry, neutrons) ....... 65

CCC-16:18-0 and 18-1 (general geometry) ........ 71

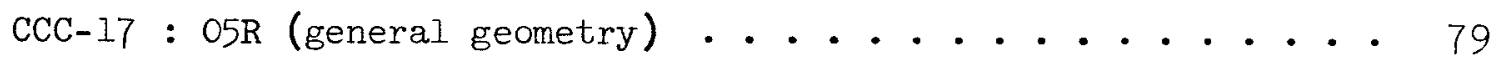

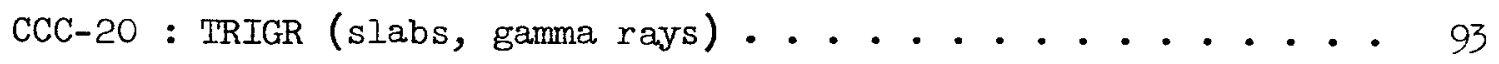

CCC-25 : TRG-SGD (secondary gamma rays, air-ground)...... 113

CCC-29 : MARTY-G (hydrogen, gamma rays) ......... 129

CCC-30 : MARTY-N (hydrogen, neutrons) .................

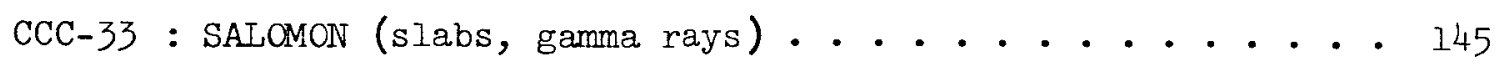

CCC-35 : DIPSEA (gamma rays, air scattering) ....... 153

CCC-37 : LIPRECAN (hydrogen, neutrons) ......... 161

KERNEL INTEGRATION

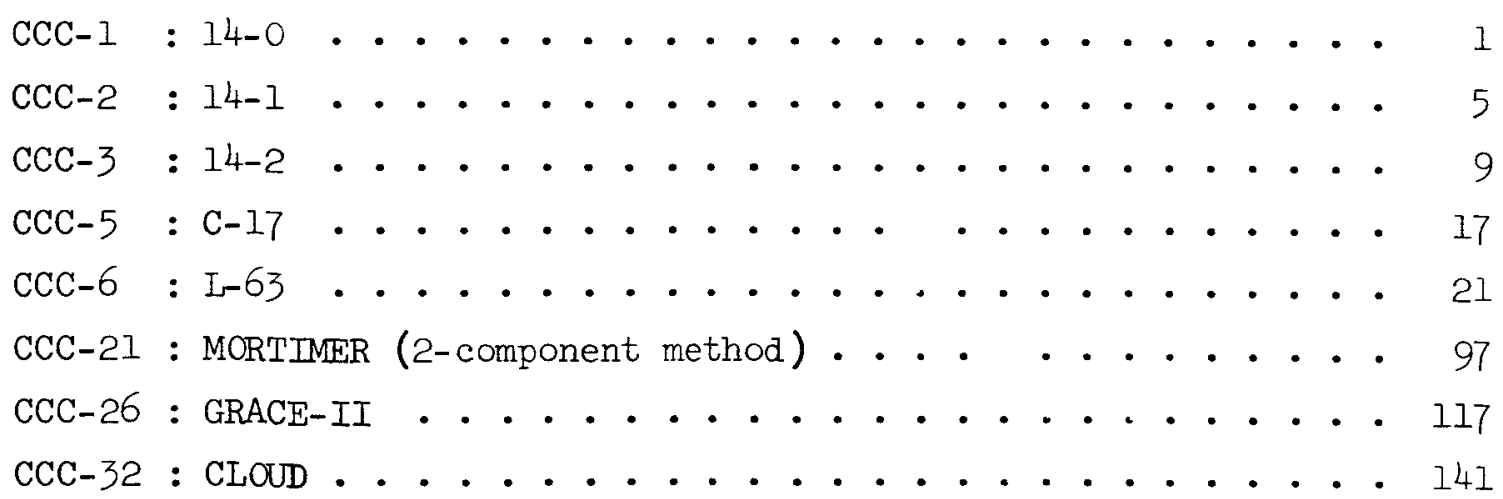


PAGE NO.

FISSION PRODUCT INVENTORY

CCC-28 : FPIC (gamma-ray sources) . . . . . . . . . 125

BREMSSTRAILUUNG

CCC-31 : BREMRAD . . . . . . . . . . . . . . .

ACTIVATION

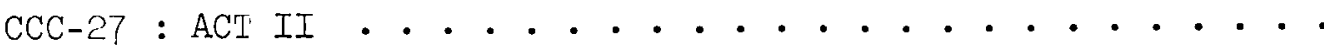

AIR-SCAITERING (Infinite Medium)

CCC-4 : 15-2 (gamma rays) . . . . . . . . . . . .

$\mathrm{CCC}-8$ : K-74 (neutrons) . . . . . . . . . . . .

CCC-18:05-0 (gamma rays) . . . . . . . . . . • •

CCC-19: 09-0 (neutrons) . . . . . . . . . . . . .

CARLSON $\mathrm{SN}_{\mathrm{N}}$

CCC-34 : TOPIC (cylinders) . . . . . . . . . . . .

DISCRETE ORDINATE

CCC-36 : EMPIRE-2 (multigroup, slabs) . . . . . . . .

REMOVAI-DIFFUSION (SPINNEY)

CCC-22 : MAC and MAC-RAD (Slabs) . . . . . . . . . .

NUMERICAI INTEGRATION

CCC-18 : 05-0 (single scattering, gamma rays) . . . . . .

CCC-19 : 09-0 (single scattering, neutrons) . . . . . . .

HIGH ENERGY

$\mathrm{CCC}-7 \quad: \mathrm{NIC}$. . . . . . . . . . . . . . . .

ASIRONAUT-VEIIICLE DOSE DISTRIBUTION 
PAGE NO.

TRAJECTORY AND ENVIRONMENT

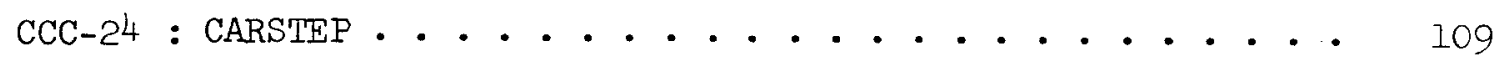

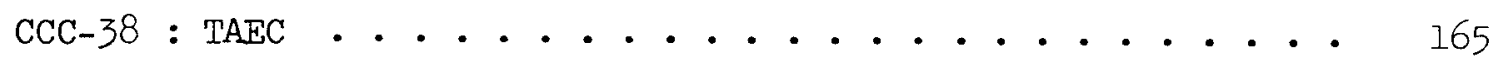

PROTON PENETRATION

CCC-39: $\mathrm{PROP}$. . . . . . . . . . . . . . . 169 
CODE PACKAGE, TITLE, CONTRIBUTOR, AND PRIMARY RHFERENCE

CCC-1: $\quad 14-0$ and $14-3$

KERNEL INTEGRATION CODE AND DATA CHECK - CALCULATHD SOURCES DESCRIBED IN CYLINDRICAI COORDINATE SYSTEM, contributed by General Electric, Cincinnati, Nuclear Materials and Propulsion Operation.

SAP-FAP, IBM 704 and 7090

(Reference: XDC 59-2-16 and XDC 59-3-52)

CCC-2: $\quad 14-1$ and $14-3$

KERNEL INIEGRATION CODE AND DATA CHECK - INPUT SOURCES

DESCRIBED IN CYLINDRICAL COORDINATE SYSTEM, contributed by

General Electric, Cincinnati, Nuclear Materials and Propulsion Operation.

SAP-FAP, IBM 704 and 7090

(Reference: XDC 59-2-16 and XDC 59-3-52)

CCC-3: $\quad 14-2$ and 14-3

KERNEL INTEGRATION CODE AND DATA CHECK - SOURCES DESCRIBED

IN RECTANGULAR COORDINATE SYSTEM, contributed by General

Electric, Cincinnati, Nuclear Materials and Propulsion Cpera-

tion.

SAP-FAP, IBM 704 and 7090

(Reference: XDC 59-6-173 and XDC 59-3-52)

CCC-4: $\quad$ 15-2

MONIE CARLO CALCJLATION - GAMMA-RAY SCATTIERING IN AIR, contributed by General Electric, Cincinnati, Nuclear

Materials and Propulsion Operation.

SAP-FAP, IBM 704 and 7090

(Reference: XDC 61-5-1 and DC 60-10-150)

CCC-5: C-17 and $\mathrm{R}-29$

KERNEI INTEGRATION CODE AND DATA GENERATOR - FRUSTRA OF RECTANGULAR PYRAMIDS AND CYLINDERS, contributed by General

Dynamics, Fort Worth, USAF Nuclear Aerospace Research

Facility.

SAP-FAP, IBM 704 and 7090

(Reference: NARF 61-39T, FZK-9-170)

CCC-6: I-63 and $\mathrm{R}-29$

KERNEL INTEGRATION CODE AND DATA GENERATOR - CYLINDERS, SPHERES, AND COMPLEX GEOMETRY, contributed by General Dynamics, Fort Worth, USAF Nuclear Aerospace Research Facility.

SAP-FAP, IBM 704 and 7090

(Reference: NARF 61-39T, FZK-9-170) 
CCC-7: NTC

MONTE CARLO HIGH ENERGY NUCLEON TRANSPORT CODE INCORPORATING

CASCADE AND EVAPORATIVE PROCESSES, contributed by Neutron

Physics Division, Oak Ridge National Iaboratory, Oak Ridge,

Tennessee.

FORIRAN/FAP, IBM 7090

(Reference: ORNL-3610)

CCC-8: $\mathrm{K}-74$

MONTE CARLO CALCULAIION OF NEUTRON FLUX IN INPINITE MEDIUM FOR

POINT ISOTROPIC SOURCES, contributed by General Dynamics,

Fort Worth, USAF Nuclear Aerospace Research Facility.

FAP, IBM 7090

(Reference: NARF 60-8T, FZK-9-147)

CCC-9: L-05

MONPE CARLO MULTIBEND-DUCT SHIEIDING CODE, contributed by

General Dynamics, Fort Worth, USAF Nuclear Aerospace Research Facility.

FAP, IBM 7090

(Reference: NARF 6I-33T, MR-N-286 and NARH 62-13T, MR-N-297)

CCC-10: C-18, R-35, and R-65

MONTE CARLO MUITIIAYER SIAB GEOMETRY SHIEIDING CODES, contributed by General Dynamics, Fort Worth, USAF Nuclear Aerospace and Research Facility and U. S. Army Tank-Automotive Center, Warren, Michigan.

SAP-FAP, IBM 704 and 7090

(Reference: FZK-134-3)

CCC-11: SAINE

MONTE CARLO SPIERICAL MULTILAYER GEOMEIRY NEUTRON TRANSPORT

SHIEIDING CODE, contributed by United Nuclear Corporation, White Plains, Development Division - NDA.

FORTRAN-FAP, IBM 7090

(Reference: UNUCOR-633 and UNUCOR-634)

CCC-12: SAGE

MONIE CARLO SPHERICAL MULTIIAYER GEOMETRY GAMMA TRANSPORT

SHIEIDING CODE, contributed by United Nuclear Corporation, White Plains, Development Division - NDA.

FORTRAN-FAP, IBM 7090

(Reference: UNUCOR-633 and UNUCOR-634)

CCC-13: ADONIS

MONIE CARLO THREE-DIMENSIONAL RECTANGULAR GEOMETRY SHIEIDING

CODE, contributed by United Nuclear Corporation, White Plains, Development Division - NDA.

FORTRAN-FAP/CODAP, IBM 7090 and CDC 1604

(Reference: UNUCOR-635) 
CCC-14: FMC-G

MONTE CARLO STMULATION OF GAMMA-RAY LIFE HISTORIES IN A SOURCE-

SHIELD CONFIGURATION, contributed by General Electric, Cincinnati, Nuclear Materials and Propulsion Operation.

SAP-FAP, IBM 704 and 7090

(Reference: APEX-706)

CCC-15: FMC-N

MONTE CARLO SIMULATION OF NEUTRON LIFE HISTORIES IN A SOURCE-

SHIEID CONFIGURATION, contributed by General Electric, Cincinnati, Nuclear Materials and Propulsion Operation.

SAP-FAP, IBM 704 and 7090

(Reference: APEX-706)

CCC-16: 18-0, 18-1 and Auxiliary Routines

MONIE CARLO SIMULATION OF NEUTRON AND GAMMA-RAY LIPE HISTORIES

IN REACTOR-SHIELD ASSEMBLIES, contributed by General Electric, Cincinnati, Nuclear Materials and Propulsion Operation.

FORTRAIN-FAP, IBM 7090

(Reference: XDC 61-1-91, GEMP-272)

CCC-17: O5R

GENERAL PURPOSE MONTE CARLO NEUTRON TRANSPORT CODE, contributed by Neutron Physics Division, Oak Ridge National Laboratory, Oak Ridge, Tennessee. FORTRAN-FAP/CODAP, IBM 7090 and CDC 1604

(Reference: CRNI-3622)

CCC-18: 05-0

ANISOTROPIC POINT SOURCE CODE - SINGLE SCATTERED GAMMA RAYS IN INFINITE HOMOGENEOUS MEDIUM, contributed by General Electric, Nuclear Materials and Propulsion Cperation, Cincinnati, Ohio. SAP-FAP, IBM 704 and 7090

(Reference: XDC 50-8-218)

CCC-19: 09-0

ANISOTROPIC POINT SOURCE CODE - SINGLE SCATTERED NEUTRONS IN INFINIIE HOMOGENEOUS MEDTUM, contributed by General Electric, Nuclear Materials and Propulsion Operation, Cincinnati, Ohio. SAP-FAP, IBM 704 and 7090

(Reference: APEX-533)

CCC-20: TRIGR

MONTE CARLO GAMMA-RAY PENETRATION CODE - PLANE GEOMETRY, contributed by TRG, Incorporated, Melville, New York, and Aeronautical Research Laboratories, Wright Air Development Center, Wright-Patterson Air Force Base, Ohio.

SAP, IBM $/ 04$

(Reference: WADC 59-771) 
CCC-21: MORTIMER

KERNEL INTEGRATION CODE - TWO-COMPONENT ANALYSIS FOR SNAP

SHIEID GEOMETRIES, contributed by Atomics International, Canoga

Park, California.

FORTRAN-FAP, IBM 7090

(Reference: NAA-SR-9327)

CCC-22: MAC (A)

NEUTRON GAMMA-RAY ATTENUATION CODE - SPINNEY (REMOVAL-DIFFUSION)

CALCULATION IN PLAINE GEOMETRY, contributed by General Electric,

Hanford Atomic Products Operation, Richland, Washington.

FORTRAN, IBM 7090

(Reference: $\mathrm{HW}-73381$ )

MAC-RAD (B)

NEUTRON GAMMA-RAY ATTENUATION CODE - SPINNEY (REMOVAL-DIFPUSION)

CALCULATION IN PLANE GEOMETRY, contributed by Nuclear Energy

Plants, AEC, Frankfurt, Germany, and European Atomic Energy

Community-EURATOM, Joint Nuclear Research Center, ISPRA Establish-

ment, Italy.

FORTRAN, IBM-7090

(References: KERNENERGIEANIAGEN Bericht No. 116 (ORNI-tr-610),

EUR 2152.e, and ENEA Computer Programme Library, Abstract No.

006)

CCC-23: MAVRAC

MODEL ASTRONAUT AND VEHICIE RADIATION ANALYSIS CODT, contributed by Northrop Space Laboratories, Hawthorne, California, and Aerospace Medical Research Laboratory, Wright-Patterson

Air Force Base, Ohio.

FORTRAN, IBM 7090

(Reference: NSL 63-159)

CCC-24: CARSTEP

TRAJECTORY AND ENVIRONMENT CODE - EIECTRON AND PROTON FLUXES

IMPINGING ON SPACECRAFT IN ORBIT, contributed by Northrop

Space Laboratories, Hawthorne, California, and Aerospace Medical

Research Laboratory, Wright-Patterson Air Force Base, Ohio.

FORIRAN, IBM 7090

(Reference: NSL 63-63R-I)

CCC-25: TRG-SGD

MONTE CARLO CAICUIATION - SECONDARY GAMMA-RAY DCSE FROM A

NUCIFAR WEAPON DETONATION, contributed by Research and Technology

Division, Air Force Weapons Laboratory, Kirtland Air Force Base,

New Mexico.

FORIRAN, CDC 1604

(Reference: WL-TDR-64-46) 


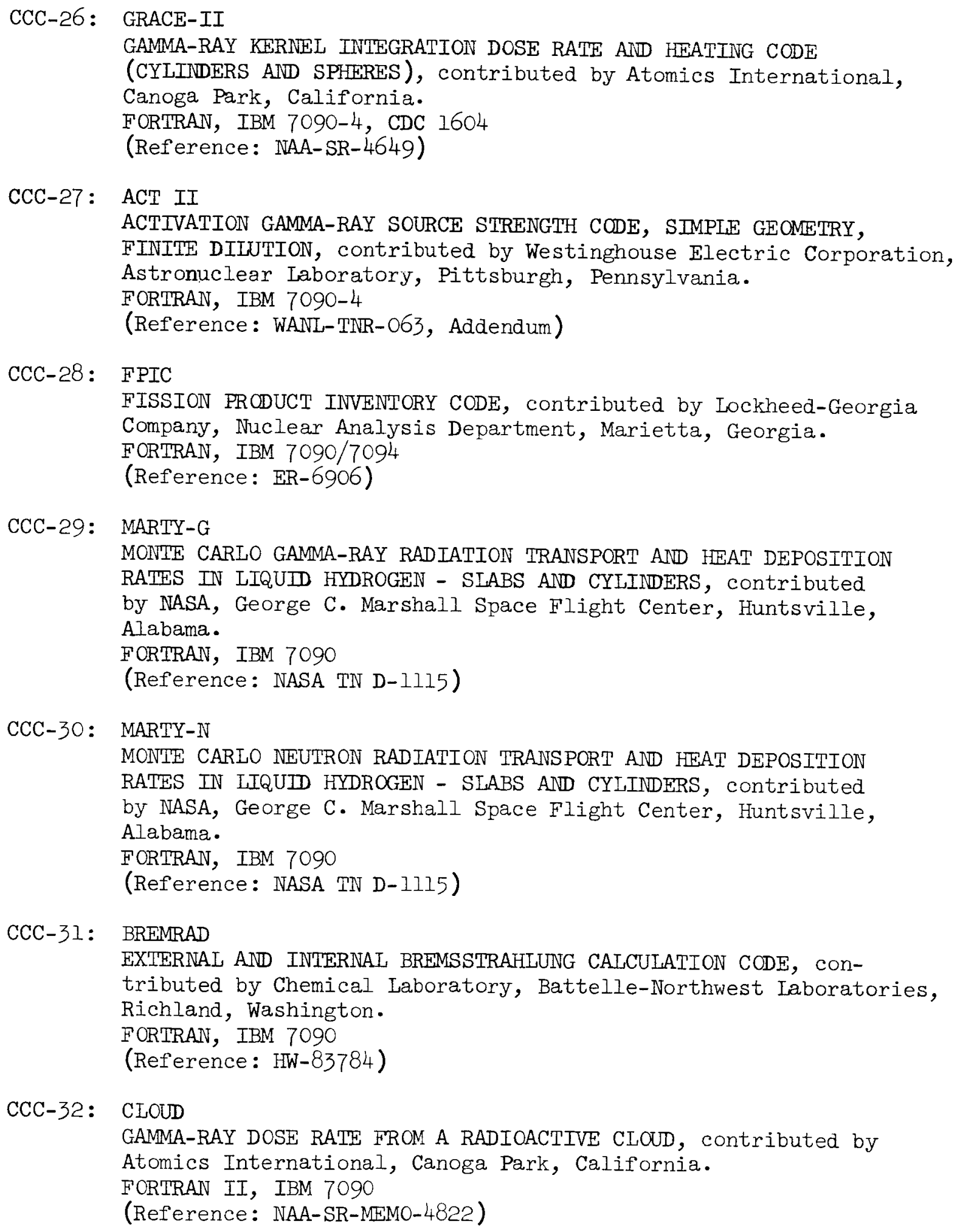


CCC-33: SALOMON

MONTE CARLO GAMMA TRANSPORT CODE - LAMINATED SIABS, contributed by Research Institute of National Defense, Stockholm, Sweden. FORTRAN, IBM 7090-4

(Reference: FOA 4 RAPPORT A-4403-441)

CCC-34: TOPIC

$S_{n}$ NEUTRON TRANSPORT CODE - CYLINDRICAL GEOMETRY, contributed by Phillips Petroleum Co., Atomic Energy Division, Idaho Falls, Idaho.

IBM $7090-4$

(Reference: DDO-16968)

CCC-35: DIPSEA

MONTE CARLO DOSE CALCULATION, ISOTROPIC POINT SOURCE, EXPONENTIAI ATMOSPHERE, contributed by Technical Operations Research, Burlington, Massachusetts, and MIT Lincoln Laboratory, Lexington, Massachusetts. FORTRAI-FAP, IBM 7090-4

(Reference: TO-B 64-12)

CCC-36: EMPIRE-2

MULII-GROUP DISCRETE ORDINATE TRANSPORT CODE, SLAB GEOMETRY, contributed by Westinghouse Electric Corporation, Bettis Atomic Power Laboratory, Pittsburgh.

FORTRAN, PHILCO 2000 and IBM 7090

(Reference: WAPD-TM-436)

CCC-37: IIPRECAN

MONTE CARLO TWO DIMENSIONAL NEUTRON PENETRATION AND ENERGY

DEPOSITION IN LIQUD HYDROGEN, contributed by Missile and

Space Systems Division, Douglas Aircraft Company, Inc., Santa

Monica, California.

FORIRAN, IBM 7090

(Reference: SM-43594)

CCC-38: TAEC

TRAJECTORY AND ENVIRONMENT CODE, contributed by Air Force

Weapons Laboratory, Kirtland Air Force Base, New Mexico, and

The Boeing Company, Seattle, Washington.

FORTRAN, CDC 1604

(Reference: WL-TDR-64-71, Vol. I and Vol. II)

CCC-39: PROP

PRIMARY PROTON PENETRATION CODE, contributed by Air Force Weapons Laboratory, Kirtland Air Force Base, New Mexico, and The Boeing Company, Seattle, Washingtor.

FCRIRAN, CDC 1604

(Ret'erence: Wi-TDR-64-7I, Vol. I and Vol. II) 
ABSTRACTS

$\mathrm{OF}$

RSIC

COMPUTHR CODE PACKAGES 


\section{RSIC CODE PACKAGE CCC-1}

1. NAME AND TITLE OF CODE

14-0: Kernel Integration Code - Calculated Sources Described in Cylindrical Coordinate System.

AUXILIARY ROUTINE

14-3: Data Check.

The names of the above codes follow a Shielding Program Number sequence established by the contributing installation, the number following the dash indicating the version or revision of a family of codes. In addition, a department code numbering system is followed: internally, the codes are known respectively as GE-NMPO No. 69 and GE-NMPO No. 128.

2. CONTRIBUTOR

Nuclear Materials and Propulsion Operation, General Electric Company, Cincinnati, Ohio.

3. CODING IUANGUAGE AND COMPUTERS

FAP; IBM 704 and 7090.

4. NATURE OF PROBLEM SOLVED

Shielding computer program 14-0 evaluates point-to-point kernels and integrates over source regions to perform reactor-shield penetration calculations for neutrons and gamma rays. Neutron and gamma-ray fluxes, spectra, and the dose and energy absorption rates can be computed for positions in and around complex shields containing multiple sources described in a cylindrical coordinate system. In addition, the program can compute reactor shield weight. Computation of any of these quantities in a single problem is optional.

Reactor and shield geometries are described by combinations of regions formed by rotation of rectangles and trapezoids about the reactor-shield axis or parallel axes or by translation of convex quadrilaterals parallel to any axis of the rectangular coordinate 
system. Compositions are expressed as volume fractions for each material in the reactor-shield assembly and are associated with the appropriate geometrical regions by code numbers.

Source-region integration limits are specified for each of as many as six source types, and location dimensions are specified for the axis of each of a possible 200 source regions. Sourceregion nodal points are located by intersection of axial lines in shells concentric about the source region axes and planes normal to the axes. The provisions for spacing these lines, shells, and planes permit description of cylindrical volume, cylindrical or plane surface, axial or radial line, or point sources. A different source-point spacing is permitted for each source type.

Source-density distributions are assumed to be independent of angular position. They are also assumed to be separable along the axis and radius of the regions of each source type, and they may be described by either cosine or exponential functions. The functions may differ in as many as four ranges along either the axis or radius of a source region.

\section{METHOD OF SOLUTION}

A modification of the Albert-Welton theory of neutron attenuation is used for fast-neutron flux or dose-rate calculations in hydrogenous materials. Moments method differential number spectra and differential scattered gamma-ray energy spectra are used in the computation of differential neutron spectra and gamma-ray energy spectra. Buildup factors computed by empirical expressions are used in conjunction with exponential attenuation to computer gamma-ray fluxes and dose and energy absorption rates.

Integration over source regions is performed according to the trapezoidal rule. The integration procedure is automatically adjusted to correctly integrate over volume, surface, or line sources. No integration is performed for point sources. Contributions from multiple source regions are summed to obtain total calculated detector responses.

14-3 performs an extensive check of input data to 14-0 for range of values, sign, sequencing, and completeness. 


\section{RESTRICTIONS OR LIMITATIONS}

The physical and source-description capability of the code enables nuclear analysis of the referenced reactor-shield assemblies with little uncertainty except for that associated with the pointto-point kernels as applied to specific geometries. Inhomogeneities generally increase the error since it is necessary to use arbitrary prescriptions for combining homogeneous media data.

7. TYPICAL RUNNING TIME

The computation time varies from short to long depending on the number, size, and complexity of the regions used to describe the reactor-shield assembly; the number of compositions, materials, source-region nodal points; and gamma-ray energy groups; and the output requested.

Estimated running time of sample problem: 14-0, 3 minutes; 14-3, 1 minute.

8. COMPUTER HARDWARE REQUIREMENTS

The codes were originally designed for a 32K IBM 704 computer. They were revised at the originating installation to be operable on the IBM 7090 and 7094 .

Two magnetic tape units, a 32,768 core memory, and an on-line card reader are required.

\section{COMPUTER SOFTWARE REQUIREMENTS}

a. The PK3 Manager routine is furnished with the packaged card decks. 14-0 and 14-3 are nonmonitor jobs, initiated by an on-line one-card loader. The PK3 Manager, an I-O package in use at GE-NMPO, includes absolute FAP assembly versions of FLOP, MINIM, and DIP.

b. The working deck is complete with all necessary library-type routines included.

c. Only A channel assignments are used, $A 2$ and $A 3$, input and output respectively. 
10. REFERENCES

J. T. Martin, J. P. Yalch, and W. E. Edwards, "Shielding Computer Programs 14-0 and 14-1, Reactor Shield Analysis," GE-ANPD, XDC 59-2-16 (January 23, 1959).

M. D. McDonald, "Shielding Computer Program 14-3, Data Check for Shielding Computer Programs 14-0, 14-1, and 14-2," GE-ANPD, XDC 59-3-52 (December 10, 1958).

11. CONTENTS OF CODE PACKAGE

The package contains the following items:

a. the referenced documents,

b. instruction and source listings of PK3,

c. a reel of magnetic tape on which is written in eight files: the source card decks, the binary card decks, and input and output of a sample problem,

a. one binary card on-line loader.

12. HOW TO OBIAIN PACKAGE

Inquiries or requests for the code package may be mailed to CODES COORDINATOR

Radiation Shielding Information Center

Oak Ridge National Laboratory

P. O. Box X

Oak Ridge, Tennessee 37830

or telephoned to

Area Code 615; 483-8611, extension 3-6944, or to

FTS $\mathrm{xx}-615-483-6944$.

Persons requesting the package should send a reel of magnetic tape to the above address.

\section{DATE OF ABSTRACT}

January 1966. 
RSIC CODE PACKAGE CCC-2

1. NAME AND TITLE OF CODE

14-1: Kernel Integration Code - Input Sources Described in Cylindrical Coordinate System.

AUXILIARY ROUTINE

14-3: Data Check.

The names of the above codes follow a Shielding Program sequence for shielding codes established by the contributing installation, the number following the dash indicating the version or revision of a family of codes. In addition, a department code numbering system is followed: internally the codes are known respectively as GE-NMPO No. 70 and GE-NMPO No. 128.

2. CONTRIBUTOR

Nuclear Materials and Propulsion Operation, General Electric Company, Cincinnati, Ohio.

3. CODING LANGUAGE AND COMPUTER

FAP; IBM 704 and 7090.

4. NATURE OF PROBLEM SOLVED

Shielding computer program 14-1 evaluates point-to-point kernels and integrates over source regions to perform reactorshield penetration calculations for neutrons and gamma rays. Neutron and gamma-ray fluxes, spectra, and the dose and energy absorption rates can be computed for positions in and around complex shields containing multiple sources described in a cylindrical coordinate system. In addition, the program can compute reactor shield weight. Computation of any of these quantities in a single problem is optional.

Reactor and shield geometries are described by combinations of regions formed by rotation of rectangles and trapezoids about the reactor-shield axis or parallel axes or by translation of convex quadrilaterals parallel to any axis of the rectangular coordinate 
system. Compositions are expressed as volume fractions for each material in the reactor-shield assembly and are associated with the appropriate geometrical regions by code numbers.

Source-region integration limits are specified for each of as many as six source types, and location dimensions are specified for the axis of each of a possible 200 source regions. Source-region nodal points are located by intersection of axial lines in shells concentric about the source region axes and planes normal to the axes. The provisions for spacing these lines, shells, and planes permit description of cylindrical volume, cylindrical or plane surface, axial or radial line, or point sources. A different sourcepoint spacing is permitted for each source type.

Source-density distributions are assumed to be independent of angular position. The source density must be specified as input for each ring of source points in each different source type.

\section{METHOD OF SOLUTION}

A modification of the Albert-Welton theory of neutron attenuation is used for fast-neutron flux or dose-rate calculations in hydrogenous materials. Moments method differential number spectra and differential scattered gamma-ray energy spectra are used in the computation of differential neutron spectra and gamma-ray energy spectra, respectively. Buildup factors computed by empirical expressions are used in conjunction with exponential attenuation to compute gamma-ray fluxes and dose and energy absorption rates.

Integration over source regions is performed according to the trapezoidal rule. The integration procedure is automatically adjusted to correctly integrate over volume, surface, or line sources. No integration is performed for point sources. Contributions from multiple source regions are summed to obtain total calculated detector responses.

14-3 performis an extensive check of input data to 14-1 for range of values, sign, sequencing and completerless. 


\section{RESTRICTIONS OR LIMITATIONS}

The physical and source description capability of the programs enables nuclear analysis of the referenced reactor-shield assemblies with little uncertainty except for that associated with the point-to-point kernels as applied to specific geometries. Inhomogeneities generally increase the error since it is necessary to use arbitrary prescriptions for combining homogeneous media data.

7. TYPICAL RUNNING TIME

The computation time varies from short to long, depending on the number, size, and complexity of the regions used to describe the reactor-shield assembly; the number of compositions, materials, source-region nodal points, and gamma-ray energy groups; and the output requested.

Estimated running time of sample problem: 14-1, 3 minutes; 14-3, 2 minutes.

\section{COMPUTER HARDWARE REQUIREMENTS}

The codes were originally designed for a 32K IBM 704 computer. They were revised at the originating installation to be operable on the IBM 7090 and 7094 .

Two magnetic tape units, a 32,768 core memory, and an online card reader are required.

9. COMPUTER SOFTWARE REQUIREMENTS

a. PK3 Manager routine is furnished with the packaged card decks. 14-1 and 14-3 are nonmonitor jobs, initiated by an on-line card loader. PK3, an I-O package in use at GE-NMPO, includes absolute FAP assembly versions of FLOP, MINIM, and DIP.

b. The working deck is complete with all necessary library-type routines included.

c. Only A channel assignments, $\mathrm{A} 2$ and $\mathrm{A} 3$, input and output respectively, are used. 


\section{REFERENCES}

J. T. Martin, J. P. Yalch, and W. E. Edwards, "Shielding Computer Programs 14-O and 14-1, Reactor Shield Ana]ysis," GE-ANPD, XDC 59-2-16 (January 23, 1959).

M. D. McDonald, "Shielding Computer Program 14-3, Data Check for Shielding Computer Programs 14-0, 14-1, and 14-2," GE-ANPD, XDC 59-3-52 (December 10, 1958).

1.1. CONTENTS OF CODE PACKAGE

The package contains the following items:

a. the referenced documents,

b. instructions and source listings of PK3,

c. a reel of magnetic tape on which is written in eight files: the source card decks, the binary card decks, and input and output of a sample problem,

d. one binary card on-line loader.

\section{HOW TO OBTAIN PACKAGE}

Inquiries or requests for the code package may be mailed to

CCDES COORDINATOR

Radiation Shielding Information Center

Oak Ridge National Iaboratory

P. O. Box X

Oak Ridge, Tennessee 37830

or telephoned to

Area code 615; 483-8611, extension 3-6944, or to

FTS xx 615-483-6944.

Persons requesting the package should send a reel of magnetic tape to the above address.

13. DAFIE, OT ABSTRACT

Jinuary 1966. 
RSIC CODE PACKAGE CCC-3

1. NAME AND TITLE OF CODE

14-2: Kernel Integration Code - Sources Described in Rectangular Coordinate System.

AUXILIARY ROUTINE

14-3: Data Check.

The names of the above codes follow a Shielding Program Number sequence established by the contributing installation, the number following the dash indicating the version or revision of a family of codes. In addition, a department code numbering system is followed: internally, the codes are known respectively as GE-NMPO No. 71 and GE-NMPO No. 128.

2. CONTRIBUTOR

Nuclear Materials and Propulsion Operation, General Electric Company, Cincinnati, Ohio.

3. CODING IAANGUAGE AND COMPUTERR

FAP; IBM 704 and 7090 .

4. NATURE OF PROBLEM SOLVED

Shielding computer program $14-2$ evaluates point-to-point kernels and integrates over source regions to perform reactor shield penetration calculations for neutrons and gamma rays. Neutron and gamma-ray fluxes, spectra, and the dose and energy absorption rates can be computed for positions in and around complex shields containing sources described in a rectangular coordinate system. In addition, the program can compute reactor shield weight. Computation of any or all of these quantities in a single problem is optional.

Reactor and shield geometries are described by combinations of regions formed by rotation of rectangles and trapezoids about the system axis or parallel axes or by translation of convex quadrilaterals parallel to any axis of the rectangular coordinate 
system. Compositions are expressed as volume fractions for each material in the reactor-shield assembly and are associated with the appropriate geometrical regions by code numbers.

Source location and dimensions are described in rectangular coordinates. Integration limits, which are specified for each space variable, may be equal for any or all variables. Planes of source region nodal points may be equally or unequally spaced between the integration limits of each space variable. Consequently, rectangular parallelepiped volume or rectangular plane surface, line, or point sources may be described.

Source density distributions, which must be identical for neutrons and gamma rays, are assumed to be nonseparable. They must be continuous over $X$, but may be discontinuous over $Y$ and $Z$. A table of source densities is required as input data. Gamma-ray source energy spectra are assumed to be independent of position.

\section{METIICD OF SOLUTICN}

A modification of the Albert-Welton theory of neutron attenuation is used for fast-neutron flux or dose-rate calculations in hydrogenous materials. Moments method differential number spectra and differential scattered gamma-ray spectra are used in the computation of differential neutron spectra and gamma-ray energy spectra, respectively. Buildup factors computed by empirical expressions are used in conjunction with exponential attenuation to compute gamma-ray fluxes and dose and energy absorption rates.

Integration over source regions is performed according to the trapezoidal rule. The integration procedure is automatically adjusted to correctly integrate over volume, plane, or line sources. No integration is performed for point sources.

14-3 performs an extensive check of input data to 14-2 for range of values, sign, sequencing and completeness. 
6. RESTRICTIONS OR LIMITATIONS

The physical and source description capability of the code enables nuclear analysis of the referenced reactor-shield assemblies with little uncertainty except for that associated with the pointto-point kernels as applied to specific geometries. Inhomogeneities generally increase the error since it is necessary to use arbitrary prescriptions for combining homogeneous media data.

7. TYPICAL RUNNING TIME

The computation time varies from short to long, depending on the number, size, and complexity of the regions used to describe the reactor-shield assembly; the number of compositions, materials, source-region nodal points, and gamma-ray energy groups; and the output requested.

Estimated running time of sample problem: 14-2, 3 minutes; 14-3, 2 minutes.

8. COMPUTER HARDWARE REQUIREMENTS

The codes were originally designed for a 32K IBM 704 computer. They were revised at the originating installation to be operable on the IBM 7090 and 7094 .

Two magnetic tape units, a 32,768 core memory, and an on-line card reader are required.

9. COMPUTER SOFTWARE REQUIREMENTS

a. PK3 Manager routine is furnished with the packaged card decks. The codes are nonmonitor jobs, initiated by an on-line one card loader. The PK3 Manager, an I-O package in use at GE-NMPO, includes absolute FAP assembly versions of FLOP, MINIM, and DIP.

b. The working deck is complete with all necessary library-type routines included.

c. Only A channel assignments, A2 and A3, input and output respectively, are used. 
10. REPERENCES

J. T. Martin, J. P. Yalch, and W. I. Edwards, "Shielding Computer Program 14-2, Reactor Shield Analysis," GE-ANPD, XDC 59-6-173 (June 15, 1959).

M. D. McDonald, "Shielding Computer Program 14-3, Data Check for Shielding Programs 14-0, 14-1, and 14-2," GE-ANPD, XDC 59-3-52 (December 10, 1958).

11. CONTENTS OF CODE PACKAGE

The package contains the following items:

a. the referenced documents,

b. description and source listing of $\mathrm{PK} 3$,

c. a reel of magnetic tape on which is written in eight files: the source card decks, the binary card decks, and input and output of a sample problem,

d. one binary card on-line loader.

12. HOW TO OBTAIN PACKAGE

Inquiries or requests for the code package may be mailed to CODES COORDINATOR

Radiation Shielding Information Center

Oak Ridge National Laboratory

P. O. Box X

Oak Ridge, Tennessee 37830

or telephoned to

Area Code 615; 483-8611, extension 3-6944, or to

FTS $x x-615-483-6944$.

Persons requesting the package should send a reel of magnetic tape to the above address.

13. DATE OF ABSTRACT

January 1966. 


\section{RSIC CODE PACKAGE CCC-4}

\section{NAME AND TITLE OF CODE}

15-2: Monte Carlo Calculation - Gamma-Ray Scattering in Air.

The name of the above code follows a Shielding Program Number sequence established by the contributing installation, the number following the dash indicating the version or revision of a family of codes. In addition, a department code numbering system is followed: internally, $15-2$ is also known as GE-NMPO No. 648 .

\section{CONTRIBUTOR}

Nuclear Materials and Propulsion Operation, General Electric Company, Cincinnati, Ohio.

3. CODING LANGUAGE AND COMPUTER

FAP; IBM 704 and 7090 .

4. NATURE OF PROBLEM SOLVED

Shielding computer program $15-2$ calculates the energy spectrum and angular distribution of gamma rays at a point detector due to single and multiple scattering in an infinite homogeneous medium of air from a monoenergetic, monodirectional point source.

5. METHOD OF SOLUTION

The single-scattering contribution to the detector energyangle distribution is computed by numerical integration, while the contribution due to second- and higher-order scattering is determined by means of Monte Carlo techniques.

First-collision points for the Monte Carlo calculation are obtained by use of systematic sampling, with subsequent collision points determined randomly. A quota sampling scheme, which assigns $N_{k}$ histories to the kth first-collision point, is used to allow a more intensive study of those histories that contribute the most error to the problem. Scoring is done at second- and higher-order collision points by a statistical estimation technique. At each 
collision point the product of the weight of the particle and the conditional probability that the particle will reach the detector without further collision, assuming that it had a scattering collision, is scored for the appropriate detector energy-angle bin. The detector-angle bins are determined by dividing the space about the detector into a number of solid angles with the apex at the detector. A scheme is provided to prevent very large scores from colliding close to the detector.

Tw. options in the program provide for further possible reduction of the variances of the estimates. One is the biased sampling of the scattering angle from the isotropic distribution. The program uses an isotropic distribution and corrects by weighting the particle properly according to the Klein-Nishina relationship. In the other option, called "exponential transformation," the mean free path of a gamma ray is altered depending on the energy, position, and direction of the gamma ray with respect to the detector.

The gamma-ray events treated are photoelectric effect, pair production, and compton scattering. The total cross sections for air are computed by means of a power series fit to the ratio of the total-to-Compton cross sections. There is also an option which allows the generation and tracking of $0.5-\mathrm{MeV}$ photons following pairproduction events.

\section{RESIRICIICNS OR LIMITATIONS}

Maximum number of detector energy intervals, 30.

Maximum number of detector polar-angle intervals, 30 .

Maximum number of detector azimuth-angle intervals, 4 .

Maximum number of multiple collisions per history, 50 .

\section{TYPICAI, RUNNING TIME}

The IBM 704 machine time for the documented sample problem was 2] minutes. The packaged sample problem ran for 5 minutes on the I3M 7090. There are no records available for statistics on typical running time, nor is there information available to indicate that the sampling scheme used in the packaged problem is optimum. 


\section{COMPUTER HARDWARE REQUIREMENTS}

The code was originally designed for a 32K IBM 704 computer. It was revised at the originating installation to be operable on the IBM 7090 and 7094 .

Two magnetic tape units, a 32,768 core memory, and an on-line card reader are required.

9. COMPUTER SOFTWARE REQUIREMENTS

a. The PK3 Manager routine is furnished with the packaged card decks. $15-2$ is a nonmonitor job, initiated by an on-line onecard loader. The PK3 Manager, an I-O package in use at GE-NMPO, includes absolute FAP assembly versions of FLOP, MINIM, and DIP.

b. The working deck is complete with all necessary library-type routines included.

c. Only A channel assignments, A2 and A3, input and output respectively, are used.

10. REFERENCES

N. R. Baumgardt, A. Trampus, and J. E. MacDonald, "Program 15-2, Monte Carlo Calculation of Gamma-Ray Scattering in Air," GEANPD, XDC 61-5-1 (May 1961).

M. A. Capo, "Determination of Suitable Parameters for Compiling Gamma Ray Air Scattering Probabilities," GE-ANPD, DC 60-10-150 (October 26, 1960) (classification cancelled 10-2-64 for the Atomic Energy Commission by H. F. Carroll, Chief, Declassification Branch).

\section{CONTENTS OF CODE PACKAGY}

The package contains the following items:

a. the referenced documents,

b. description and source listing of PK3,

c. a reel of magnetic tape on which is written in three files: the source card deck, the binary card deck, and input and output for a sample problem,

d. one binary card on-line loader. 
12. HOW TO OBTAIN PACKAGE

Inquiries or requests for the code package may be mailed to

CODES COORDINATOR

Radiation Shielding Information Center

Oak Ridge National Laboratory

P. O. Box X

Oak Ridge, Tennessee 37830

or telephoned to

Area Code 615; 483-8611, extension 3-6944, or to

FTS $\mathrm{xx}-615-483-6944$.

Persons requesting the package should send a reel of magnetic tape to the above address.

\section{DATE OF ABSTRACT}

January 1966. 
RSIC CODE PACKAGE CCC-5

1. NAME AND TITLE OF CODE

C-17: Kernel Integration Code - Frustra of Rectangular Pyramids and Cylinders.

\section{AUXILIARY ROUTINE}

\section{R-29: Data Generator.}

The code names were originally internal accounting designations assigned by the GD Digital Computing Laboratory to these particular calculation procedures. In the absence of a formal name given by the originators of the codes, RSIC adopted the above designations.

2. CONTRIBUTOR

USAF Nuclear Aerospace Research Facility, General Dynamics, Fort Worth, Texas.

3. CODING LANGUAGE AND COMPUTER

FAP (C-17), FORTRAN (R-29); IBM 704, 709, 7090 and 7094.

4. NATURE OF PROBLEM SOLVED

The shield penetration code C-I7 calculates the neutron and/or gamma-ray spectra, heat generation rate, and/or dose rate at each of a group of point sources. The sources may be divided into sets, with each set having a unique source spectra. The spectrum, heating rate, and/or dose rate for each detector, summed over each sourcepoint set and over the entire source group, may also be computed.

\section{METHOD OF SOLUTION}

Point-to-point kernels, based upon the differential energy spectra calculated for a point isotropic source in an infinite medium, are integrated over various sources. The data used are based on the moments method solution of the fast-neutron or gammaray transport equation. The stepping-point method is used to solve for the path lengths from source to detector in each region. 
The gamma-ray absorption coefficients are based on interpolations of the photoelectric and pair-production cross sections so that the coefficients may be computed for all media of the system. The eftective atomic number is interpolated from a table of atomic numbers versus the absorption coefficient per electron.

The mode of distributing the source points is chosen (either equal interval or according to Gaussian quadrature abscissa) which locates the coordinate planes that are perpendicular to the coordinate axes. The intersections of these planes are source point locations.

\section{RESTRICTIONS OR IIMITATIONS}

The physical and source description capability provided by the programs should involve little uncertainty except for that associated with the point-to-point kernels as applied to specific geometries. Inhomogeneities generally increase the error since it is necessary to use arbitrary prescriptions for combining homogeneous media data.

\section{TYPICAL RUNNING TIME}

The machine time, in minutes, required to calculate one $\mathrm{C}-17$ problem on the IBM 7090 may be estimated by the following equation:

$$
\mathrm{T}=3+.1 \mathrm{~L}+\mathrm{ND}(\operatorname{VNS}(.01+.020+.02 \mathrm{~N})
$$

where $T$ is the time in minutes, $L$ is the number of libraries to write on tape, $\mathbb{N D}$ is the number of detectors, $\Sigma N S$ is the total number of source points, $G$ is $I$ if gamma calculations are to be made and zero if they are not, and $N$ is 1 if neutron calculations are to be made and zero if they are not.

R-29 machine time may be estimated as follows:

$$
\mathrm{T}(\min )=.20(\mathrm{NMD})+1.0(\mathrm{NSG})
$$

where NMD represents the number of material decks to be generated, and NSG is the number of source groups to be generated. 
The packaged sample problem ran for 9 minutes on $\mathrm{C}-17$ and for 5 minutes on $\mathrm{R}-29$.

\section{COMPUTER HARDWARE REQUTREMENTS}

The codes were originally designed for the IBM 704 computer. They were revised at the originating installation to be operable on the 32K IBM 709, 7090 and 7094.

Execution requires 11 magnetic tape units for C-17 and 5 units for $\mathrm{R}-29$.

9. COMPUTER SOFTWARE REQUIREMENTS

C-17 is designed to run in STRAP, the GD/FW operating system for the IBM 7090. The STRAP deck is included as a part of the program deck, and is executed as a standard execute job in the IBM Fortran II Monitor System. The STRAP system has a tape unit table built in, assigning 6 units to $A$ and 6 to $B$ channels. The format is identical to the FORIRAN IOU table and may be altered at will. The packaged STRAP control deck is in binary. It has been unscrambled by RSIC and a FAP listing is included in the package.

The C-17 source program was written for STRAP assembly. If assembled in any other operating system, program linkage instructions must be deleted or modified.

The job deck, consisting of STRAP, calculation predure and problem data including data library, is written as a file on the standard input tape. When the FORTRAN Monitor reaches this file, control is transferred to the STRAP Monitor via the XEQ card which, in turn, transfers control to C-17. Upon completion of the jobs, control returns to proper position in the monitor system.

R-29 is written in FORIRAN, designed to run in the STRAP system.

10. REFERENCES

D. M. Peterson, "Shield Penetration Programs," NARF-61-39T, FZK-9-170 (December 29, 1961).

G. E. Miller and C. E. Humphries, General Dynamics N-S Memo I/348 (March 19, 1962). 
11. CONTENTS OF CODE PACKAGE

The package contains the following items:

a. the referenced documents,

b. a description of the STRAP calculation procedure,

c. a reel of magnetic tape on which is written in seven files: the source card decks, and the binary card decks for C-17, R-29 and STRAP; input and output for a sample problem, and an extensive $\mathrm{C}-1 \overline{7}$ library.

12. HOW TO OBTAIN PACKAGE

Inquiries or requests for the code package may be mailed to CODES COORDINATIOR

Radiation Shielding Information Center

Oak Ridge National Iaboratory

P. O. Box X

Oak Ridge, T'ennessee 37830

or telephoned to

Area Code 615; 483-8611, extension 3-6944, or to

FTS xx-615-483-6944.

Persons requesting the package should send a reel of magnetic tape to the above address.

13. DATE OF ABSTRACT

January 1966. 
RSIC CODE PACKAGE CCC-6

1. NAME AND TITIE OF CODE

L-63: Kernel Integration Code - Cylinders, Spheres, and Complex Geometry •

AUXILIARY ROUTINE

R-29: Data Generator.

The code names were originally internal accounting designations assigned by the GD Digital Computing Laboratory to these particular calculation procedures. In the absence of a formal name given by the originators of the codes, RSIC adopted the above designations.

2. CONTRIBUTOR

USAF Nuclear Aerospace Research Facility, General Dynamics, Fort Worth, Texas.

3. CODING IAANGUAGE AND COMPUTER

FAP (I-63), FORTRAN (R-29); IBM 704, 709, 7090 and 7094.

4. NATURE OF PROBLEM SOLVED

Shield penetration code I-63 calculates the neutron and/or gammaray spectra, heat generation rate, and/or dose rate at each of a group of point detectors, due to each of a group of point sources. The sources may be divided into sets, with each set having a unique source spectra. The spectrum, heating rate, and/or dose rate for each detector, summed over each source-point set and over the entire source group may also be computed.

The geometry accepts a general class of solids, specifically, cylinders and their annuii which are defined about arbitrary axes, sectors of these cylinders, and frustra of pyramids whose bases are quadrilaterals. In addition, spheres, hollow spheres or hemispheres, spherical sectors, and spherical sectors with one or two ends cut off may be defined. The code also accepts regions within regions and regions within regions within regions in which the geometry types can be varied. 


\section{METHOD OF SOLUTION}

Point-to-point kernels, based upon the differential energy spectra for a point isotropic source in an infinite medium, are integrated over various sources. The data used is based on the moments-method solution of the fast-neutron or gamma-ray transport equation. The stepping-point method is used to solve for the path lengths from source to detector in each region.

The gamma-ray absorption coefficients are based on interpolations of the photoelectric and pair production cross sections so that the coefficients may be computed for all media of the system. The effective atomic number is interpolated from a table of atomic numbers versus the absorption coefficient per electron.

The mode of distributing the source points is chosen (either equal interval, or according to Gaussian quadrature abscissa) which locates the coordinate planes that are perpendicular to the coordinate axes. The intersections of these planes are source point locations.

\section{RESIRICTIONS OR IIMITATIONS}

Enough physical and source description capability is provided by the programs that there should be little uncertainty except that associated with the point-to-point kernels as applied to specific geometries. Inhomogeneities generally increase the error since it is necessary to use arbitrary prescriptions for combining homogeneous media data.

7. TYPICAI RUNNING IIME

The IBM 7090 time, in minutes, required to calculate one $\mathrm{I}_{-}-63$ problem may be estimated by the following equation:

$$
T=.1 I+N D[N S(.01+.02 G+.02 N)]
$$

where $T$ is time in minutes, $I$ is the number of libraries to write on tape, $\mathbb{N D}$ is the number of detectors, NS is the total number of source points, $G$ is 1 if gamma calculations are to be made and zero if they are not, and $N$ is 1 if the neutron calculations are to be made and zero if they are not. 
The formula for estimating R-29 running time is $T($ min.) $=0.2$ (number of material decks to be generated) + the number of source groups to be generated.

Estimated running time of sample problem: I-63, 5 minutes; R-29, 5 minutes.

\section{COMPUTER HARDWARE REQUIREMENTS}

The codes were originally designed for the IBM 704. They were revised at the originating installation to be operable on the $32 \mathrm{~K}$ IBM 709, 7090 and 7094 .

L-63 execution requires 8 magnetic tape units, 3 on $A$ and 5 on B channels. R-29 requires fewer tape units.

9. COMPUTER SOFTWARE REQUIREMENTS

L-63 is designed to run in STRAP, the GD/FW operating system for the IBM 7090. The SIRAP deck is included as a part of the program deck, and is executed as a standard execute job in the IBM Fortran II Monitor System. The STRAP system has a tape unit table built in, assigning 6 units to $A$ and 6 to $B$ channels. The format is identical to the FORTRAN IOU table and may be altered at will. The packaged STRAP control deck is in binary. It has been unscrambled by RSIC and a FAP listing is included in the package.

The I-63 source program was written for STRAP assembIy. If assembled in any other operating system, program linkage instructions must be deleted or modified.

The job deck, consisting of STRAP, calculation procedure and problem data including data library, is written as a file on the standard input tape. When the FORTRAN Monitor reaches this file, control is transferred to the STRAP Monitor via the XEQ card which, in turn, transfers control to I-63. Upon completion of the job, control returns to proper position in the monitor system.

R-29 is written in FORTRAN, designed to run in the STRAP system. 
10. REFEREINCES

D. M. Peterson, "Shield Penetration Programs," NARF-61-39T, FZK-9-170 (December 29, 1961).

G. E. Miller and C. E. Humphries, General Dynamics N-S Memo 1/348 (March 19, 1962).

11. CONTENTS OF CODE PACKAGE

The package contains the following items:

a. the referenced documents,

b. a description of the STRAP calculation procedure,

c. a reel of magnetic tape on which is written in seven files: the source and binary card decks for I-63, R-29, and STRAP; input and output for a sample problem; and an extensive I-63 library.

12. HOW TO OBIAIN PACKAGE

Inquiries or requests for the code package may be mailed to CODES COORDINATOR Radiation Shielding Information Center oak Ridge National Laboratory

P. O. Box $\mathrm{X}$

Oak Ridge, Tennessee 37830

or telephoned to

Area Code 615; 483-8611, extension 3-6944, or to

FTS $\mathrm{xx}-615-483-6944$.

Persons requesting the package should send a reel of magnetic tape to the above address.

13. DATE OF ABSTRACT

January 1966. 
RSIC CODE PACKAGE CCC-7

1. NAME AND TITIE OF CODE

NTC: Monte Carlo High Energy Nucleon Transport Code Incorporating Cascade and Evaporative Processes.

AUXILIARY ROUTINES

PREP: Library Tape Input Generator.

CSH: Cross Section Handling Codes.

05R-05RANAL: Monte Carlo Neutron Transport Code.

The 05R code contained in this package is the original version written in FAP. Further development of the code has resulted in a Fortran version contained in $\mathrm{CCC}-17$.

2. CONTRIBUTOR

Neutron Physics Division, Dak Ridge National Laboratory, Oak Ridge, Tennessee.

3. CODING LANGUAGE AND COMPUTER

FORIRAN and FAP, IBM 7090 and 7094

4. NATURE OF PROBIEM SOLVED

NTC calculates the transport of neutrons and protons having initial energies up to $400 \mathrm{MeV}$ through arbitrary complex geometrical configurations containing a maximum of 4 material media each of which may be composed of up to 10 nuclides. Cascade processes and particle evaporation from excited nuclei are taken into account.

The code yields detailed information concerning the interactions of high-energy nucleons with matter for use in the design of radiation shields for space vehicles and high-energy particle accelerators.

5. METHOD OF SOLUTION

The Monte Carlo method has been applied in the con truction of NTC, a linked series of codes for the treatment of high-energy transport, and for the treatment of neutrons of energies below $50 \mathrm{MeV}$. 
The end result of NTC is one or more magnetic tapes containing the detailed records of all quantities pertinent to the transport of the nucleon. These tapes can be independently analyzed by the individual user of NTC to produce desired solutions to specific problems.

The calculation proceeds in four parts:

a. the high-energy transport code introduces the nucleons into the system and transports them down through the energy region between 400 and $50 \mathrm{MeV}$,

b. the high-energy analysis routine uses the history tapes produced by the code in item (a): to estimate the highenergy nucleon distributions; to complete the intranuclear cascades by evaporating nucleons from the highly excited residual nuclei; to estimate the distribution of protons below the boundary energy; and to prepare an $05 \mathrm{R}$ source tape for neutrons having energy below the boundary region of $50 \mathrm{MeV}$,

c. the 05R code reads the source tape produced by the highenergy analysis routine in (b) and traces the neutron histories from $50 \mathrm{MeV}$ to thermal energies, producing a neutron history tape,

d. the $05 R$ analysis routine reads the neutron history tape and estimates the low-energy neutron distributions.

\section{RESTRICTIONS OR LIMITATIONS}

Nucleon energies should be less than $400 \mathrm{MeV}$. No more than 4 material media, each containing no more than 10 nuclides, are allowed.

\section{TYPICAL RUNNING TIME}

Total running time for 701 neutrons on NTC and the auxiliary codes is about 27 minutes, with $\mathrm{CSH}$ requiring 3 minutes, NIC, $191 / 2$ minutes, and 05R-05RANAL, 4 1/2 minutes. 
8. COMPUTER HARDWARE REQUIREMENTS

Execution of ITC requires a 32,768 core memory and 10 tape units; PREP and CSH require 5 units each; 05R-05RANAL requires 8 units.

9. COMPUTER SOFTWARE REQUIREMENTS

The NTC system was written in FORTRAN and FAP. Several major routines were written completely in FAP. It was designed for the IBM FORTRAN II Monitor System and could not easily be made compatible with other systems.

A special IOU table has been added to each separate code, and may be changed at will.

NTC is a 5-link chain job; 05R-O5RANAL is constructed of 3 chain links.

\section{REFERENCES}

W. E. Kinney, "The Nucleon Transport Code, NTC," ORNI-3610 (August 1964).

I. Dresner, "EVAP - A Fortran Program for Calculating the Evaporation of Various Particles from Excited Compound Nuclei," ORNL-TM-196 (December 1961).

Hugo W. Bertini, "Low-Energy Intranuclear Cascade Calculation," Phys. Rev., 131, 1801 (1961).

\section{CONIEN'IS OF CODE PACKAGE}

The package includes typical analysis routines; a user's manual for the low-energy portion of the code and for the geometry routine; and a full-scale demonstration problem, complete in all details, which can be used to verify satisfactory performance by all parts of the code group.

The package contains the following items:

a. the referenced documents, including a utilization manual for each of the basic codes and the auxiliary routines,

b. a reel of magnetic tape on which is written in twelve files: the source and binary card decks for NTC and the auxiliary routines, a library of data (BERTINI data) in binary, input data for a sample problem, and output from the problem. 
12. HOW TO OBTAIN PACKAGE

Inquiries or requests for the code package may be mailed to

CODES COORDINATOR

Radiation Shielding Information Center

Oak Ridge National Iaboratory

P. O. BoX X

Oak Ridge, Tennessee 37830

or telephoned to

Area Code 615; 483-8611, extension 3-6944, or to

FTS $x x-615-483-6944$.

Persons requesting the package should send a reel of magnetic tape to the above address.

13. DAIE OF ABSTRACT

January 1966. 
RSIC CODE PACKAGE CCC-8

1. NAME AND TITLE OF CODE

K-74: A Monte Carlo Calculation of Neutron Flux in Infinite Medium for Point Isotropic Sources.

The code name was originally an internal accounting designation assigned by the GD Digital Computing Laboratory to this particular calculation procedure. In the absence of a formal name given by the originators of the code RSIC adopted the above designation.

2. CONTRIBUTOR

USAF Nuclear Aerospace Research Facility, General Dynamics, Fort Worth, Texas.

3. CODING LANGUAGE AND COMPUTHER

FAP; IBM 704, 7090 and 7094.

4. NATURE OF PROBLEM SOLVED

$\mathrm{K}-74$ is a calculation of fast neutron energy spectra. It is designed to compute the energy spectrum and angular distribution of the neutron flux in an infinite medium of an arbitrary material for point isotropic sources which are either monoenegetic or from fission.

5. METHOD OF SOLUTION

The Monte Carlo method is used to calculate the energy spectrum and angular distribution of the neutron flux across spherical boundaries located at various distances from the source. The procedure includes optional provisions for the use of such variance reduction techniques as systematic sampling, forced first-collisions, antithetic variates, and the exponential transformation.

6. RESTRICTIONS OR LIMITATIONS

There are no known restrictions implied by storage allocation or argument range restrictions due to approximations. Problem restrictions are detailed in procedure instructions. 
7. TYPICAL RUNNING TIME

There are no records available (at RSIC) for estimation of typical running time on the IBM 7090 .

Estimated running time for sample problem: 6 minutes.

\section{COMPUTER HARDWARE REQUIREMENTS}

The code was originally designed for the IBM 704 computer. It was revised at the originating installation to be operable on the 32K IBM 7090 and 7094 .

Execution requires 6 magnetic tape units on two channels.

\section{COMPUTER SOFTWARE REQUIREMENTS}

$\mathrm{K}-74$ is designed to run in STRAP, the GD/FW operating system for the IBM 7090. The STRAP deck is included as a part of the program deck. It is run as a standard execute job in the IBM Fortran II Monitor System. STRAP has a tape unit table built in, assigning 7 units to $A$ and 6 to $B$ channels. The format is identical to the FORIRAN IOU table and may be altered at will.

The packaged STRAP control deck is in binary. It has been unscrambled by RSIC; a FAP listing is included in the package.

K-74 source was written for STRAP assembly. If assembled in any other operating system, program linkage instructions must be deleted or modified.

The job deck, consisting of STRAP, calculation procedure, and problem data including data library, is written as a file on the standard input tape. When the FORTRAN Monitor reaches this file, control is transferred to the STRAP Monitor via the XIQ card which, in turn, transfers control to $\mathrm{K}-74$. Upon completion of the job, control returns to proper position in the monitor system.

In addition to systems, input, and output tapes, $\mathrm{K}-74$ uses tape units $31, B 2$, and $B 4$.

\section{REFERENCES}

M. B. Wells, "Monte Carlo Calculations of Fast-Neutron Scattering in Air," NARF-60-8I, FZK-9-147, Vol. I and Vol. II. 
M. B. Wells, "Monte Carlo Calculations of Fast-Neutron Energy Spectra," FZM-1267, Paper presented at the ANP Shielding Information Meeting, 2-3 December 1958, Convair Nuclear Laboratories, Fort Worth, Texas.

11. CONTENTS OF CODE PACKAGE

The package contains the following items:

a. the referenced documents,

b. a description of the STRAP calculation procedure,

c. a reel of magnetic tape on which is written in four files: the source and binary card decks for K-74 and STRAP; input and output for a sample problem; and an extensive $K-74$ library.

12. HOW TO OBTAIN PACKAGE

Inquiries or requests for the code package may be mailed to CODES COORDINATOR

Radiation Shielding Information Center

Cak Ridge National Laboratory

P. O. Box X

Oak Ridge, Tennessee 37830

or telephoned to

Area Code 615; 483-8611, extension 3-6944, or to FTS $\mathrm{xx}-615-483-6944$.

Persons requesting the package should send a reel of magnetic tape to the above address.

13. DATE OF ABSTRACT

January 1966. 
RSIC CODE PACKAGE CCC-9

\section{NAME AND TITLE OF CODE}

L-05: Monte Carlo Multibend-Duct Shielding Code.

The name of the above code was originally an internal accounting designation assigned by the GD Digital Computing Laboratory to this particular calculation procedure. In the absence of a formal name given by the originators of the code, RSIC adopted the above designation.

2. CONTRIBUTOR

USAF Nuclear Aerospace Research Facility, General Dynamics, Fort Worth, Texas.

3. CODING LANGUAGE AND COMPUTER

FAP; IBM 704, 7090 and 7094 .

4. NATURE OF PROBLEM SOLVED

I-05 is a procedure to evaluate the energy, angular distribution, and intensity of either the scattered neutron or gamma-ray flux that penetrates a straight cylindrical or a multibend duct. A neutron or gamma-ray source may be described with a set of from 1 to 30 point sources. The energy and angular distribution and the intensity of the scattered flux are calculated for each of a set of from 1 to 30 detector points.

The code has also been used extensively in the analysis of the gamma radiation environment above a fallout field, where the effect of the air-ground interface is taken into account.

The geometry routine is sufficiently flexible for the description of many of the shield configurations encountered in reactor, weapons, and space shielding. 


\section{METHOD OF SOLUTION}

The Monte Carlo method is presented as an approximation of the Neumann series solution of the integral transport equation. Included in the sampling techniques are splitting, Russian Roulette, statistical estimations, and a method of biasing the sampling from the source angular distributions.

The code provides for the calculation of the energy and angular distribution of the scattered neutron or gamma-ray flux, the total scattered neutron or gamma-ray flux and dose rates, and the direct beam neutron or gamma-ray flux and dose rate.

6. RESTRICTIONS OR IIMITATIONS

There are no known restrictions implied by storage allocation or argument range due to approximations.

7. TYPICAi, RUNNING TIME:

A rough approximation may be made by the expression: T(minutes) = (total number of collisions expected) $X$ (the number of detectors +1 ) $X$ (the number of material planes) all divided by the constant K (6,000 for neutrons and 10,000 for gamma-ray problems).

A direct beam problem uses very little machine time. These problems usually run from one to three minutes. An ll-detector problem uses approximately one minute of machine time.

Estimated running time of sample problem: 7 minutes.

8. COMPUTER HARDWARE REQUIREMENTS

The code was originally designed for the 32K IBM 704 computer. It was revised at the originating installation to be operable on the IBM 7090 and 7094 .

Execution requires 6 magnetic tape units on two channels.

\section{COMPUILR SOFIWARE REQUIREMENTS}

L-Ob) is designed to run in SIRAP V, the GD/IW operating system for the IBM 7090. The STRAP deck is included as a part of the program deck. It is run as a standard execute job in the IBM Fortran II Monitor System. SIRAP has a tape unit table built in, 
assigning 6 units to $\mathrm{A}$ and 6 to $\mathrm{B}$ channels. The format is identical to the FORTRAN IOU table and may be altered at will.

The packaged STRAP control deck is in binary. It has been unscrambled by RSIC; a FAP listing is included in the package.

L-05 source was written for SIRAP assembly. If assembled in any other operating system program linkage instructions must be deleted or modified.

The job deck, consisting of STRAP, calculation procedure and problem data including data library, is written as a file on the standard input tape. When the FORTRAN Monitor reaches this file, control is transferred to the STRAP Monitor via the XEQ card which, in turn, transfers control to L-05. Upon completion of the job, control returns to proper position in the monitor system.

The code uses B1, B2, and B4 tape units in addition to systems, input and output tapes.

10. REFERENCES

D. G. Collins, "A Monte Carlo Procedure for Calculating Penetration of Neutrons Through Straight Cylindrical Ducts," NARF-61-33T, MR-N-286 (November 24, 1961).

D. G. Collins, "A Monte Carlo Multibend Duct Procedure," NARF-62-13T, MR-N-297 (September 15, 1962).

D. G. Collins, "Utilization Instructions for General Application of the I-05 Monte Carlo Procedure," RRA-T44 (May 29, 1964).

\section{CONTENTS OF CODE PACKAGE}

The package contains the following items:

a. the referenced documents,

b. a description of the STRAP calculation procedure,

c. a reel of magnetic tape on which is written in four files respectively: the binary card deck set up to run the sample problem with $B C D$ input, including the library, the source card deck, output from the sample problem; a BCD listing of the STRAP unscramble. 
12. HOW TO OBTAIN PACKAGE

Inquiries or requests for the code package may be mailed to CODES COORDINATOR

Radiation Shielding Information Center

Oak Ridge National Laboratory

P. O. Box X

Oak Ridge, Tennessee 37830

or telephoned to

Area Code 615; 483-8611, extension 3-6944, or to

Fl'S xx-615-483-6944.

Persons requesting the package should send a reel of magnetic tape to the above address.

13. DATE OF ABSTRACT

January 1966. 


\section{RSIC CODE PACKAGE CCC-10}

1. NAME AND TITLE OF CODE

C-18: Monte Carlo Multilayer Slab Geometry Code. AUXILIARY ROUTINES

R-65: Data Generator.

R-35: Analysis and Dose Calculator.

RRA-02, -03, -11, and -18: Auxiliary Analysis and Converters of C-18 Results.

The code names $\mathrm{C}-18, \mathrm{R}-65$ and $\mathrm{R}-35$, were originally internal accounting designations assigned by the GD/FW Digital Computing Laboratory to these particular calculation procedures. In the absence of a formal name given by the originators of the codes RSIC adopted the above designations.

\section{CONTRIBUTORS}

USAF Nuclear Aerospace and Research Facility, General Dynamics, Fort Worth, Texas.

U. S. Army Tank Automotive Center, Warren, Michigan.

The auxiliary routines, RRA-02, $-03,-11$, and -18 were added to the code package by Radiation Research Associates, Fort Worth, Texas.

3. CODING LANGUAGE AND COMPUTER

FAP (C-18), STRAP FORTRAN (R-35 and R-65), FORTRAN II (RRA-02), FORIRAN IV (RRA-03, -11, and -18); IBM 7090 and 7094.

4. NATURE OF PROBLEM SOLVED

The code C-18 computes the spatial-energy distribution and the transmitted angular distribution of incident monodirectional primary neutron or gamma radiation for slab geometry. The calculated results are obtained in histogram form as printed output. The flux distribution within the slab is also obtained in the form of punched-card output for use in computing the production and transport of secondary particles. 
The code R-65 produces the coefficients of a Legendre expansion of the differential cross sections and will produce the corresponding normalized probability functions for use in C-18.

The code $\mathrm{R}-35$ computes the scattered dose rate at a detector behind a siab using the shield penetration probabilities generated by $\mathrm{C}-18$.

The code RRA-02 converts $\mathrm{C}-18$ results from transmitted dose rate currents in $10^{\circ}$ angular intervals to dose rate current per steradian and also calculates the total transmitted dose rate by integrating over the angular distribution of the transmitted dose rate current.

The code RRA-03 regroups the flux calculations from $\mathrm{C}-18$ over spatial and energy intervals and also computes the spatial distribution of the dose rate throughout the slab shield.

The code RRA-Il computes the dose received by a detector from radiation leaving a circular area on a plane slab using data obtained from RRA-C2.

The code RRA-18 converts RRA-02 output for monoenergetic sources to data for sources with a given energy distribution.

\section{METHOD OF SOLUTION}

The collision density and transmission probabilities are determined by Monte Carlo methods. All primary particles enter the slab assembly at the origin of the coordinate system and their direction of motion is defined by the polar and azimuthal angles. The primary source may be either monoenergetic or described by an input energy distribution function. Secondary source energies are described by input distribution functions. The spatial distribution is determined from a previous run.

Systematic sampling is used in sampling particle source energies and first-collision path lengths. The methods of forced collisions, exponential transformations, Russian Roulette, and statistical estimation are used. In addition there is available an importance sampling technique for choosing polar and azimuthal scattering angles. 
Provision is incorporated for continuing the transport of neutrons after reaching thermal energy. No further energy change is permitted.

In gamma ray problems, pair production and photoelectric processes are treated as absorption.

\section{RESTRICTIONS OR LIMITATIONS}

Exactly 5 laminar material regions

Maximum number of elements: 10

Maximum number of cross section energy points: 75

Maximum number of transmitted dose azimuthal-angle intervals: 16

Exactly nine transmitted dose polar-angle intervals

Exactly 25 flux energy intervals

Exactly 50 flux spatial intervals.

\section{TYPICAL RUNNING TIME}

The machine time required for a $\mathrm{C}-18$ problem is a function of the number of problems loaded at one time, the number of library decks required by the problems and the use of angle biasing. The machine initialization time may be approximated as two minutes plus 1-1/2 minutes for each library deck loaded. The time required for the solution of each problem may be approximated by the following formula:

$$
\mathrm{T} \text { (minutes) }=\frac{\mathrm{H}}{1000}[\mathrm{NC}][2+\mathrm{AB}]+1 \text { minute }
$$

where $\mathrm{H}$ is the total number of histories, NC is an estimate of the number of collisions per history, and $A B$ is the angle biasing option (o or 1).

A typical C-18 case of 5000 histories took 9.6 minutes on the IBM 7090. About 21000 collisions were processed. Fission spectrum neutrons entered a 25-cm-thick water slab at normal incidence.

No known recent studies on timing have been made for $\mathrm{R}-35$ and R-65. 
The packaged sample problem's estimated running time is as follows: R-65, 1 minute, $\mathrm{C}-18,12.7$ minutes, and $\mathrm{R}-35,4$ minutes.

\section{COMPUITER HARDWARE REQUIREMENTS}

The codes $\mathrm{C}-18, \mathrm{R}-65$ and $\mathrm{R}-35$ were originally designed for the $32 \mathrm{~K}$ IBM 704 computer. They were revised at the originating installation to be operable on the IBM 709, 7090, and 7094.

The code RRA-O2 is written in FORTRAN II language. The remaining auxiliary codes are written in FORTRAN IV.

Execution requires 8 magnetic tape units, 4 on $A$ and 4 on $B$ channels.

\section{COMPUTER SOFTWARE REQUIREMENTS}

$\mathrm{C}-18$ is designed to run in STRAP, the GD/FW operating system for the IBM 7090. The STRAP deck is included as a part of the program deck. It is run as a standard execute job in the IBM Fortran II Monitor System. STRAP has a tape unit table built in, assigning 7 units to $A$ and 6 to $B$ channels. The format is identical to the FORTRAN IOU table and may be altered at will.

The packaged STRAP control deck is in binary. It has been unscrambled by RSIC. A FAP listing is in the package.

C-I8 source was written for STRAF assembly. If assembled in any other operating system problem linkage instructions must be deleted or modified.

The job deck, consisting of STRAP, calculation procedure and problem data including data library, is written as a file on the standard input tape. When the FORTRAN Monitor reaches this file, control is transferred to the STRAP Monitor via the XEQ card which, in turn, transfers control to C-18. Upon completion of the job, control returns to proper position in the monitor system.

In addition to system, input, and output tapes, $\mathrm{C}-18$ uses tape units $\mathrm{A} 5, \mathrm{BI}, \mathrm{B} 2, \mathrm{~B} 3$, and $\mathrm{B} 4 ; \mathrm{R}-35$ uses $\mathrm{Bl}$ and $\mathrm{B} 4$; and $\mathrm{R}-65$ uses $\mathrm{A} 4, \mathrm{~B} 1, \mathrm{~B} 2$, and $\mathrm{B} 4$. 


\section{REFERENCES}

M. B. Wells, "Radiation Resistance Combat Vehicle Investigation-Final Report; Vol. III, Monte Carlo Multilayer Slab Geometry Shield Code C-18," FZK-134-3 (December 1961).

J. M. Newell, "Utilization Instructions for Radiation Research Program," RRA-N413 (July 1964).

\section{CONIENTS OF CODE PACKAGE}

The package contains the following items:

a. the referenced documents,

b. a description of the STRAP calculation procedure,

c. a reel of magnetic tape on which is written in seven files: the source and binary card decks for C-18, the auxiliary routines, and STRAF; BCD input and output for a sample problem; and an extensive C-18 library.

12. HOW TO OBTAIN PACKAGE

Inquiries or requests for the code package may be mailed to CODES COORDINATOR

Radiation Shielding Information Center

Oak Ridge National Laboratory

P. O. BoX X

Cak Ridge, Tennessee 37830

or telephoned to

Area Code 615; 483-8611, extension 3-6944, or to FTS Xx-615-483-6944.

Persons requesting the package should send a reel of magnetic tape to the above address.

13. DATE OF ABSTRACT

January 1966. 


\section{RSIC CODE PACKAGE CCC-II}

1. NAME AND TITLE OF CODE

SANE: Monte Carlo Spherical Multilayer Geometry Neutron Transport Shielding Code.

AUXILIARY ROUTINES

GENPRO and 80-Group GENDA: Element Data Tape Generator and Cross Section Iibrary.

DATORG: Organized Data Tape Generator.

The code SANE is the product of an evolutionary process. It started with the conception and flow charts of MIS by G. Goertzel. A Datatron 205 code was written by $F$. Oswald and R. Schaffer. It was recoded for the IBM 7090 by Celestron Associates, under subcontract to United Nuclear, and called MISCEL. Further development and a name change made by $W$. Guber, under the guidance of M. Kalos, provided the packaged code, SANE.

2. CONIRIBUTOR

United Nuclear Corporation, Development Division - NDA, White Plains, New York.

3. CODING LAIVGUAGE AND COMPUTER

FORTRAN (SANE) and FAP (GENPRO and DATORG); IBM 7090 and 7094.

4. NATURE OF PROBLEM SOLVED

SANE solves the neutron transport problem in spherically symmetric multilayer geometry. It computes neutron fluxes at the interior of the assembly. Fast dose at the exterior is also calculated. The code handles volume distribution fission or monoenergetic sources.

By the use of response functions and the flux output, the strength of secondary gamma sources produced by any neutron induced reaction can be computed throughout the configuration. 
5. METHOD OF SOLUTION

SANE is a Monte Carlo code that tracks neutrons through spherical shields composed of different physical compositions. All physical boundaries are flux boundaries and can also be splitting boundaries. Particle splitting is employed to improve the efficiency of the calculation. Flux boundaries may be placed anywhere and can be used to get detailed results.

The source energies are picked from a complete or truncated fission spectrum. The neutron starting region and radius are picked by a rejection technique using starting probabilities supplied as input.

The code considers the following neutron interactions: isotropic and anisotropic elastic scattering, discrete and continum inelastic scattering, scattering by hydrogen, the $(n, 2 n)$ reaction in beryllium, and absorption.

Particle histories are terminated when: an absorption occurs, the particle degrades below an arbitrary cutoff energy, a kill occurs due to splitting, or the particle escapes.

Cross-section data for the codes are obtained from a Master Element Data Tape. Cross-section data are stored on the tape by element. For each element the following data appear on the tape:

(a) probability of exciting a given level, as a function of the primary neutron energy, by inelastic scattering,

(b) list of possible excitation levels,

(c) tables of energies scattered with equal probability from the incident energy (for inelastic continuum scattering),

(d) tables of angular distributions for anisotropic scattering,

(e) probability of inelastic scattering,

(f) probability of elastic scattering,

(g) probability of absorption,

(h) microscopic total cross section,

(i) energy table.

Items (e) through (i) are tabulated as a function of energy in equal lethargy steps. The present codes allow for a maximum of 120 energies. Items (a), (c), and (d) are tabulated for those energy steps in which they are applicable. 
In addition to the usual output the code will also deliver the following: standard deviations for each flux, total absorptions for each radial region, total degradations for each radial region, total latents produced in each radial region, total kills for each radial region, and the total number of escapes.

6. RESTRICTIONS OR IIMITATIONS

Seventy-five flux or physical regions and 40 output energy bins are allowed.

7. TYPICAL RUNNING TIME

Time is a function of the statistical accuracy desired. Shields having attenuations of the order of $10^{7}$ have been fully studied (primary neutrons and secondary gammas) in approximately 80 minutes of 7090 time. An average collision time averaged over many different problems gives about 5 milliseconds per collision.

8. COMPUTER HARDWARE REQUTREMENTS

Execution requires a 32K IBM 7090 or 7094 , and 6 tape units on each of two channels. Standard off-line card-to-tape and printer equipment may be used. On-line printer is used under sense switch option. Sense switches 1, 2, 4, and 5 are used for various types of edits.

\section{COMPUIER SOFTWARE REQUIREMENTS}

The codes are designed for the IBM 7090 and are executed through the FORTRAN II Monitor System. Provisions are available for generating a master program tape for routine production.

The SANE code contains intermediate dump and intermediate edit options. It is possible to obtain an edit through the use of sense switches although the input number of histories has not been processed. On-line print-outs are available as sense switch options.

The intermediate tape dump and restart are accomplished through a FAP-coded saving and restore subroutine (NU RSOS) obtained from the AEC Computing Center, New York University.

An IOU table was added by RSIC. It may be easily altered. There are $6 \mathrm{~A}$ and $6 \mathrm{~B}$ channel units assigned. 
10. REFERENCES

Walter Guber and Martin Shapiro, "Advanced Shield Calculational Techniques - Volume III: A Description of the Sane and Sage Programs," UNUCOR-633 (March 1963).

Morton R. Fleishman, "Advanced Shield Calculational Techniques Volume IV: A Sane-Sage User's Guide," UNUCOR-634 (March 1963).

11. CONTENTS OF CODE PACKAGE

The package contains the following items:

a. the referenced documents,

b. a description of NU RSOS and its use,

c. a reel of magnetic tape on which is vitten in separate files: the source and binary card decks for each code, BCD input and output for a sample problem, and the library of cross sections for use with the code.

12. HOW TO OBTAIN PACKAGE

Inquiries or requests for the code package may be mailed to CODFS COORDINATOR

Radiation Shielding Information Center

Oak Ridge National Laboratory

P. O. Box X

Cak Ridge, rennessee 37830

or telephoned to

Area Code 615; 483-8611, extension 3-6944, or to

FTS $x x-615-483-6944$.

Persons requesting the package should send a reel of magnetic tape to the above address.

\section{DATE OF ABSTRACT}

January 1966. 
RSIC CODE PACKAGE CCC-12

1. NAME AND TITLE OF CODE

SAGE: Monte Carlo Spherical and Multilayer Geometry Gamma Transport Shielding Code.

\section{AUXIIIARY ROUTINES}

GENPRO and Gamma GENDA: Element Data Tape Generator and Cross Section Library.

DATORG: Organized Data Tape Generator.

A gamma-ray version of the SANE code (CCC-11), SAGE, was prepared by $W$. Guber following flow charts prepared by J. Celnik (source generation) and under the guidance of M. Kalos.

2. CONTRIBUTOR

United Nuclear Corporation, Development Division - NDA, White Plains, New York.

3. CODING IAANGUAGE AND COMPUTER

FORIRAN (SAGE) and FAP (GENPRO and DATORG); IBM 7090 and 7094.

4. NATURE OF PROBLEM SOLVED

SAGE solves the gamma transport problem in spherically symmetric multilayer geometry. It computes gamma fluxes at the interior of the assembly. Fast dose at the exterior is also calculated. It handles volume distributed monoenergetic gamma sources.

5. METHOD OF SOLUTION

SAGE is a Monte Carlo Code which tracks gammas through spherical shields composed of different physical compositions. All physical boundaries are flux boundaries and can also be splitting boundaries. Particle splitting is employed to improve the efficiency of the calculation. Flux boundaries may be placed anywhere and can be used to get detailed results.

SAGE handles a monoenergetic source. The source is specified as piece-wise exponential in the radial source regions. A rejection technique is used to pick from the exponential distribution.

$$
-47-
$$


The Compton scattering of photons is considered. The photoelectric effect and pair production are regarded as absorption processes.

Particle histories are terminated when: an absorption occurs, the particle degrades below an arbitrary cutoff energy, a kill occurs due to splitting, or the particle escapes.

Cross-section data are obtained from a Master Element Data Tape on which the data are stored by element. For each element the following data appear on the tape: probability of elastic scattering, probability of absorption, microscopic total cross section, and an energy table. These data are tabulated as a function of energy in equal lethargy steps. The present programs allow for a maximum of 120 energies.

In addition to the usual output, the code will also deliver the following: standard deviations for each flux, total absorptions for each radial region, total degradations for each radial region, total latents produced in each radial region, total kills for each radial region, and the total number of escapes.

6. RESTRICTIONS OR IIMITATIONS

Seventy-five flux or physical regions and 40 output energy bins are allowed.

7. TYPICAL RUNNING TIME

Time is a function of the statistical accuracy desired. Shields having attenuations of the order of $10^{7}$ have been fully studied (primary and secondary gammas) in approximately 80 minutes of 7090 time. An average collision time averaged over many different problems gives about 5 milliseconds per collision.

8. COMPUTER IAARDWARE REQUIREMENTS

Execution requires a $32 \mathrm{~K}$ IBM 7090 or 7094 , and 6 tape units on each of two channels. Standard off-line card-to-tape and printer equipment may be used. The on-line printer is used under sense switch option. Sense switches 1, 2, 4, and 5 are used for various types of edits. 


\section{COMPUTER SOFTWARE REQUTREMENTS}

The codes are designed for the IBM 7090 and are executed through the FORTRAN II Monitor System. Provisions are available for generating a master program tape for routine production.

The SAGE code contains intermediate dump and intermediate edit options. It is possible to obtain an edit through the use of sense switches although the input number of histories has not been processed. On-line print-outs are available as sense switch options.

The intermediate tape dump and restart are accomplished through a FAP coded saving and restore subroutine NU RSOS obtained from the AEC Computing Center, New York University.

An IOU table was added by RSIC. It may be easily altered. Six tape units are assigned to A channel and 6 to $\mathrm{B}$ channel.

10. REFERENCES

Walter Guber and Martin Shapiro, "Advanced Shield Calculational Techniques - Volume III: A Description of the Sane and Sage Programs," UNUCOR-633 (March 1963).

Morton R. Fleishman, "Advanced Shield Calculational Techniques Volume IV: A Sane-Sage User's Guide," UNUCOR-634 (March 1963).

11. CONTENTS OF CODE PACKAGE

The package contains the following items:

a. the referenced documents,

b. a description of NU RSOS and its use.

c. a reel of magnetic tape on which is written in separate files: the source and binary card decks for each code, BCD input and output for a sample problem, and the library of cross sections for use with the code.

12. HOW TO OBTAIN PACKAGE

Inquiries or requests for the code package may be mailed to CODES COORDINATOR

Radiation Shielding Information Center

Oak Ridge National Laboratory

P. O. Box X

Oak Ridge, Tennessee 37830 
or telephoned to

Area Code 615; 483-8611, extension 3-6944, or to

FTS $x x-615-483-6944$.

Persons requesting the package should send a reel of magnetic tape to the above address.

13. DATE OF ABSTRACT

January 1966. 
RSIC CODE PACKAGE CCC-13A

1. NAME AND TITLE OF CODE

ADONIS: Monte Carlo Three-Dimensional Rectangular Geometry Shielding code.

AUXILIARY ROUTINES

GENDA and GENPRO: Element Data Tape Generators - Neutron and Gamma-Ray Cross Sections.

DATORG: Organized Data Tape Generator.

STGEN, PSGEN, ANGEN, GASP: Source Data Generators.

EZGEOM: Geometry Data Generator.

TEST-G: Geometry Diagnostic Routine.

UNIGEOM: Modified EZGEOM, Incorporating TEST-G.

\section{CONIRIBUTORS}

United Nuclear Corporation, Development Division - NDA, White Plains, New York.

The auxiliary code, UNIGEOM, was added to the package by the U. S. Naval Civil Engineering Laboratory, Port Hueneme, California.

3. CODING IAINGUAGE AND COMPUTER

ADONIS (FORTRAN and FAP); GENDA (FAP); GENPRO (FAP); DATORG (FAP); STGEN, PSGEN, AIVGEN, GASP, TEST-G, EZGEOM, and UNIGEOM (FORTRAN); IBM 7090 and 7094.

4. NATURE OF PROBLEM SOLVED

ADONIS calculates the solution to the transport equation for primary neutrons (or gamma rays) in a three-dimensional rectangular geometry. The program computes either neutron or gamma-ray fluxes and their standard deviations in each of up to 80 regions. By use of response functions, dose and strength of secondary gamma rays from any neutron induced reaction can be computed throughout the configuration. In addition, it is possible to generate a population of secondary gamma rays as input to a gamma ADONIS problem by appropriate editing of a tape record of interactions generated 
in an associated neutron ADONIS problem. In particular the code has proved useful in analyzing the penetration of neutrons or gamma rays through ducted shields.

\section{METHOD OF SOLUTION}

ADONIS is a Monte Carlo code that tracks either neutrons or gamma rays through shields composed of rectangular parallelepipeds of differing compositions. Particle splitting is employed to improve the efficiency of the calculation by assigning importance weights to each of the regions.

A source tape containing the position coordinates, direction cosines, and the initial energy of the neutron or gamma ray is required.

The code considers the following neutron interactions: isotropic and anisotropic elastic scattering, discrete and continuum inelastic scattering, scattering by hydrogen, the $(n, 2 n)$ reaction in beryllium, and absorption.

The gamma portion of the code considers the Compton scattering of photons. The photoelectric effect and pair production are regarded as absorption processes.

Particle histories in ADONIS are terminated when: an absorption occurs, the particle degrades below an arbitrary cutoff energy, a kill occurs due to splitting, or the particle escapes.

Cross-section data are obtained from a Master Element Data Tape for either neutrons or gamma rays prepared from GENDA and GENPRO.

The source may be a plane, uniformly distributed over a particular rectangular area on the incoming surface of the shield, either normal to the surface or isotropically distributed (STGEN). The code PSGEN generates data for a point source, isotropically distributed within a region. If the source is a point with an anisotropic angular distribution ANGEN may be used. GASP is used to generate a secondary gamma ray source tape from an interaction tape generated by the associated neutron ADONIS problem.

UNIGIOM is a special routine designed to handle duct problems. 


\section{RESTRICTIONS OR LIMITATIONS}

A maximum of 80 regions may be used, where a region is defined as a rectangular parallelepiped of either finite or infinite dimensions. The totality of all such regions covers $x, y$, and $z$ space. A maximum of 80 complex surfaces is permitted. A complex surface is defined as a side of a parallelepiped adjacent to more than one region. A maximum of 10 energy bins in which fluxes are stored may be used.

7. TYPICAL RUNNING TIME

The computation time required for a given thickness depends upon the choice of the importance veights assigned to the various regions, therefore, it is impossible to give a good estimate of the time required to obtain a given accuracy. However, in a series of problems having a 2-foot shield of steel and paraffin, an average of 15 minutes per problem was required for statistics good to 25\%, in a 40-region problem having 10,000 source neutrons.

8. COMPUTER HARDWARE REQUIREMENTS

To execute ADONIS, an IBM 7090 or 7094 and 10 tape units are required.

\section{COMPUTER SOFTWARE REQUIREMENTS}

The codes were designed for IBM FORTRAN II and may be run on any of the standard versions. An IOU table has been added and may be changed at will.

\section{REFERENCES}

Burton Eisenman and Elinor Hennessy, "ADONIS - An IBM 7090 Monte Carlo Shielding Code Which Solves for the Transport of Neutrons or Gamma Rays in Three-Dimensional Rectangular Geometry," United Nuclear Corporation, UNUCOR-635 (March 1963).

Leonard B. Gardner and Alan J. Mettler, "Monte Carlo Calculation of Neutron Streaming Through Two-Legged Duct Entranceways," USNCEI-tr-R379 (June 1965). 
11. CONTENTS OF CODE PACKAGE

The package contains the following items:

a. the referenced documents,

b. supplemental data sheets and other written material,

c. a reel of magnetic tape on which is written in separate files: the source card decks, the binary card decks, input and output for a sample problem for each of the codes in the package,

d. a reel of magnetic tape on which is written the libraries of neutron and gamma-ray cross sections.

12. HOW TO OBTAIN PACKAGE

Inquiries or requests for the package may be mailed to CODES COORDINATOR Radiation Shielding Information Center

Oak Ridge National Laboratory

P. O. BoX X

Cak Ridge, Tennessee 37830

or telephoned to

Area Code 615; 483-8611, extension 3-6944, or to

FTS $\mathrm{xx}-615-483-6944$.

Persons requesting the package should send two reels of magnetic tape to the above address.

13. DAIE OF ABSTRACT

January 1966. 
RSIC CODE PACKAGE CCC-13B

1. NAME AID TITIE OF CODE

ADONIS: Monte Carlo Three-Dimensional Rectangular Geometry Shielding Code.

AUXILIARY ROUTINES

GENDA, GENPRO: Element Data Tape Generators - Neutron and Gamma-Ray Cross Sections.

DATORG: Organized Data Tape Generator.

GASP, VANGEN: Source Data Generators.

EZGEOM: Geometry Data Generator.

GRDDCNT: Analysis Code.

2. CONIRIBUTORS

United Nuclear Corporation, Development Division - NDA, White Plains, New York.

3. CODING IANGUAGE AND COMPUTER

ADONIS (FORTRAN and CODAP); GENDA and GENPRO (FORTRAN); DATORG (FORTRAN, CODAP); GASP, VANGEN, EZGEOM, and GRDDCNT (FORTRAN); CDC 1604.

4. NTATURE OF PROBLEM SOLVED

ADONIS calculates the solution to the transport equation for primary neutrons (or gamma rays) in a three-dimensional rectangular geometry. The program computes either neutron or gamma-ray fluxes and their standard deviations in each of up to 80 regions. By use of response functions, dose and strength of secondary gamma rays from any neutron induced reaction can be computed throughout the configuration. In addition, it is possible to generate a population of secondary gamma rays as input to a gamma ADONIS problem by appropriate editing of a tape record of interactions generated in an associated neutron ADONIS problem. In particular the code has proved useful in analyzing the penetration of neutrons or gamma rays through ducted shields. 


\section{METHOD OF SOLUTION}

ADONIS is a Monte Carlo Code that tracks either neutrons or gamma rays through shields composed of rectangular parallelepipeds of differing compositions. Particle splitting is employed to improve the efficiency of the calculation by assigning importance weights to each of the regions.

A source tape containing the position coordinates, direction cosines, and the initial energy of the neutron or gamma ray is required.

The code considers the following neutron interactions: isotropic and anisotropic elastic scattering, discrete and continuum inelastic scattering, scattering by hydrogen, the $(n, 2 n)$ reaction in beryllium, and absorption.

The gamma-ray portion of the code considers the Compton scattering of photons. The photoelectric effect and pair production are regarded as absorption processes.

Particle histories in ADONIS are terminated when: an absorption occurs, the particle degrades below an arbitrary cutoff energy, a kill occurs due to splitting, or the particle escapes.

Cross-section data are obtained from a Master Element Data Tape for either neutrons or gamma rays prepared from GENDA and GENPRO.

VANGEN and GASP are the source data generators for the CCC-13B version of ADONIS. The VAINGEN code generates data for the point source, the plane source, and the volume source, replacing PSGEN, ANGEN, and STGEN of CCC-13A and adding a new volume source option.

There is no dump feature in this version.

\section{RESTRICTIONS OR ITMITATIONS}

A maximum of 80 regions may be used, where a region is defined as a rectangular parallelepiped of either finite or infinite dimensions. The totality of all such regions covers $x, y$, and $z$ space. A maximum of 80 complex surfaces is permitted. A complex surface is defined as a side of a parallelepiped adjacent to more than one region. A maximum of 10 energy bins in which fluxes are stored may be used. 
7. TYPICAL RUNNING TIME

The computation time required for a given thickness depends upon the choice of the importance weights assigned to the various regions, therefore, it is impossible to give a good estimate of the time required to obtain a given accuracy. However, in a series of problems having a 2-foot shield of steel and paraffin, an average of 15 minutes per problem was required for statistics good to $25 \%$, in a 40-region problem having 10,000 source neutrons.

8. COMPUTER HARDWARE REQUTREMENTS

CDC 1607, 1604; 088 Card Reader; 1612 Printer; 10 tape units on at least two channels.

9. COMPUIER SOFTWARE REQUIREMENTS

The CCC-13B version of ADONIS may be run on FORTRAN 62 or FORTRAN 63 Monitor System. An IOU table has been added and may be shanger a.t. wi 11 .

\section{REFERENCE}

Burton Eisenman and Elinor Hennessy, "ADONIS - An IBM 7090 Monte Carlo Shielding Code Which Solves for the Transport of Neutrons or Gamma Rays in Three-Dimensional Rectangular Geometry," United Nuclear Corporation, UNUCOR-635 (March 1963).

11. CONIEENTS OF PACKAGE

The package contains the following items:

a. the referenced document,

b. supplemental data sheets and other written material,

c. a reel of magnetic tape on which is written in fifteen files: the source card decks, the binary card decks, input and output for sample problems for each of the codes in the package,

d. a reel of magnetic tape on which is written cross section libraries for neutrons and gamma rays. 
12. HOW TO OBTAIN PACKAGE

Inquiries or requests for the code package may be mailed to CODES COORDINATOR

Radiation Shielding Information Center

Oak Ridge National Laboratory

P. O. Box X

Oak Ridge, Tennessee 37830

or telephoned to

Area Code 615; 483-8611, extension 3-6944, or to

FTS $\mathrm{xx}-615-483-694_{4}$.

Persons requesting the package should send two reels of magnetic

tape to the above address.

13. DATE OF ABSTRACT

January 1966. 
RSIC CODE PACKAGE CCC-14

1. NAME AND TITLE OF CODE

FMC-G: Monte Carlo Simulation of Gamma-Ray Life Histories in a Source-Shield Configuration.

AUXILIARY ROUTINES

20-2: Iruclear Data Generator (Elastic and inelastic cross sections as functions of energy).

20-4: Nuclear Data Generator (Angular distribution data for elastic scattering events).

SG: Source Generator.

The lames of the first two auxiliary codas follow a Shiclaing Program Number sequence for shielding codes established by the contributing installation, the number following the dash indicating the version or revision of a family of codes. In addition, a department code numbering system is followed: interna11y, the codes are known respectively as GE-NMPO Nos. 481, 483, 484, and 485; $\mathrm{FMC}-\mathrm{G}$ is numbered 515 and $\mathrm{SG}$ is known as NMPO No. 707 .

2. CONIRIBUTOR

Nuclear Materials and Propulsion Operation, General Electric Company, Cincinnati, Ohio.

3. CODING IANGUAGE AND COMPUTER

FAP (FMC-G, SG), FORTRAN II (20-2, 20-4); IBM 7090 and 7094.

4. NATURE OF PROBIEM SOLVED

FMC-G solves the transport equation, as related to radiation shielding, with some degree of generality. It provides flexibility in the geometrical, material, nuclear, and source descriptions of source-shield configurations and variance reduction techniques. Homogeneous regions are enclosed by surfaces described by the genera] equation

$$
A X^{2}+X_{O} X+B Y^{2}+Y_{O} Y+C Z^{2}+Z_{O} Z-K=0
$$


Output includes independently optional absorption or energy deposition tallies, Monte Carlo entrance and leakage tallies, expectation entrance and leakage tallies, Monte Carlo or expectation flux tallies, and history tallies of particles reaching selected regions. The absorption or energy deposition, entrance, leakage and flux tallies are made by region and energy group. Parameters of secondary gamma rays are stored on tape for later analysis.

\section{METHOD OF SOLUTION}

A non-optional statistical estimation technique of weighting for absorption escape is applied at each collision. Optional statistical estimation technique may be used for scoring entrance tallies and mandatory leakage tallies. Flexibility in sampling from source spectra is achieved by using energy group-averaged acceleration factors. Importance sampling options are: (1) splitting and Russian Roulette depending on energy, region, and location within a region, (2) Russian Roulette on particles whose weight falls below the veight cutoff, and (3) exponential transformation.

The Source Generator applies statistical methods to generate the seven parameters required to describe source particles for FMC-G. These parameters are stored on magnetic tape for later Monte Carlo processing. The code provides three methods for generation of the source-particle's direction cosines, three methods for generation of the source-particle's spatial coordinates, and one method for generation of the source-particle's energy. Any or all of these parameters may also be entered as input.

The code 20-2 approximates cross-section dependence on energy by discontinuous straight line segments across specified energy groups. Output is available on punched cards suitable for input to FMC. A printed listing is also prepared.

The code 20-4 averages input differential-scattering cross sections over specified energy grours to obtain angular distribution 
data in the form of cumulative probability tables suitable for use in FMC. Differential-scattering cross-section input data can be either in the form of a two-dimensional tabular array of $\sigma_{e}^{m}(\bar{\Sigma}, \mu)$ or a set of one-dimensional tabular arrays of Legendre polynomial coefficients. Output is available as a printed listing and as punched card input to FMC.

6. RESTRICTIONS OR LIMITATIONS

There are no limitations on size of individual input quantities to FMC. The following table indicates limitations in connection with auxiliary codes.

20-2: Number of energy groups $\leq 100$

ivumber of materiais $\leq 20$

20-4: Number of energy groups $\leq 100$

Number of entries of angle variable $\leq 100$

Order of Legendre polynomial $\leq 15$.

7. TYPICAI RUNNING TIME

FMC-G: The sample problem described in APEX-706 ran 2.0 minutes on the IBM 7090.

20-2: Neutron cross sections prepared for 11 materials and 19 energy groups ran in 12 minutes.

20-4: Data prepared for 3 materials, 19 energy groups, and 10 angle intervals ran in 4.5 minutes.

\section{COMPUTER HARDWARE REQUIREMENTS}

Eight magnetic tape units and a 32,769 core memory are necessary for processing on the IBM 704 computer. IBM 7090 processing requires 32,768 core memory and ten magnetic tape units on two data channels.

\section{COMPUTER SOFTWARE REQUIREMENTS}

FMC is a nonmonitor job with tape read initialized by an on-line one-card binary loader. Transfer is made to a manager routine, either PKl or 9ULOAD, depending on which code is used. Those written in FAP require PKI. 9ULOAD is used for the relocatable FORTRAN decks. 
PKI, a GE-NMPO written Manager and I-O package, includes absolute FAP assembly versions of FIOP, MINIM, and DOP. 9ULOAD is an IBM distributed routine.

The working deck is complete with all necessary library-type routines included.

\section{REFERENCES}

J. J. Loechler and J. E. MacDonald, "Flexible Monte Carlo Programs FMC-N and FMC-G," APEX-706 (April 1961).

J. P. Yalch and J. E. MacDonald, "Program 20-2, A Program for Approximating Cross Section Dependence on Energy," GEMP-113 (June 1962).

J. P. Yalch and J. E. MacDonald, "Program 20-4, A Program for Averaging Differential Scattering Cross Sections," GEMP-115 (June 1962 ).

J. J. Loechler, "Flexible Monte Carlo Source Generation," XDC 61-4-52 (April 1961).

\section{CONTENTS OF CODE PACKAGE}

The package contains the following items:

a. the referenced documents,

b. a description of PKl Manager routine,

c. a one-card binary on-line loader,

d. a reel of magnetic tape on which is written in separate files: the source and binary card decks of FMC-G and the auxiliary routines; $B C D$ input and output for sample problems set up for each code.

12. HOW TO OBTAIN PACKAGE

Inquiries or requests for the code package may be mailed to CODES COORDINATOR

Radiation Shielding Information Center

Oak Ridge National Laboratory

P. O. Box X

Oak Ridge, Tennessee 37830

or telephoned to

Area Code 615; 483-8611, extension 3-6944, or to

FTS xx-615-483-6944. 
$14 \cdot 5$

Persons requesting the package should send a reel of magnetic tape to the above address.

13. DAIE OF ABSTRACT

January 1966. 
RSIC CODE PACKAGE CCC-15

1. NAME AND TITLE OF CODE

FMC-N: Monte Carlo Simulation of Neutron Life Histories in a Source-Shield Configuration.

AUXILIARY ROUTINES

20-2: Nuclear Data Generator (Elastic and inelastic cross sections as functions of energy).

20-4: Nuclear Data Generator (Angular distribution data for elastic scattering events).

20-5: Nuclear Data Generator (Inelastic neutron spectrum probability tables).

20-6: Nuclear Data Generator (Excitation and transition probabilities).

$\mathrm{SG}$ : Source generator.

The names of the first four auxiliary codes follow a shielding Program Number sequence for shielding codes established by the contributing installation, the number following the dash indicating the version or revision of a family of codes. In addition, a department code numbering system is followed: internally, the codes are known respectively as GE-NMPO Nos. 481, 483, 484, and 485; FMC-N is numbered 516 and SG is known as NMPO No. 707 .

2. CONTRIBUTOR

Nuclear Materials and Propulsion Operation, General Electric Company, Cincinnati, Ohio.

3. CODING LANGUAGE AND COMPUTER

FAP (FMC-N, SG), FORTRAN II (20-2, 20-4, 20-5, 20-6); IBM 7090 and 7094 .

4. NATURE OF PROBLEM SOLVED

FMC-N solves the transport equation, as related to radiation shielding, with some degree of generality. It provides flexibility in the geometrical, material, nuclear, and source descriptions of source-shield configurations and variance reduction techniques. 
Homogereous regions are enclosed by surfaces described by the general equation

$$
A X^{2}+X_{O} X+B Y^{2}+Y_{O} Y+C Z^{2}+Z_{O} Z-K=0
$$

Output includes independently optional absorption or energy deposition tallies, Monte Carlo entrance and leakage tallies, expectation entrance and leakage tallies, Monte Carlo or expectation flux tallies, and history tallies of particles reaching selected regions. The absorption or energy deposition, entrance, leakage and flux tallies are made by region and energy group. Parameters of secondary neutrons are stored on tape for later analysis.

\section{METHOD OF SOLUTION}

FMC-N applies Monte Carlo methods to simulate neutron histories in source-shield configurations. A non-optional statistical estimation technique of weighting for absorption escape is applied at each collision. Optional statistical estimation technique may be used for scoring entrance tallies and mandatory leakage tallies. Flexibility in sampling from source spectra is achieved by using energy group-averaged acceleration factors. Importance sampling options are: (1) splitting and Russian Roulette depending on energy, region, and location within a region, (2) Russian Roulette on particles whose weight falls below the weight cutoff, and (3) exponential transformation.

The Source Generator applies statistical methods to generate the seven parameters required to describe source particles for FMC-N. These parameters are stored on magnetic tape for later Monte Carlo processing. The code provides three methods for generation of the source-particle's direction cosines, three methods for generation of the source-particle's spatial coordinates, and one method for generation of the source-particle's energy. Any or all of these parameters may also be entered as input. 
The code 20-2 approximates cross-section dependence on energy by discontinuous straight line segments across specified energy groups. Output is available on punched cards suitable for input to FMC. A printed listing is also prepared.

The code 20-4 averages input differential-scattering cross sections over specified energy groups to obtain angular distribution data in the form of cumulative probability tables suitable for use in FMC. Differential-scattering cross-section input data can be either in the form of a two-dimensional tabular array of $\sigma_{e}^{m}(E, \mu)$ or a set of one-dimensional tabular arrays of Legendre polynomial coefficients. Output is available as a printed listing and as punched card input to FMC.

The code 20-5 applies the evaporation model of nuclear reactions to determine cumulative probability tables for energy spectra of inelastically scattered neutrons. Output includes a printed listing and punched cards suitable for input to FMC.

The code 20-6 computes excitation and transition probabilities for excited states of the residual nucleus from a neutron inelasticscattering reaction given the relative gamma-ray intensities of the

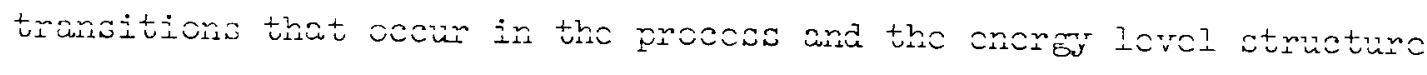
of the nucleus. Output is of printed form only.

\section{RESTRICTIONS OR LIMITATIONS}

There are no limitations on size of individual input quantities to FMC. The following table indicates limitations in connection with auxiliary codes.

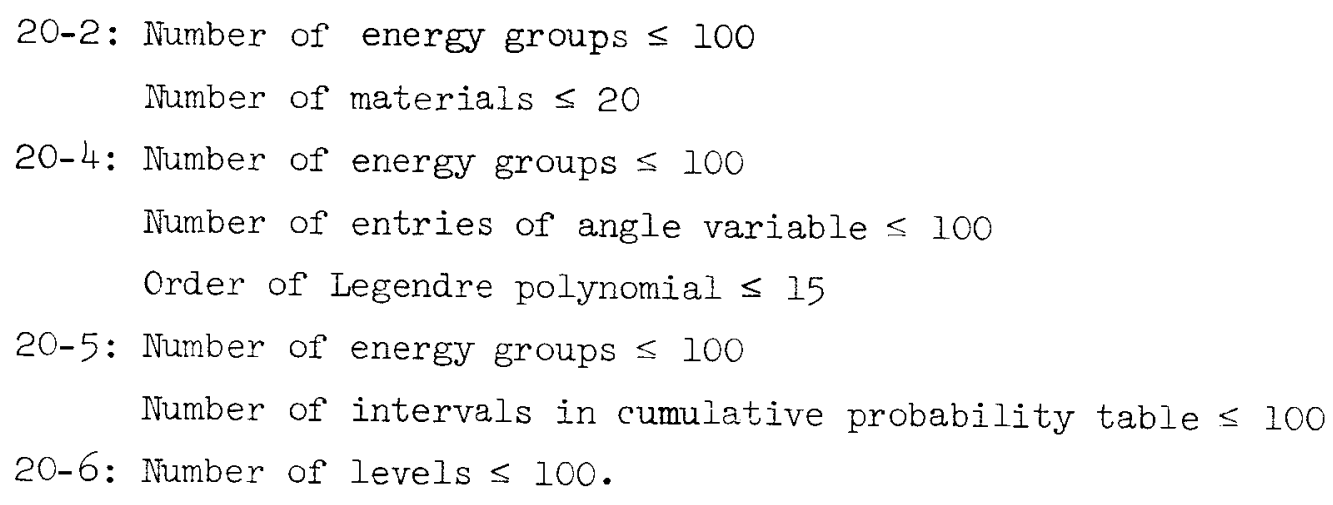




\section{TYPICAI RUNNING TIME}

FMC-N: The sample problem described in APEX-706 ran 3.1 minutes on the IBM 7090.

20-2: Neutron cross sections prepared for 11 materials and 19 energy groups in 12 minutes.

20-4: Data prepared for 3 materials, 19 energy groups, and 10 angle intervals in 4.5 minutes.

20-5: Data prepared for 4 materials and 10 energy groups in 0.6 minute.

20-6: Sample problem ran for approximately 0.75 minute.

\section{COMPUTER HARDWARE REQUIREMENTS}

Eight magnetic tape units and a 32,769 core memory are necessary for processing on the IBM 704 computer. IBM 7090 processing requires a 32,768 core memory and ten magnetic tape units on two data channels.

9. COMPUTER SOFTWARE REQUIREMENTS

FMC is a nonmonitor job with tape read initialized by an online one-card binary loader. Transfer is made to a manager routine, either PKl or 9ULOAD, depending on which code is used. Those written in FAP require $\mathrm{PKI}$. GULOAD is used for the relocatable FORTRAN decks.

PKl, a GE-NMPC written Manager and I-O package, includes absolute FAP assembly versions of FLOP, MINIM, and DOP. GULOAD is an IBM distributed routine.

The working deck is complete with all necessary library-type routines included.

10. REFERENCES

J. J. Loechler and J. E. MacDonald, "Flexible Monte Carlo Programs FMC-N and FMC-G," AFEX-706 (April 1961).

J. P. Yalch and J. E. MacDonald, "Program 20-2, A Program for Approximating Cross Section Dependence on Energy," GEMP-113 (June 1962). 
J. P. Yalch and J. E. MacDonald, "Program 20-4, A Program for Averaging Differential Scattering Cross Sections," GEMP-115 (June $1962)$.

J. P. Yalch and J. E. MacDonald, "Program 20-5, A Program for Preparation of Spectrum Tables from Evaporation Model, "GEMP-116 (June 1962).

J. P. Yalch and J. E. MacDonald, "Program 20-6, A Program for Computing Nuclear Excitation and Transition Probabilities from Measured Gamma Ray Intensities," GEMP-117 (June 1962).

J. J. Loechler, "Flexible Monte Carlo Source Generation," XDC 61-4-52 (April 1961).

L. S. Burns, "A Neutron Cross Section Library for Monte Carlo Codes FMC-N, 18-0, and 18-1," GEMP-384 (August 1965).

11. CONTENTS OF CODE PACKAGE

The package contains the following items:

a. the referenced documents,

b. a description of PKI Manager routine,

c. a one-card binary on-line loader,

d. a reel of magnetic tape on which is written in separate files: the source and binary card decks of FMC-N and the auxiliary routines; BCD input and output for sample problems set up for each code; a library of neutron cross sections.

12. HOW TO OBTAIN PACKAGE

Inquiries or requests for code package may be mailed to

CODES COORDINATOR

Radiation Shielding Information Center

Cak Ridge National Laboratory

P. O. BoX X

Oak Ridge, Tennessee 37830

or telephoned to

Area Code 615; 483-8611, extension 3-6944, or to

FTS xx-615-483-6944.

Persons requesting the package should send a reel of magnetic tape to the above address. 
13. DATE OF ABSTRACT

January 1966. 
RSIC CODE PACKAGE CCC-16

1. NAME AND TITLE OF CODE

18-0: Monte Carlo Simulation of Neutron and Gamma-Ray Life Histories in Reactor-Shield Assemblies (CCC-16A). 18-1: Modified 18-C (CCC-16B).

AUXILIARY ROUTINES

20-0: Source Generator.

20-2: Nuclear Data Generator (Elastic and inelastic cross sections as functions of energy).

20-3: Nuclear Data Generator (Macroscopic total cross sections and individual cross-section ratios, as functions of energy).

20-4: Nuclear Data Generator (Angular distribution data for elastic scattering events).

20-5: Nuclear Data Generator (Inelastic neutron spectrum probability tables).

20-6: Nuclear Data Generator (Excitation and transition probabilities).

20-7: Shield-Region Data Converter (Geometry).

20-8: Particle Tape Analyzer (Source and escape particies, for 18-0).

The names of the above codes follow a Shielding Program Number sequence for shielding codes established by the contributing installation, the number following the dash indicating the version or revision of a family of codes. In addition, a department code numbering system is followed: internally, the codes are known respectively as GE-NMPO Nos. 349, 398, 481, 482, 483, 484, 485, 486 and 487 .

2. CONTRIBUTOR

Nuclear Materials and Propulsion Operation, General Electric Company, Cincinnati, Ohio. 
3. CODING LANGUAGE AND COMPUTER

CCC-16A: FAP (18-0, 20-0, 20-7), FORTRAN II and FAP (20-8), FORTRAN II (20-2, 20-3, 20-4, 20-5, 20-6); IBM 7090 and 7094. CCC-16B: FAP (18-1); IBM 7090 and 7094 .

4. NATURE OF PROBIEM SOIVIID

The code 18-0 is designed to provide: energy deposition in each shield region due to certain neutron and gamma-ray reactions; energy-angle leakage distribution for neutrons and gamma rays for a point source equivalent to the assembly, or, optionally, a tape record of the parameters of escaping particles. Parameters of generated secondary particles may form part of the output.

Source particles are generated in source tubes defined by right circular cylinders with mutually parallel axes of symmetry. A point source and treatment of an entire reactor as a single source tube can also be handled.

The code $18-1$ is an extension of $18-0$ to include determination of flux distributions in energy in specified shield regions and preparation of a collision parameter tape.

\section{MELIIOD OF SOLUTION}

The code 18-0 applies Monte Carlo methods to simulate neutron and gamma-ray histories in reactor-shield assemblies.

A shield region geometry routine is used by $18-0$ for source and shield regions that can be approximated by contiguous homogeneous regions that are formed by rotation of a class of simply connected quadrilaterals about the reactor-shield assembly axis. A reactor geometry subroutine is provided for approximate analysis of reactors with off-axis cylindrical fuel cells.

Importance sampling techniques of splitting and Russian Roulette on energy and region for neutrons and on region for gamma rays are optionally allowed.

The code 20-0 generates and writes on tape the source-particle parameters to be used as input for 18-0. In this code sourceparticle spatial coordinates are chosen from appropriate sourcedensity distributions by one of two methods: a random method based 
on uniformly distributed random numbers, and a systematic method that determines the number of source particles to be started from specified volume elements. The systematic method is the only method that can be used for the special case of a single source tube. The energy of each source particle is chosen by a random method from an energy spectral distribution that is space independent.

The code 20-2 approximates cross-section dependence on energy by discontinuous straight line segments across specified energy groups. Cutput is available on punched cards suitable for input to 18-0. A printed listing is also prepared.

The code 20-3 computes the total macroscopic cross section and collision probabilities for a material composition, given the densities, atomic weights, volume fractions and the microscopic cross sections of all constituent materials. In addition to the usual printed output, output is available on punched cards suitable for input to $18-0$.

The code 20-4 averages input differential-scattering cross sections over specified energy groups to obtain angular distributinn data in the form of cumulative probability tables suitable for use in 18-0. Differential-scattering cross-section input data can be either in the form of a two-dimensional tabular array of $\sigma_{e}^{m}(E, \mu)$ or a set of one-dimensional tabular arrays of Legendre polynomial coefficients. Output is available as a printed listing and as punched card input to $18-0$.

The code 20-5 applies the evaporation model of nuclear reactions to determine cumulative probability tables for energy spectra of inelastically scattered neutrons. Output includes a printed listing and punched cards suitable for input to 18-0.

The code 20-6 computes excitation and transition probabilities for excited states of the residual nucleus from a neutron inelasticscattering reaction given the relative gamma-ray intensities of the transitions that occur in the process and the energy level structure of the nucleus. Output is in printed form only. 
The code 20-7 prepares data necessary to describe a shield configuration in the form of binary cards for direct insertion in the 18-0 binary deck. The code 18-0 requires extensive and somewhat redundant information about a shield configuration in order to operate efficiently. Approximately $45 \%$ fewer input data are required in 20-7 for description of the same configuration, and the data are considerably less complex. Output contains printed listings of the volumes of the shield regions and comparisons of the coordinates included in the input with the adjusted coordinates used in setting up the data. The code also searches for errors in the input.

The code 20-8 interprets and analyzes 18-0 source- and escapeparticle tapes. A 20-O generated source-particle output tape is interrogated to determine the number of neutrons or gamma rays generated in specified source volume elements and source spectrumenergy intervals. The expected and actual number of neutrons or gamma rays in each volume element and energy interval are compared. An 18-0 generated output escape tape is interrogated to determine the number of neutrons or gamma rays leaving the reactor-shield assembly through specified surface area elements with energy and direction in specified energy-angle increments. Energy-angle distributions for the leaking radiation are then computed from these data.

\section{RESTRICTIONS OR LIMITATIONS}

$$
\begin{aligned}
& \text { 18-0: Number of regions } \leq 300 \\
& \text { Number of neutron energy groups } \leq 25 \\
& \text { Number of gamma-ray energy groups } \leq 100 \\
& \text { 20-2: Number of energy groups } \leq 100 \\
& \text { Number of materials } \leq 20 \\
& \text { 20-3: Number of materials } \leq 20 \\
& \text { Number of collision types } \leq 6 \\
& \text { Number of energy groups } \leq 100 \\
& \text { 20-4: Number of energy groups } \leq 100 \\
& \text { Number of entries of angle variable } \leq 100 \\
& \text { Order of Legendre polynomial } \leq 15
\end{aligned}
$$


20-5: Number of energy groups $\leq 100$

Number of intervals in cumulative probability table $\leq 100$

20-6: Number of levels $\leq 100$

20-7: Number of regions $\leq 300$

Number of intersection points $\leq 602$

Number of current count boundaries $\leq 100$

Number of exterior boundaries $\leq 50$

Number of boundaries colinear with axis $\leq 25$

20-8: Number of energy groups $\leq 50$

Number of perimeter line segments $\leq 50$

Number of intervals in polar-angle mesh $\leq 50$

Number of intervais in aximutral-arlyie uiesh $\leq 50$.

7. TYPICAL RUNNIING TIME

Time given is for the IBM 7090 .

18-0: Approximately 3.6 minutes for 5000 histories, with splitting on region, of $3-4 \mathrm{MeV}$ gamma rays in 48 regions of fast-spectrum refractory-metal reactor.

20-0: Source tape for 55000 gamma rays, 11 energy groups, and 3 radial distributions prepared in 3.4 minutes.

20-2: Neutron cross sections prepared for 11 materials and 19 energy groups in 12 minutes.

20-3: Neutron cross sections prepared for 7 compositions and 19 energy groups in 0.66 minute.

20-4: Data prepared for 3 materials, 19 energy groups, and 10 angle intervals in 4.5 minutes.

20-5: Data prepared for 4 materials and 10 energy groups in 0.6 minute.

20-6: Sample problem ran for approximately 0.75 minute.

20-7: Sample problem ran for approximately 0.75 minute.

20-8: Interrogated tape of 20000 source-particle parameters in 2 minutes.

Total machine time for the sample problem run on $18-0$ and the auxiliary codes, including loading and unloading tapes, was 16 minutes 5 seconds. 


\section{COMPUTER HARDWARE REQUIREMENTS}

The codes are operable on the IBM 7090 and 7094 computers. Seven magnetic tape units are required to execute 18-0 and three units are required for each of the auxiliary codes.

An on-line card reader is needed with present one-card binary loader.

9. COMPUTER SOFTWARE REQUIREMENTS

18-0 and 18-1 are each a nonmonitor job with tape-read initialized by an on-line one-card binary loader. Transfer is made to a manager routine, either PK3 or 9ULOAD, depending on which code is used. Those written in FAP require PK3. 9ULOAD is used for the relocatable FORTRAN decks.

PK3, a GE-NMPO written Manager and I-O package, includes absolute PAP assembly versions of FIOP, MINIM and DIP. 9ULOAD is an IBM distributed routine.

The working deck is complete with all necessary library-type routines included.

Both $\mathrm{A}$ and $\mathrm{B}$ channels are used with $5 \mathrm{~A}$ and $2 \mathrm{~B}$ the maximum assigned. The G=-NMPO codes call and rewind Al on execution.

\section{REFEREINCES}

J. E. MacDonald, J. T. Martin and J. P. Yalch, "Specialized Reactor-Shield Monte Carlo Program 18-0," GEMP-102 (October 1962).

J. E. MacDonald and J. T. Martin, "Shielding Computer Program 20-0,"APIX-610 (August 1961).

J. P. Yalch, and J. E. MacDonald, "Program 20-2, A Program for Approximating Cross Section Dependence on Energy, "GEMP-113 (June 1962).

J. P. Yalch and J. E. MacDonald, "Program 20-3, A Program for Computation of Total Macroscopic Cross Section and Collision Probabilities for Specified Material Composition," GEMP-114 (June 1962).

J. P. Yalch and J. E. MacDonald, "Program 20-4, A Programi for Averaging Differential Scattering Cross Sections," GEMP-115 (June $1962)$. 
J. P. Yalch and J. E. MacDonald, "Program 20-5, A Program for Preparation of Spectrum Tables from Evaporation Model, " GEMP-116 (June 1962).

J. P. Yalch and J. E. MacDonald, "Program 20-6, A Program for Computing Nuclear Excitation and Transition Probabilities from Measured Gamma Ray Intensities," GEMP-117 (June 1962).

J. M. Martin, "Shield Region Data Converter Program 20-7," APEX-605 (August 1961).

J. P. Yalch and J. E. MacDonald, "Program 20-8, A Program for Interpreting Program 18-0 Source and Escape Particle Tapes," GEMP-123 (July 1962).

J. P. Yalch and J. E. MacDonald, "Addenda to GEMP-102 Describing Program 10-1," GEMP-âe (Jainuary 1964).

\section{CONIENTS OF CODE PACKAGE}

The package contains the following items:

a. the referenced documents,

b. a description of PK3 Manager routine,

c. a one-card binary on-line loader,

d. CCC-16A - a reel of magnetic tape on which is written in separate files: all of the source and binary carả aeciks uf 18-O and all auxiliary routines; BCD input and output for sample problems set up for each code. CCC-16B - a reel of magnetic tape on which is written in separate files: all of the source and binary card decks of 18-1 and all auxiliary routines; BCD input and output for sample problems set up for each code.

\section{HOW TO OBTAIN PACKAGE}

Inquiries or requests for the code package may be mailed to CODES COORD INATCR Radiation Shielding Information Center

Oak Ridge National Laboratory

P. O. BoX X

Oak Ridge, Tennessee 37830

or telephoned to

Area Code 615; 483-8611, extension 3-6944, or to FTS $x x-615-483-6944$. 
Persons requesting the package should send a reel of magnetic tape to the above address.

13. DATE OF ABSTRACT January 1966. 
RSIC CODE PACKAGE CCC-17

1. NAME AND TITLE OF CODE

05R: A General-Purpose Monte Carlo Neutron Transport Code System.

PROTOTYPES

O5R-STATEST: Sample Shielding Calculation.

05R-K: Sample Reactor Calculation; Multiplication Constant. PRIMARY ROUTINE

05R-Generator: Collision Tape Generator.

AUXILIARY ROUTINES

XSECT: Cross Section Handling code.

IEGENDRE: Data Generator.

STATEST: Statistical Estimation - Special Analysis Routine for Sample Problem.

05R was originally written in FAP for the IBM 7090. This original version has been incorporated into the NTC code (CCC-7). A Fortran version was written for the CDC 1604 and underwent extensive devel nnment. The final code was checked out on both the CDC 1604 and IBM 7090 and constitutes the present package.

2. CONTRIBUTOR

Neutron Physics Division, Oak Ridge National Laboratory, Oak Ridge, Tennessee.

3. CODING IANGUAGE AND COMPUTER

CCC-17A: FORTRAN and FAP, IBM 7090

CCC-17B: FORTRAN and CODAP, CDC 1604

4. NATURE OF PROBLEM SOLVED

The 05R code system was designed to calculate, by Monte Carlo methods, any quantity related to neutron transport in reactor or shielding problems. The system is represented by two examples: O5R-STAITST which calculates the neutron flux, for various energy bins, at various points by statistical estimation; and 05R- $K$ which 
calculates the multiplication constant of a chain-reacting system.

Sources may have arbitrary spatial, energy, and angular distributions via a subroutine written by the user. Arbitrary threedimensional geometries bounded by quadric surfaces may be treated. Anisotropic scattering can be included for both elastic and inelastic processes. Fissionable as well as non-fissionable media can be treated. Several variance reduction techniques are available.

5. METITCD OF SOLUTICN

For maximum flexibility, a calculation generally consists of two main uperations. The code 05R-Generator is used to generate neutron case histories and produce "collision tapes" on which are written any, or all, of 34 distinct parameters describing each collision. These tapes are subsequently processed by "analysis" routines to produce Monte Carlo estimates of any desired quantity The analysis routine STATEST is supplied as part of a prototype of the O5R system as applied to shielding problems. Statistical estimation of the flux in energy bins $i$ s computed for an array of space points. The multiplication constant is estimated in the reactor prototype $05 \mathrm{R}-\mathrm{K}$ by obtaining Monte Carlo estimates of the number of neutrons emerging from successive generations. The special subroutine OUTPT is used and no analysis of a collision tape is required.

A batch system of generating case histories is employed to obtain a very detailed table of cross sections in fast memory. The cross sections in memory at one time encompass only a small energy range. All collisions of a batch, for which these cross sections are needed, are generated before reading from tape another group of cross sections. Cross-section data is prepared for use in 05R by XSECT, a code which performs a variety of manipulations: preparing, updating, and editing a master tape, and performing crosssection arithmetic.

Source data is generated by subroutine SOURCE, usually written by the code package user for his specific problem. A sourge generator is jncluded in the package for the sample problem. 
A very general geometry subroutine permits the treatment of complicated geometries. As many as 16 media are permitted and boundaries may be either planes or quadric surfaces, arbitrarily oriented and intersecting in arbitrary fashion.

6. RESTRICTIONS OR ITMITATIONS

Number of different media allowed: 16

Number of scatterers allowed per medium: 8

Number of anisotropic scatterers allowed: 10

Energy range covered: $77.13 \mathrm{MeV}$ to $0.07 \times 10^{-13} \mathrm{eV}$.

Treatment of thermal neutrons is limited to a one-velocity approximation unless the user supplies subroutines for thermal scátterings.

7. TYPICAL RUNNING TTME

Running time for 05R on various types of problems varies extremely from 10 minutes to 2 hours.

Estimated running time of the 05R-K sample problem: 20 minutes.

8. COMPUIER HARDWARE REQUIREMENTS

Thers are two separate code packages, the difference being the hardware configuration. The packaged O5R can be run on the following computers:

CCC-17A, IBM 7090 and 7094; CCC-17B, CDC 1604.

In addition to tape units needed for input, output and systems, a maximum of four units are needed for a reactor problem, and three units for a shielding problem. The Calcomp plotter may be used with CDC 1604 version, CCC-17B.

9. COMPUTER SOFIWARE REQUIREMENTS

The codes are almost entirely written in FORTRAN, with a few small assembly language routines for random number generation, word packing and unpacking, etc.

Software requirements for the two code versions are as follows:

CCC-17A, FORTRAN II, version 3 Monitor system, CCC-17B, FORTRAN 63, CO-OP Monitor system. 
All library-type routines are standard with the exception of a non-standard Calcomp Plot subroutine which has been made a part of the CCC-17B package only.

Logical tape numbers of auxiliary tapes may be specified as input to a given problem.

The standard input, output and systems tapes are used.

\section{REFERENCES}

R. R. Coveyou, J. G. Sullivan, I1. P. Carter, D. C. Irving, R. M. Ireestone, Jr., and F. B. K. Kam, "05R, A General-Purpose Monte Carlo Neutron Transport Code," CRNL-3622 (February 1965).

W. E. Kinney, "Program STATEST, An Application of the Method of Statistical Estimation to the Calculation of Neutron Flux in Anisotropically Scattering Media by Monte Carlo," ORNI-3715 (November 1964).

J. T. Mihalczo, G. W. Morrison, and D. C. Irving, "SOURCE, A Neutron Distribution Routine for the O5R Monte Carlo Code," ORNI-TM-1192 (July 1965).

G. W. Morrison, J. T. Mihalczo, and D. C. Irving, "SPCTRMAn 05R Monte Carlo Analysis Routine for Calculating the Neutron Energy Spectrum," CRNL-TM-1245 (August 1965).

\section{CONIENIS OE CODE PACKAGE}

Each package contains the following items:

a. the referenced documents,

b. sample data sheets and additional written material,

c. a reel of magnetic tape on which is written in separate files: the source and binary card decks, input and output for a sample problem,

d. a library of cross sections on an additional reel of magnetic tape. 
12. HOW TO OBTAIN PACKAGE

Inquiries or requests for the code package may be mailed to CCDES COCRDINATOR

Radiation Shielding Information Center

Cak Ridge National iaboratory

P. C. Box X

Cak Ridge, Tennessee 37830

or telephoned to

Area Code 615; 483-8611, extension 3-6944, or to FTS $x x-615-483-6944$.

Persons requesting the package should mail two reels of magnetic tape to the above address, indicating whether they want CCC-17 A or $\mathrm{CCC}-17 \mathrm{~B}$.

13. DAIE CF ABSTRACT

January 1966. 
RSIC CODE PACKAGE CCC-18

1. NAME AND TITLE OF CODE

05-0: Anisotropic Point Source Code - Single Scattered Gamma Rays in an Infinite Homogeneous Medium.

The name of the above code follows a numbering sequence for shielding codes established by the contributing installation. The number following the dash in the Shielding Program Number indicates the version or revision of a family of codes. In addition, a department code numbering system is followed: internally, 05-0 is known as GE-NMPO No. 59.

2. CONIRIBUTOR

Nuclear Materials and Propulsion Operation, General Electric Company, Cincinnati, Ohio.

3. CODING LANGUAGE AND COMPUTERR

FAP; IBM 7090 and 7094 .

4. NATURE OF PROBLEM SOLVED

The 05-0 code calculates the gamma-ray dose rate at any specified unshielded point detector due to uncollided and singlescattered gamma rays in a homogeneous infinite medium from an anisotropic point source. The gamma-ray source energy spectrum may be approximated by ten energy levels.

Exponential attenuation may be considered on either leg as desired. The dose rate arising from the source spectrum is obtained by summation of the dose rates computed for each initial energy •

5. METHOD OF SOLUTION

The dose rate in air due to unscattered and single-scattered gamma rays is computed by numerical integration (trapezoidal rule). The total cross section and the flux-to-dose rate conversion factors are evaluated with the use of special functions. Coefficients for these functions are input. 
Attenuation may be omitted in the single-scatter portion of the calculation which can approximately account for buildup (dose rate due to subsequent collisions).

\section{RESTRICTIONS OR LIMITAMIONS}

The following restrictions should be noted:

Maximum number of angular intervals in angle integration - 500, Maximum number of source energy groups - 10 . The results of this calculation are strictly valid only within a short distance $(<1 \mathrm{mf} p)$ from the source where the dose rate due to multiple collisions are negligible.

7. TYPICAL RUNNING TINE

Typical running time is less than one minute per receiver point.

Estimated running time of sample problem: 0.5 minute.

8. COMPUTIR HARDWARE REQUIRENENIS

The code was first designed for the IBM 704 computer and later made operable on the IBM 7090 by the contributing installation. Two tape units and a 32,768 core memory are required.

\section{COMPUTER SOFIWARE REQUIREMENTS}

PKL Manager routine is furnished with program decks. It is a nonmonitor job, initiated by an on-line one-card loader. PKI is a GE-NMPO written I-C package, including absolute FAP assembly versions of FIOP, MINIM, and DOP.

The working deck is complete with all necessary library-type routines included.

Cnly A channel assignments are used, $A 2$ and $A 3$, input and output respectively.

10. REFERENCE

J. J. Loechler, J. E. MacDonald, and H. M. Van Valkenbury, "Program Report, Aircraft Nuclear Propulsion Shielding Program 05-C," XDC-59-8-218 (July 1959). 
11. CONIENTS OF CODE PACKAGE

The package contains the following items:

a. the referenced document,

b. a reel of magnetic tape on which is written in three files: the source card deck, the binary card deck set up with sample problem input, and output from the sample problem,

c. one binary card on-line loader.

12. HOW TO OBTAIN PACKAGE

Inquiries or requests for the code package may be mailed to CODES CCORDINATOR

Radiation Shiolding Information Center

Oak Ridge National Laboratory

P. O. Box X

Oak Ridge, Tennessee 37830

or telephoned to

Area Code 615; 483-8611, extension 3-6944, or to

FTS xx-615-483-6944.

Persons requesting the package should send a reel of magnetic tape to the above adaress.

13. DATE OF ABSTRACT

January 1966. 
RSIC CODE PACKAGE CCC-19

\section{NAME AND TITLE OF CODE}

09-0: Anisotropic Point Source Code - Single Scattered Neutrons in an Infinite Homogeneous Medium.

The name of the above code follows a numbering sequence for shielding codes established by the contributing installation. The number following the dash indicates the version or revision of a family of codes. In addition, a department code numbering system is followed: internally, 09-O is known as GE-NMPO No. 64.

\section{CONTRIBUTIOR}

Nuclear Materials and Propulsion Operation, General Electric Company, Cincinnati, Ohio.

\section{CODING ILANGUAGE AND COMPUTER}

FAP; IBM 7090 and 7094 .

4. NATURE OF PROBLFM SOLVED

Program 09-0 calculates the dose rate due to single-scattered fast neutrons in an infinite, homogeneous medium from an anisotropic point source at any specified, unshielded point detector. The source energy spectrum may be approximated by ten discrete values of the energy. Exponential attenuation may be considered on either scattering leg as desired. The dose rate is determined by trapezoidal integration for each source energy, and the total dose rate is obtained by summation over all source energies.

5. METHOD OF SOLUTION

The dose rate in air due to unscattered and single-scattered neutrons is computed by numerical integration (trapezoidal rule). The total cross section differential scattering cross sections and the flux-to-dose rate conversion factors are evaluated with the use of special functions. Coefficients for these functions are input. 
Attenuation may be omitted in the single-scatter portion of the calculation which can approximately account for buildup (dose rate due to subsequent collisions).

\section{RESTRICTIONS OR ITMITATIONS}

The following restrictions should be noted:

Maximum number of angular intervals in angle integration - 500,

Maximum number of source energy groups - 10 .

The results of this calculation are strictly valid only within a short distance $(<1 \mathrm{mf}$ ) from the source where the dose rate due to multiple collisions are negligible.

7. TYPICAL RUNNING TIME

Typical running time is less than one minute per receiver point.

Estimated running time of sample problem: 5 minutes.

8. COMPUTER HARDWARE REQUIREMENTS

A 32,768 core memory and two tape units are required. The code was first designed for an IBM 704 computer and later made operable on the IBM 7090 by the contributing installation.

\section{COMPUIIER SOFTWARE REQUTREMENTS}

PKl Manager routine is furnished with program decks. It is a nonmonitor job, inititated by an on-line one-card loader. $\mathrm{PKL}$ is a GE-MMPO written I-O package, including absolute FAP assembly versions of PLOP, MINIM, and DOP.

The working deck is complete with all necessary library-type routines included.

only A channel assignments are used, $A 2$ and $A 3$, input and output respectively.

10. REFERENCE

J.W. IIaffner, J. J. Loechler, and J. E. MacDonald, "IBM 704 Program Report, Aircraft Nuclear Propulsion Shielding, Program 09-0," APEX 533 (December 1958). 
11. CONTENTS OF CODE PACKAGE

The package contains the following items:

a. the referenced document,

b. a reel of magnetic tape on which is written in three files: the source card decks, the binary card deck set up with input for a sample problem, and output from the sample problem,

c. one binary card on-line loader.

12. HOW TO OBTAIN PACKAGE

Inquiries or requests for the code package may be mailed to CODES COORDINATOR

Kadiaicin Shiclaing Information Center

Oak Ridge National Laboratory

P. O. BoX X

Oak Ridge, Tennessee 37830

or telephoned to

Area Code 615; 483-8611, extension 3-6944, or to

FTS $\mathrm{xx}-615-483-6944$.

Persons requesting the package should send a reel of magnetic tape to the above adaress.

13. DATE OF ABSTRACT

January 1966. 
RSIC CODE PACKAGE CCC-20

1. NAME AND TITTE OF CODE

TRIGR-P: Monte Carlo Gamma-Ray Penetration Code - Plane Geometry.

2. CONIRIBUTORS

Technical Research Group, Inc., Melville, New York. USAF, Aeronautical Research Laboratories, Wright-Patterson Air Force Base, Ohio.

3. CODING IAANGUAGE AID COMPUTER

SAP, IBM 704 .

4. NATURE OF PROBLEM SOLVED

TRIGR-P is a Monte Carlo calculation of gamma-ray transmission through a multislab infinite plane shield. The source is monoenergetic and monodirectional, making a fixed angle with the slab normal.

Data obtained consist of energy flux and spectrum, energy current and spectrum, and dose.

5. METHOD OF SOLUTION

The code uses Monte Carlo methods to solve for the gamma-ray transmission. The scoring is done by statistical estimation. The code makes extensive use of importance sampling. Each random variable (position, wavelength, or azimuthal angle) is picked from an exponential distribution.

Fractional deviations in transmitted current of above five percent are obtained for shields up to fifteen or twenty mean free paths thick in about three minutes running time on the IBM 704 by use of importance sampling. A similarity transformation enables one to compute transmission for shields of several thicknesses at once, with only a small increase in running time. Results have been obtained for transmission of radiation incident on plane lead slabs 2-12 mean free paths thick and on iron and 
aluminum slabs 2-10 mean free paths thick at angles of $0^{\circ}, 15^{\circ}$, $30^{\circ}, 45^{\circ}, 60^{\circ}$, and $75^{\circ}$ with the normal. The transmitted energy spectrum of 8 and $10-\mathrm{MeV}$ bremsstrahlung radiation incident on 4- and 6-inch lead slabs was also computed.

\section{RESTRICTIONS OR LIMITATIONS}

The following limits should be noted:

Maximum number of layers, 7 slabs

Maximum number of materials, 7

Maximum number of similar geometries, 16

Maximum spectral energy divisions, 30.

7. TYPICAL RUNNING TIME

To obtain deviations less than 5\%, 3 minutes for normal incidence, 10 minutes for angles around $45^{\circ}$, at source energies around $3 \mathrm{MeV}$, shield 15 mean free paths thick along source direction.

8. COMPUTER HARDWARE REQUIREMEN'IS

Drums, $8 \mathrm{~K}$ memory, 1 tape unit, and card reader are required. Although designed for the IBM 704 computer, the hardware can be simulated by the standard IBM 704-7090 compatibility package.

9. COMPU'IER SOFTWARE REQUIREMENTS

IRIGR-P was written in SAP assembly language for an $8 \mathrm{~K}$ IBM 704 with drums. It is operable on the IBM 7090 under compatibility. This card job also uses sense switches. The work deck is in row binary

The IBM 704-7090 compatibility package is required.

10. REFERENCE

Herbert Steinberg and Raphael Aronson, "Monte Carlo Calculations of Gamma Ray Penetration," WADC TR-59-771 (August 1960). 
11. CONTENTS OF CODE PACKAGE

The package contains the following items:

a. the referenced document,

b. the source card decks,

c. the binary card decks,

d. input and output of a sample problem.

12. HOW TO OBTAIN PACKAGE

Inquiries or requests for the code package may be mailed to CODES COORDINATOR

Radiation Shielding Information Center

Oak Ridge National Laboratory

P. O. Box X

Oak Ridge, Tennessee 37830

or telephoned to

Area Code 615; 483-8611, extension 3-6944, or to

FTS xx-615-483-6944.

Persons requesting the package should send a reel of magnetic tape to the above address.

13. DATE OF ABSTRACT

January 1966. 
RSIC CODE PACKAGE CCC-2I

1. NAME AND TITLE OF CODE

MORTIMER: Kernel Integration Code, Tro-Component Analysis for SNAP Shield Geometries.

The above code is listed in the Argonne Code Center Collection as Reactor Code Abstract 142. It is possible that the CCC-2l version has additional code development by AI, as a later version was submitted to RSIC. No comparisons have been made between the two versions.

With development of the code at the contributing installation there was a corresponding name change. It was uurn FARST and becamo in succession RATRAP and MORTIMER. Only MORTIMER is packaged in RSIC, as it includes all of the features of the earlier versions, plus additional development.

2. CONIRIBUTOR

Atomics International, Canoga Park, California.

3. CODING LANJGUAGE AND COMPUTER

FORTRAN and FAP, IBM 7090 and 7094.

4. NATURE OF PROBIFM SOLVED

The code computes the neutron dose rate as the sum of collimated and diffuse components calculated by an integration of a removal cross section kernel over a cylindrical source.

MORTIMER is designed to include the effects of scattered particles, as well as essentially uncollided particles, in the calculation of dose rate at designated points outside the shield system. The code is designed for preliminary investigation of shield sizes and weights for SNAP systems. 
5. MEIHOD OF SOLUTION

The collimated dose rate integration is calculated by a summation over source points of an exponential kernel which uses "collimated" removal cross sections. The diffuse dose rate integration is calculated by a double summation over source points and shield surface points using a kernel involving the difference between exponential functions. Each function employs either a "broad beam" or a "collimated" removal cross section.

The following dose rate calculations are available:

a. that based on an attenuation model incorporating mean free paths traversed along a straight line trajectory,

b. angularly dependent leakage surface dose rate,

c. a two component calculation with broad beam cross sections, to account for scattered particle dose rate.

\section{RESTRICIIONS CR LIMITAIIONS}

The following restrictions must be noted:

1000 core-reflector source points, 640 shield mesh points (for the diffuse dose calculation), 50 dose points.

\section{TYPICAL RUNNING TIME}

About 100 points/second will run on the IBM 7094. The total number of points in a given problem may be estimated by computing the product of the number of points itemized in (6) above. Estimated running time of the sample problem: 7 minutes.

8. COMPUTER HARDWARE REQUIREMENTS

The code is designed for an IBM 7090 computer. A 32,768 core memory and three magnetic tape units are required.

9. COMPUI'ER SOF'IWARE REQUIREMENTS

This code is written in FORTRAN and FAP. It is designed for the IBM FORTRAN II Monitor System, using the standard IBM system, input, and output tapes. 
10. REFERENCES

W. B. Green, "Mortimer, A Modification of the Ratrap Code Which Includes the Two Component Method of Shield Analysis," NAA-SR-9327 (December 1963).

W. B. Green, "The RATRAP Code - A Modification of the FARSE Method for SNAP Shield Geometry," NAA-SR-MEMO-8968 (September $1963)$.

W. Granter, "FARSE, A First Neutron Shielding Code Designed for SNAP Systems," TIM No. 798 (December 1963).

K. L. Rooney and M. A. Boling, "FARSE - A First Crder Approximation of Reactor Shields for SNAP Systems," NAA-TDR-5772 (October 1960).

11. CONTENTS OF CODE PACKAGE

The package contains the following items:

a. the referenced documents,

b. a reel of magnetic tape on which is written in five files: the source card decks, the binary card deck, $\mathrm{BCD}$ input data for a sample problem, and output of the sample problem.

12. HOW TO OBTAIIN SACKAGE

Inquiries or requests for the code package may be mailed to CODES COORDINATOR

Radiation Shielding Information Center

Oak Ridge National Laboratory

P. O. Box X

Oak Ridge, Tennessee 37830

or telephoned to

Area Code 615; 483-8611, extension 3-6944, or to

FTS xx-615-483-6944.

Persons requesting the package should send a reel of magnetic tape to the above address.

13. DATE OF ABSTRACT

January 1966. 
1. NAME AND TITLE OF CODE

CCC-22A/MAC: Neutron and Gamma-Ray Attenuation Code Spinney (Removal-Diffusion) Calculation in Plane Geometry.

CCC-22B/MAC-RAD: Revised and Developed MAC.

A version of MAC-RAD is a part of the ENEA Computer Programme Library collection. It is listed as Abstract No. 006: MAC-RAD in the ENEA-CPL Newsletter No. 1, September 1964.

2. CONTRIBUTORS

CCC-22A/MAC - Hanford Atomic Products Operation, General Electric Company, Richland, Washington.

Responsibility for the code is now vested in Pacific Northwest Laboratory, Battelle-Northwest, Richland, Washington. CCC-22B/MAC-RAD - Allgemeine Elektricitäts - Gesellschaft, Kernenergieanlagen (AEG-KEA), Frankfurt (Main), Germany.

The code was placed in the RSIC collection through the services of Pacific Northwest Laboratory, Battelle-Northwest, Richland, Washington

3. CODING LANGUAGE AND COMPUTER

FORIRAN II, IBM 7090 .

\section{NATURE OF PROBLEM SOLVED}

The MAC code calculates the neutron energy spectrum and dose rate and gamma-ray dose rate as a function of distance through large reactor shields (slab geometry) of concrete or hydrogenous material. The following information is given as calculated results:

a. multigroup neutron filuxes for as many as 35 energy groups,

b. neutron dose rates,

c. approximate neutron spectrum,

d. total gamma-ray dose rate, with a breakdown of the contribution from each region in the shield to the total dose rate, 
e. approximate gamma-ray spectrum.

\section{METHOD OF SOLUTION}

The spinney method of using a high-energy kernel as the source of neutrons in a multigroup diffusion procedure is utilized. This kernel is proportional to the energy depende.t "removal" flux which is similar to the uncollided flux except for the use of a removal cross section equal in magnitude to the usual transport cross section. The removal flux, divided into 18 groups, is calculated for neutrons above $0.5 \mathrm{MeV}$.

The gamma ray dose rate is calculated for 7 source energy groups using buildup factor kernels. A quantity called "gamma spectrum" is the contribution of various source energy groups to the dose divided by the group averaged flux-to-dose factor.

The reactor power distribution is taken to be linear near the core-shield interface.

The diffusion equation is reduced to a system of three firstorder differential equations which are numerically integrated. Boundary conditions are: assigned flux at the core-shield interface, and zero incoming flux at the outside.

MAC-RAD adds removal flux at core interface to input boundary values to get total. In the first group, the entire flux is removal. Secondary gamma sources are discontinuous at boundaries.

\section{RESIRICIIONS OR LIMITATIONS}

I'he following limitations must be noted:

a. slab geometry,

b. shield material for which the spinney model diffusion theory and buildup factors will apply,

c. the aisembly may contain up to 20 homogeneous regions, 21 aiff'erent elements or isotopes, 2020 mesh points for neutron flux- and 900 for gamma-ray flux-calculations.

1. IYPICAL RUNNING TIME

A typical problem with 1150 mesh points and gamma-ray fluxes computed in 30 points runs in about 12 minutes. 
Estimated running time of sample problem in the package:

18 minutes.

8. COMPUTER HARDWARE REQUIREMENTS

The code was designed for the IBM 7090 computer. Four tape units are required.

9. COMPUTER SOFTWARE REQUIREMENTS

MAC is an all-FORTRAN code designed for and operable on the IBM FORTRAN II Monitor System. Input, output, system and one scratch tape, assigned to Channel A, are used.

10. REFERENCES

E. G. Peterson, "MAC-A Bulk Shielding Code," HW-T558I (ÁpriI 1962).

J. Greenborg, "Two Cross Section Libraries for Use with MAC Shielding Code," HW-73381 SUP 1 (January 1964).

H. Preusch and H. Ilsemann, "MAC-RAD, A Multigroup Attenuation Code for Plane Geometry," AEG-KEA-116 (ORNL-TR-610) (October $1963)$.

U. Canali and C. Ponti (Euratom), and H. Ilsemann and H. Preusch (A.E.G.), "MAC-RAD, A Reactor Shielding Code," EUR 2l52.e $(1964)$.

11. CONTENTS OF CODE PACKAGE

Each package contains the following items:

a. the referenced documents,

b. a reel of magnetic tape on which is written in four files: the source card decks, the binary card decks with input data for a sample problem, a library of data (15-group as listed in HW-73381, SUP 1), and output from the sample problem. 


\section{HOW TO OBTAIN PACKAGE}

Inquiries or requests for the code package may be mailed to CODES COORD INATOR

Radiation Shielding Information Center

Oak Ridge National Laboratory

P. O. Box X

Oak Ridge, Tennessee 37830

or telephoned to

Area Code 615; 483-8611, extension $5-6944$, or to

FTS xx-615-483-6944.

Persons requesting the package should mail one reel. of magnetic tape to the above address, specifying whether CCC-22A or CCC-22B is desired.

13. DATE OF ABSTRACT

January 1966. 
RSIC CODE PACKAGE CCC-23

1. NAME AND TITLE OF CODE

MAVRAC: Model Astronaut and Vehicle Radiation Analysis Code.

2. CONTRIBUTORS

Northrop Space Laboratories, Hawthorne, California.

Aerospace Medical Research Laboratory, Wright-Patterson Air Force Base, Ohio.

3. CODING IANGUAGE AND COMPUTER

FORTRAN; IBM 7090 .

4. NATTIRE OF PROBTEM SOIVED

The MAVRAC code calculates the dose distribution in a model astronaut inside a space vehicle or the dose distribution in the vehicle.

The spacecraft is assumed to be represented by the combination of several geometrical surfaces: spherical, conical, and toroidal. Two right elliptical cylinders are utilized to represent the astronaut. Mathematical models of astronaut and the spacecraft are constructed.

\section{METHOD OF SOLUTION}

The dose rate as a function of wall and tissue thickness is represented by a polynomial expression fit to data obtained by other means. The dose rate is calculated at a specified number of points by computing the slant wall thickness of the vehicle in various directions. The mean dose for a model astronaut is then determined.

For the dose distribution in a space vehicle, material slant thicknesses for each given point is given as input data. Tissue thicknesses are set equal to zero and the same expressions are used to calculate dose rate. 


\section{RESTRICTIONS OR LIMITATIONS}

Polynomial expressions of up to 8 terms (in powers of tissue thickness) allow up to 10 vehicle wall thicknesses. In addition, the following limitations are to be considered:

Solid angle increments up to $30 \times 30$ array

Geometric sections of spacecraft $\leq 20$

Number of dose points calculated $\leq 200$.

7. TYPICAI RUNINING TIME

Estimated running time of sample problem: 5 minutes.

8. COMPUTER HARDWARE REQUIREMENTS

The IBM 7090 or 7094 computer with a minimum of three tape units may be used to run the code.

9. COMPUTER SOFTWARE REQUIREMENTS

The FORTRAN II Monitor System, any standard version, may be used. The only tapes assigned are those for input, output, and the system.

Logical tape numbers for input and output are defined in the main routine of MAVRAC and may be changed by the user.

10. REFERENCE

G. Duckworth, "Model Astronaut and Vehicle Radiation Analysis Code," NSIr63-159 (September 1963).

11. CONTENTS OF CODE PACKAGE

The package contains the following items:

a. the referenced document,

b. a reel of magnetic tape on which is written in three files: the source card deck, the binary card deck set up with control cards, input data for a sample problem, and output from the sample problem. 
12. HOW TO OBTAIN PACKAGE

Inquiries or requests for the code package may be mailed to CODES COORDINATOR

Radiation Shielding Information Center

Oak Ridge National Laboratory

P. O. Box X

Oak Ridge, Tennessee 37830

or telephoned to

Area Code 615; 483-8611, extension 3-6944, or to

FTS xx-615-483-6944.

Persons requesting the package should send a reel of magnetic tape to the above address.

13. DATTE OF ABSTRACT

January 1966. 


\section{RSIC CODE PACKAGE CCC-24}

1. NAME AND TITLE OF CODE

CARSTEP: Trajectory and Environment Code - Electron and Proton Fluxes Impinging on Spacecraft in Orbit.

This code was developed by combining a two-body trajectory program with NASA Goddard's environment routine.

2. CONTRIBUTORS

Northrop Space Laboratory, Fawthorne, California.

Aerospace Medical Research Laboratory, Wright-petterson Air Force Base, Onilo.

3. CODING LANGUAGE AND COMPUTER

FORIRAN II, IBM 7090.

4. NATURE OF PROBLEM SOLVED

The CARSTEP code determines the flux of particles from the Van Allen zones that strike a space vehicle which is executing a mission in that volume of space. Using latitude, longitude, altitude of perigee, inclination and eccentricity of orbits, and mission time as input, the following data is given: latitude, longitude, and altitude of the vehicle at points along the trajectory, the flux of particles at these points, and the time integrated flux for the total mission.

\section{METHOD OF SOLUTION}

The position of the vehicles as a function of time is determined by a tio-body analysis. The program is divided into three parts: Iunar transfer trajectories, lunar return trajectories, and geocentric orbits.

The environment portion of CARSTEP uses a coordinate system $(B, L)$ for mapping the distribution of geomagnetically trapped particles which has been developed by C. E. McIlwain. 
6. RESTRICTIONS OR LIMITATIONS

The earth is considered a perfect sphere and atmospheric drag is neglected. One energy spectrum for particles is valid throughout the volume of space.

7. TYPICAL RUNNING TIME

Estimated running time of sample problem: 5 minutes.

8. COMPUIER IIARDWARE REQUIREMENTS

The code was designed for an IBM 7090 or 7094 computer. A 32,768 core memory and three tape units are required.

9. COMPUTER SOFTWARE REQUIREMENTS

The code was designed for, and is operable on the IBM FORTRAN II Monitor System. The only tape assignments necessary are for input, output and the system. It may easily be made compatible with other FORTRAN compilers.

10. REFERENCE

M. R. Morrison and A. E. Tate, "Determination of Particle Fluxes Impinging on a Spacecraft," Northrop Space Laboratories, NSL 63-63R-1 (September 1963).

11. CONTENIS OF CODE PACKAGE

The package contains the following items:

a. the referenced document,

b. a reel of tape on which is written in three files: the source card deck, the binary card deck set up with control cards, input data for a sample problem, and output from the sample problem.

12. HOW TO OBTAIN PACKAGE

Inquiries or requests for the code package may be mailed to CODES COORDINATOR

Radiation Shielding Information Center

Oak Ridge National Laboratory

P. O. BoX X

Oak Ridge, Tennessee 37830 
or telephoned to

Area Code 615; 483-8611, extension 3-6944, or to

FTS xx-615-483-6944.

Persons requesting the package should send a reel of magnetic tape to the above address.

13. DATE OF ABSTRACT

January 1966. 
RSIC CODE PACKAGE CCC-25

1. NAME AND TITLE OF CODE

TRG-SGD: Calculation of Secondary Gamma-Ray Dose Rate from a Nuclear Weapon Detonation - Monte Carlo Method.

2. CONIRIBUTORS

Biophysics Branch, Air Force Weapons Laboratory, Kirtland Air Force Base, New Mexico.

TRG, Incorporated, Melville, Ne: York.

The code was placed in the RSIC collection through the services of the DASA Data Center, GE-TEMPO, Santa Barbara, California.

3. CODIING LANGUAGE AID COMPUTER

POPTPANT, CDC 1604.

4. NATURE OF PROBLFM SOLVED

The TRG-SGD code calculates the time and space distribution of secondary gamma-ray dose and dose rate in the atmosphere and also in the ground near the surface of the earth. The neutron source is assumed to be given as leakage from a nuclear or thermonuclear device exploded in the air.

The effects of the blast and fireball on the transport of the neutrons and gamma rays are considered.

The following neutron reactions are considered: elastic scattering, inelastic scattering, radiative capture, and nonradiative capture. The $(n, 2 n)$ reaction is treated as inelastic scattering by cross section modification. The prompt neutrons are from a degraded $14 \mathrm{MeV}$ source due to fusion, a fission source, and a bomb thermal Maxwell-Boltzmann spectrum located at the burst point. The delayed neutrons are from fission source with a time-dependent volume distribution.

The only gamma-ray reactions considered are Compton scattering and absorption, the latter being the total of pair-production and photoelectric effect reactions. 
5. METHOD OF SOLUTION

The Monte Carlo method is used to generate the neutron distribution, secondary gamma-ray source distribution, and secondary gamma-ray dose distribution. The effects of the air-ground interface, an inhomogeneous atmosphere, and the time-dependent hydrodynamics are taken into account. The type and yield of weapon and the detonation altitude determine the initial conditions. The geometric system is taken to be axially symmetric. In addition to statistical estimation of the gamma-ray source and dose distributions, various importance sampling techniques are used. These include Russian Roulette for low contribution particles and generalized quota sampling. In addition, all random variables are picked from a truncated exponential distribution. This procedure is controlled by input parameters.

6. RESTRICIIONS OR IIMITAAIONS

The following list defines the largest number possibie for the item named:

10 ground radial divisions

7 air layers

10 air radial divisions (each layer)

7. TYPICAL RUNNING TIME

No statistics are now available as to the typical running time.

8. COMPUTER IIARDWARE REQUIREMENTS

The coae is designed for a CDC 1604 Computer with a core memory of 32,000 words and 6+M tape units, where M(usually 2) is the number of tapes required by the system that are not available to the program.

\section{COMPUTER SOFIWARE REQUIREMEN'S}

Ihe code was writter in FURIRAN 62 language to be compiled and executed under the CO-OP Monitor System. It may also be compiled in the FORIKAN $6 ;$ compiler. 
The overlay feature is used, the program being divided into a main section and four overlays.

The main program's principal function is to call the four overlays into memory in their proper sequence. In addition, certain subroutines required by more than one overlay are included in the main section to eliminate the necessity of having them loaded separately with each overlay where they are needed.

\section{REFERENCE}

Herbert Steinberg and Raphael Aronson, "IRG-SGD, A Monte Carlo Program to Calculate Secondary Gamma Ray Dose from a Nuclear Woapon Detonation," Kirtland Air Force Weapons Laboratory, WL-TDR-64-46, Vol. I and Vol. II (July 1964).

\section{CONTENTS OF CODE PACKAGE}

The package contains the following items:

a. the referenced document,

b. a reel of magnetic tape on which is written in separate files: the source card decks, the binary card decks with overlay control cards, and input and output for two sample problems.

\section{HOW TO OBTAIN PACKAGE}

Inquiries or requests for the code package should be mailed to CODES COORDINATOR Radiation Shielding Information Center Oak Ridge National Laboratory

P. O. Box X Cak Ridge, Tennessee 37830

or telephoned to

Area Code 615; 483-8611, extension 3-6944, or to FTS $\mathrm{xx}-615-483-6944$.

Persons requesting the package should send a reel of magnetic tape to the above address.

\section{DATE OF ABSTRACT}

January 1966. 


\section{RSIC CODE PACKAGE CCC-26}

\section{NAME AND TITLE OF CODE}

GRACE II: Gamma Ray Kernel Integration Dose Rate and Heating Code - Cylinders and Spheres.

The above code is listed in the Argonne Code Center collection as Reactor Code Abstract 46, and in the ENEA Computer Programme Library as USCC-046.

2. CONTRIBUTOR

Atomics International, Canoga Park, California.

The code was obtained through the services of the Argonne Code Center, Argonne National Iaboratory, Argonne, Illinois.

3. CODING IANGGUAGE AND COMPUTER

Two versions of the code, differing only in hardware and software, are packaged:

CCC-26A: FORTRAN II, IBM 7090 and 7094 CCC-26B: FORTRAN 63, CDC 1604.

4. NATURE OF PROBLEM SOLVED

GRACE II is a multigroup, multiregion, gamma-ray attenuation code which computes the total dose rate or heat generation rate from either a spherical or a cylindrical source. The source, which may be located in either the central region of the system or in a concentric shell region surrounding it, may be uniform, exponential, or have a polynomial variation in the radial direction. In the case of cylindrical geometry, it may also have a polynomial variation in the axial direction. A least squares fit is used to obtain the polynomial coefficients. 
5. METHOD OF SOLUTION

The calculations are performed using buildup factors and integrating over source regions. The buildup factor is represented analytically in a double exponential form. The shield regions outside the source volume may be either semi-infinite slabs or concentric shells.

6. RESTRICTIONS OR LIMITATIONS

As many as 22 regions, 10 mesh points per region, 20 gammaray energy groups, 20 shield materials, and 20 material buildup factors may be included in a single calculation.

7. TYPICAL RUNNING TIME

A typical GRACE II problem will run from 3 to 5 minutes on either computer.

8. COMPUTER HARDWARE REQUIREMENTS

A code package is available for the following hardware configurations:

CCC-26A, the IBM 7090 or 7094 , CCC-2613, the CDC 1604 .

Three tape units on one channel are used in each version.

9. COMPUTER SOFIWARE REQUIREMENTS

The code is available for the following software environment:

CCC-17A, IBM Fortran II, Monitor System, CCC-17B, CDC FORTRAN 6z, CC-OP Monitor System.

Any non-standard library routines used have been included in the code package.

10. REFTRENCE

D. S. Duncan and A. B. Speir, "GRACE II - An IBM 709 Program fur Computing Gamma-Ray Attenuation and Heating in Cylindrical and Sphericil Geometries," NAA-SR-MEMC-4649 (November 1959). 
$26 \cdot 3$

\section{CONTENTS OF CODE PACKAGE}

Each package contains the following items:

a. the referenced document,

b. a reel of magnetic tape on which is written in three files:

the source card deck, the binary card deck set up with control cards, a library of data, input data for a sample problem, and output from the sample problem.

12. HOW TO OBTAIN FACKAGE

Inquiries or requests for the code package may be mailed to CODES CCORDINATOR

Radiation Shielding Information Center

Oak Ridge National Laboratory

P. C. Box X

Cak Ridge, Tennessee 37830

or telephoned to

Area Code 615; 483-8611, extension 3-6944, or to

FTS $\mathrm{xx}-615-483-6944$.

Persons requesting the code should mail a reel of magnetic tape to the above address.

\section{DATE OF ABSTRACT}

January 1966. 
1. NAME AND TITLE OF CODE

ACT II: Activation Gamma-Ray Source Strength Code - Simple Geometry, Finite Dilution.

2. CONIRIBUTOR

Astronuclear Laboratory, Westinghouse Electric Corporation, Pittsburgh, Pennsylvania.

3. CODING LANGUAGE AND COMPUTER

FORTRAN, IBM 7090 and 7094 .

4. NATURE OF PROBLEM SOLVED

The ACT II code was designed to determine the gamma-ray energy emission source strength (mev/cc-sec) in four energy groups for thin or infinitely dilute materials, or, for thick or finite dilutions as a function of neutron exposure and decay time. Included are nuclear properties (activation cross sections, isotopic fractions, decay constants and gamma-ray energy yields) for 44 specified elements and 129 reactions, which include radioactive captures and transmutations due to fast and thermal neutrons. Adjustment for neutron self-shielding has been made.

Results obtained include the gamma-ray sources in four energy groups for parent and daughter of each radioactive isotope and sums of these contributions for the element and the alloy as a function of exposure and decay time. These sources are then ready to be used in a gamma-ray shielding code.

\section{METHOD OF SOLUTION}

ACT II solves the differential equation describing radioactive buildup and decay. The neutron fluxes needed in the calculation are entered as input data and may be obtained from a multi- or few-group diffusion or transport code, at the will of the ACT II user. Allowance is also made for the input of removal cross sections for neutron flux groups one through four, and factors to adjust the group three and four resonance region cross sections. 
Cptions are available to either neglect or include target burnup and cycling.

6. RESTRICIIONS OR IIMITATIONS

The following limitations apply:

1. Isotopes with half lives less than 1 minute are not included.

2. Beta emissions are not included.

3. Gamma photons with energy less than $0.1 \mathrm{MeV}$ are generally omitted.

4. Neutron self-shielding and streaming due to resonances and windows are neglected. It is assumed that the absorber is thin and does not distort the leakage neutron spectrum.

7. TYPICAI RUNINING TIME

A typical problem ran 1.5 minutes for 10 elements and 50 time printouts.

Estimated running time of sample problem: 3 minutes.

8. COMPUTER HARDWARE REQUIREMENTS

The code was designed for the IBM 7090. Three tape units and a j2,768 core memory are required.

9. COMPUTER SOFTWARE REQUIREMENTS

The code was designed for the IBM 7090 and 7094 FORTRAN II Monitor: System. Only input, output and system tape assignments are made.

10. REFERENCES

P. C. Ileiser and I. O. Ricks, "Activation Source Strength Program ACT-I for the IBM 7090 Computer," WANL-TNR-063 (September 1962).

P. C. Heiser and I. O. Ricks, "Activation Source Strength Program, Act-II," WANL-TNR-063, Addendum 1. 
11. CONIENTS OF CODE PACKAGE

The package contains the following items:

a. the referenced documents and other written material,

b. a reel of magnetic tape on which is written in three files: the source card deck; the binary card deck set up with control cards; a library of permanent data and input data for a sample problem; and output from the sample problem.

12. HOW TO OBTAIN PACKAGE

Inquiries or requests for the code package may be mailed to CODES COORDINATOR

Radiation Shielding Information Center

Cak Ridge National Iaboratory

P. 0. Box X

Cak Ridge, Tennessee 37830

or telephoned to

Area Code 615; 483-8611, extension 3-6944, or to

FTS xx-615-483-6944.

Persons requesting the code package should send a reel of magnetic tape to the above address.

13. DATE OF ABSTRACT

January 1966. 


\section{RSIC CODE PACKAGE CCC-28}

1. NAME AND TITLE OP CODE

FPIC: Fission Product Inventory Code.

2. CONIRIBUTOR

Nuclear Analysis Department, Lockheed-Georgia Company, Marietta, Georgia.

3. CCDING IANGUAGE AND COMPUIER

FORTRAN, IBM 7090 and 7094.

4. NATURE OF PROBIEM SOLVED

Fission product gamma-ray sources in reactors are computed for any later heating or shielding calculation.

FPIC computes, as a function of reactor operation and shutdown time, the total decay rate, the total average beta energy release rate, total gamma energy release rate, and gamma energy release rate for each of seven energy groups from fission products generated in a U-235 thermal reactor. In addition, the program calculates the decay rate in curies and the lifetime (70 year) dose (resulting from total inhalation) in rem to twelve body organs as a function of decay time for each individual isotope and sums the inhalation dose over all isotopes for each organ and decay time.

\section{METHOD OF SOLUTION}

The program treats a doubly cyclic reactor operating schedule which may easily be specialized to the simpler case of a single operation period including instantaneous operation. The basic system of differential equations which describe the decay-buildup process for each mass chain were modified to treat the various possibilities considered in this treatment and rewritten in a form suitable for direct solution.

Efforts were made in this code version to compile input data from the best available decay schemes for all fission product nuclides with half-lives greater than 10 seconds and fission yields 
greater than $0.001 \%$. Data were compiled for 190 isotopes including: metastable states.

6. RESTRICITONS OR IIMITATIONS

The packaged nuclear data library will handle up to 200 nuclides but may be extended to a larger number. Up to 55 decay times may be handled.

7. TYPICAL RUNNING PIME

Running time per case is less than ten seconds if no individual isotope data are requested; including this request for the entire isotope library lengthens the running time to about two minutes.

8. COMPUTER IIARDWARE REQUIREMENTS

Designed for an IBM 7090 or 7094 computer, the code uses three tape units.

9. COMPUTER SOFIWARE REQUIREMENIS

FPIC is written for the IBM FORTRAN II Monitor system. It is all FORTRAN and can easily be made compatible with other systems. only input, output, and system tape assignments are made.

\section{REPERENCE}

K. O. Koebberling, W. E. Krull, J. H. Wilson, "Lockheed Fission Product Inventory Code," ER-6906 (May 1964).

11. CONTENTS OF CODE PACKAGE

The package contains the following items:

a. the referenced document,

b. a reel of magnetic tape on which is written in three files: the BCD source card deck; the binary card deck set up with BCD control cards, a nuclear data library in binary, and input for a sample problem; and BCD output from the problem. 
12. HOW TO OBTAIN PACKAGE

Inquiries or requests for the code package may be mailed to CODES COORDINATOR

Radiation Shielding Information Center

Cak Ridge National Laboratory

P. O. BoX X

Oak Ridge, Tennessee 37830

or telephoned to

Area Code 615; 483-8611, extension 3-6944, or to

FTS $\mathrm{xx}-615-483-6944$.

Persons requesting the code package should send a reel of magnetic tape to the above address.

13. DATE OF ABSTRACT

January 1966. 
RSIC CODE PACKAGE CCC-29

1. NAME AND TITIE OF CODE

MARTY-G: Monte Carlo Gamma-Ray Radiation Transport and Heat Deposition Rates in Liquid Hydrogen - Slabs and Cylinders.

2. CONTRIBUTOR

Research Projects Laboratory, INASA George C. Marshall Space Flight Center, Huntsville, Alabama.

3. CODING LANGUAGE AND COMPUTER

FORTRAIV and FAP, IBM 7090 and 7094 .

4. NATURE OF PROBLEM SOLVED

Stochastic methods are used to calculate the radiation transport and energy deposition of gamma rays in liquid hydrogen plane slabs of infinite expanse but finite thickness, and in right circular cylinders with flat ends. The results include heat rate deposition as a function of depth, albedo factors, and transmitted angular distributions of gamma rays.

5. METHOD OF SCLUTION

The MARTY code utilizes standard Monte Carlo techniques with the exception of a type of exponential transform for selecting the distance betrieen collisions.

The source is always monoenergetic. For the cylinder, the source is point isotropic and on the axis of the cylinder at any distance from the end, including inside the cylinder. The slab source is plane parallel rays incident at any specified angle.

Compton scattering is used for the gamma-ray energy deposition in plane geometry. Rejection sampling techniques are employed using the Klein-Nishina differential scattering formula. The calculation provides statistical estimates of the transmitted and reflected number current, flux, and energy as well as the heat deposition rate as a function of depth in the hydrogen. The 
angular and energy distributions of the gamma ray transmission are also calculated.

6. RESTRICTIONS OR IIMITATIONS

There are no known restrictions, at this time, implied by storage allocation.

7. TYPICAI RUNNING TIME

The typical running time for slab geometry is about one minute for 1,000 histories (varying with $\Xi_{n}$ ). Estimated running time of the sample problem: I minute.

8. COMPUIIIR ILARDWARE RIQUIREMENTS

The code was designed for the IBM 7090 and 7094. A 32,768 core memory and three tape units are required.

9. COMPUTER SOPIWART: REQQUTREMENTS

The code was designed for the IBM FCRTRAN II Monitor System. only input, output, and system tape assignments are made.

10. REFERENCE

M. O. Burrell, "Nuclear Radiation Iransfer and ieat Debosition Rates in Iiquid Iiydrogen," NASA IN I-1115.

11. CONIENIS CP CODE PACKACE

The package contains the folloving items:

a. the referened document,

b. a ros of magnetic tape on which is writtun in three filas: the source card deck, the binary card deck set up with $\mathrm{BCD}$ control cards and input data for a sample problem, and output from the sample problem.

12. IIOW IO OBIAIN PACKAGE

Inquiries or requests for the code packag: may be mailed to

CODES COURDINATUR

Radiation Shielaing Information Center

Dak Ridge National Iaboratory

P. C. Box X

Oak Ridge, Tennessee 37830 
or telephoned to

Area Code 615; 483-8611, extension 3-6944 or to

FTS $\mathrm{xx}-615-483-6944$.

Persons requesting the package should send a reel of magnetic tape to the above address.

\section{DATTE OF ABSTRACT}

January 1966. 
RSIC CODE PACKAGE CCC-30

1. NAME AND TITLE OF CODE

MARTY-N: Monte Carlo Neutron Radiation Transport and Heat Deposition Rates in Liquid Hydrogen - Slabs and Cylinders.

\section{CONTRIBUTOR}

Research Projects Laboratory, NASA George C. Marshall Space Flight Center, Huntsville, Alabama.

3. CODING LANGGUAG AND COMPUTER

FORTRAN and FAP, IBM 7090 and 7094.

4. NATURE OF PROBLEM SOLVED

Stochastic methods are used to calculate the radiation transport and energy deposition of neutrons in liquid hydrogen plane slabs of infinite expanse but finite thickness, and in right circular cylinders with flat ends. The results include heat rate deposition as a function of depth, albedo factors, and slow neutron spatial distribution.

5. METHOD OF SOLUTION

The MARTY code utilizes standard Monte Carlo techniques ith the exception of a type of exponential transform for selecting the distance between collisions.

The source is always monoenergetic. Ior the cylinder, the source is point isotropic and on the axis of the cylinder at any distance from the end, including inside the cylinder. The slab source is plane parallel rays incident at any specified angle.

Scattering is assumed to be isotropic in the center of mass coordinate system for the plane geometry. Empirical formulas are used for the total cross sections. The calculation provides statistical estimates of the transmitted and reflected number current, flux, and energy as well as the heat deposition rate as a function of depth in the hydrogen. 


\section{RESTRICTIONS OR LIMITATIONS}

There are no known restrictions, at this time, implied by storage allocation.

7. TYPICAL RUNNING TIME

Running time for a problem in cylindrical geometry: neutrons for $2 \mathrm{MeV}$ to $1 \mathrm{eV}$ energy degradation takes about 3 minutes for 10,000 histories.

8. COMPUTER HARDWARE REQUIREMENIS

The code is designed for an IBM 7090 and 7094. A 32,768 core memory and three tape units are required.

9. COMPUTIER SCFTWARE REQUIREMENTS

The code was designed for the IBM FORTRAN II Monitor system. only input, output, and system tape assignments are made.

10. REFERENCE

M. O. Burrell, "Nuclear Radiation Transfer and Ileat Deposition Rates in Iiquid iydrogen," NA.SA IN D-1115.

11. CONTENIS (F CODE PACKAGE

The package contains the following items:

a. the referenced document,

b. a reel of magnetic tape on which is written in three files: the source card deck, binary card deck set up with control cards and input data for a sample problem, and output from the sample problam.

12. HCW TO OBTAIN PACKACTí

Inquiries or requests for the code package may be mailed to

CODES COCRDINAI'UR

Radiation Shielding Infurmation Center

Oak Ridge National Laboratory

P. U. Box X

(ak Ridge, 'iennesses j/8;0

or telophoned to

Area Code 615; 483-8611, extension 3-6944, or to

जIN $x x-615-483-6944$. 
Persons requesting the package should send a reel of magnetic tape to the above address.

13. DATE OF ABSTRACT

January 1966. 


\section{RSIC CODE PACKAGE CCC-3I}

1. NAME AND TITLE OF CODE

BREMRAD: External and Internal Bremsstrahlung Calculation Code.

2. CONIRIBUTOR

Chemical Laboratory, Battelle-Northwest Laboratories, Rich land, Washington.

The contributing installation was known as Hanford Atomic Products Operation, General Electric Company, while the code, BREMRAD, was in the process of development.

3. CODING ILANGUAGE AID COMPUTER

FORTRAN, IBM 7090 and 7094 .

4. NATURE OF PROBIEM SOLVED

BREMRAD was developed to calculate bremsstrahlung spectra for a thick target for use in shielding calculations.

5. METHOD OF SOLUTION

The code BREMRAD was developed for calculating external bremsstrahlung by the method of Bethe and Heitler as extended by Elwert, and internal bremsstrahlung by the method of Knipp and Uhlenbeck. Internal bremsstrahlung is defined to be radiation emitted when a beta particle leaves a nucleus. When a beta particle is absorbed, the radiation is called external bremsstrahlung. For each photon energy, the output contains the number of photons per beta from internal bremsstrahlung, and from external bremstrahlung with up to four atomic absorbers multiplied by the photon energy interval specified as input. There is an option for obtaining the results in different units. 
6. RESTRICTIONS OR LIMITATIONS

There is no available information at this time to indicate restrictions or limitations that may apply.

7. TYPICAL RUINIVIIVG TIME

Running time estimated for a typical problem: 3 minutes.

8. COMPUTER HARDWARE REQUIREMENTS

The code is designed for an IBM 7090 and 7094. A 32,768 core memory and three tape units are used.

9. COMPUTER SOFIWARE REQUTREMENTS

The code was written to be compiled and executed in the IBM FORTRAN II Monitor System. Only input, output, and system tape assignments are made.

10. REFERENCE

H. II. Van Tuyl, "BREMRAD - A Computer Code for External and Internal Bremsstrahlung Calculations," HW-83784 (September 1964).

11. CONTENTS OF CODE PACKAGE

The package contains the following items:

a. the referenced document,

b. a reel of magnetic tape on which is written in four files: the source card deck, the binary card deck set up with control cards and input data for a sample problem, Fermi Function data, and output from the sample problem.

12. HOW TO OBTAIN PACKAGE

Inquiries or requests for the code package may be mailed to CODES COORDINATOR

Radiation Shielding Information Center

Oak Ridge National Laboratory

P. O. Box $\mathrm{X}$

Oak Ridge, Tennessee 37830

or telephoned to

Area Code 615; 483-8611, extension 3-6944, or to

FTS $x x-615-483-6944$. 
31.3

Persons requesting the package should send a reel of magnetic tape to the above address.

13. DATE OF ABSTRACT

January 1966. 


\section{RSIC CODE PACKAGE CCC-32}

1. NAME AND TITLE OF CODE

CLOUD: Gamma-Ray Dose Rate from a Radioactive Cloud - Kernel Integration Code.

The above-named code is listed in the Argonne Code Center collection as Reactor Code Abstract 47.

2. CONIRIBUTOR

Atomics International, Canoga Park, California.

CLOUD was placed in the RSIC collection through the services of the Argonne Code Center.

3. CODING IANGUAGE AND COMPUTER

FORTRAN, IBM 709, 7090, and 7094 .

4. NATURE OF PROBLEM SOLVED

CLOUD was designed to calculate the external gamma-ray dose rate and total integrated dose resulting from the accidental release of radioactive materials to the atmosphere. Meteorological parameters such as wind velocity, lateral and vertical diffusion coefficients, stability parameters and the presence of physical boundaries such as a ground surface and a temperature inversion layer, are considered. Depletion of the cloud due to wash-out and fall-out has also been included.

The degree of hazard is estimated both from the standpoint of internal as well as external exposure.

5. METHOD OF SOLUTION

A Legendre-Gauss quadrature technique is used to perform the numerical integrations of the attenuation kernel over the source regions.

A two compartment continuous release model is assumed to simulate holdup of the source material. Decay of the source material is described either by the use of a simple parent-daughter decay scheme or by a Way-Wigner type relationship. Provisions have been made to permit the use of either empirical or calculated fission product decay data. 
6. RESTRICTIONS OR IIMITATIONS

No information on restrictions or limitations is available at this time.

7. TYPICAI RUNNING TIME

Formulas are given in the referenced report by which time may be estimated. The sample problems described took 6.32 and 1.38 minutes respectively.

8. COMPUTER HARDWARE REQUIREMENTS

The code was designed for the IBM 7090 and 7094. A 32,768 core memory and three tape units are required.

9. COMPUTER SOFIWARE REQUIREMENTS

The code was designed to compile and execute in the IBM FORTRAN II Monitor System. It may easily be made compatible with other FORIRAN systems. Input, output, and system tape assignments are made.

BCD output on punched cards is controlled by an input parameter. When using this option an assignment must be made for an auxout tape.

10. REFERENCE

D. S. Duncan, A. B. Speir, G. H. Anno, D. C. Kolesar, "CLOUD An IBM 709 Program for Computing Gamma-Ray Dose Rate from a Radioactive Cloud," NAA-SR-Memo-4822 (April 1959).

11. CONTENTS OF CODE PACKAGE

The package contains the following items:

a. the referenced document,

b. a reel of magnetic tape on which is written in four files: the source card deck, the binary card deck set up with control cards, a library of permanent data and input for a sample problem, BCD punched card output, and output from the sample problem. 
12. HOW TO OBTAIN PACKAGE

Inquiries or requests for the code package may be mailed to CODES COORDINATOR

Radiation Shielding Information Center

Oak Ridge National Laboratory

P. O. Box X

Oak Ridge, Tennessee 37830

or telephoned to

Area Code 615; 483-8611, extension 3-6944, or to

FTS xx-615-483-6944.

Persons requesting the code package should send a reel of magnetic tape to the above address.

13. DATE OF ABSTRACT

January 1966. 


\section{RSIC CODE PACKAGE CCC-33}

1. NAME AND TITLE OF CODE

SALOMON: Monte Carlo Gamma Transport Code (Laminated Slabs).

The code is also included in the ENEA Computer Programme Library and is listed as Abstract ENEA 062.

2. CONTRIBUTOR

Research Institute of National Defense, Stockholm, Sweden.

3. CODING LANGUAGE AND COMPUT'ER

FORTRAN, IBM 7090 and 7094.

The ENEA abstract states that "versions exist for the Ferranti Mercury and CDC 1604 computers."

4. NATURE OF PROBLEM SOLVED

SALOMON was developed to treat gamma-ray transport problems in multi-slab one-dimensional plane geometry. The program calculates the penetrating gamma-ray dose rate and energy deposition rate in a system of slabs of infinite extension and finite thickness. An isotropic monoenergetic volume source distribution is given point-wise. One source energy is calculated at a time.

5. METHOD OF SOLUTION

The Monte Carlo method of calculation is used with various transformation techniques. Importance sampling is used to modify the spatial and directional distribution of the source as well as the transport kernel. Two versions exist, one giving better penetration accuracy and one giving better energy deposition accuracy. All biasing is completely contained in the program and is automatically optimized.

6. RESTRICTIONS OR LIMITATIONS

The maximum number of slabs allowed in a system is 60 . The maximum number of materials allowed is 100 . 
The maximum number of values in the energy scale for presenting cross section data is 30 .

7. TYPICAI RUNNING TIME

Typical running time is about 15 minutes, depending on the problem and the desired accuracy.

Estimated running time of sample problem: 12 minutes.

8. COMPUTER HARDWARE REQUIREMENTS

The code was designed for the IBM 7090. Three tape units and a 32,768 core memory are required.

9. COMPUTER SOFIWARE REQUIREMENTS

The code is operable in the IBM Fortran II Monitor System. only A-Channel assignments, input, output, and system tapes are used.

The program may also be run in FORTRAN II under the IBSYS operating system on the IBM 7090 or 7094 .

10. REFERENCE

G. Ingstrom, "A User's Manual for Salomon, An IBM-7090 Code fur Gamma Transpont Calculations," FOA 4A-4403-411 (November 1964).

11. CONTENTS OF CODE PACKAGE

The package contains the following items:

a. the referenced report,

b. a reel of magnetic tape on which is written in three files: the source card deck, the binary card deck set up with control cards, input data for a sample problem, and output from the sample problem.

12. HOW TO CBTAIN PACKAGE

Inquiries or requests for the code package may be mailed to

CODES CCORDINATOR

Radiation Shielding Information Center

Cak Ridge National Laboratory

F. O. Box X

Cak Ridge, Tennessee 37830 
or telephoned to

Area Code 615; 483-8611, extension 3-6944, or to

FTS xx-615-483-6944.

Persons requesting the package should send a reel of magnetic tape to the above address.

\section{DATE OF ABSTRACT}

January 1966. 


\section{RSIC CODE PACKAGE CCC-34}

\section{NAME AND TITLE OF CODE}

TOPIC: $\mathrm{S}_{\mathrm{n}}$ Neutron Transport Code - Cylindrical Geometry •

The above named code is based on MIST (slab geometry, reported as IDO-16856) developed by Intranuclear Company, Clayton, Missouri, for Philiips Petroleum Company.

2. CONIRIBUTOR

Phillips Petroleum Company, Atomic Energy Division, Idaho Falls, Idaho.

3. CODING LANGUAGE AND COMPUTHER

FORIRAN, IBM 7040, 7090 and 7094.

4. NATURE OF PROBIEM SOLVED

The TOPIC code is designed to solve the one-dimensional Boltzmann equation in cylindrical geometry with up to six energy groups, two hundred and forty space points, forty regions, and anisotropic $\left(P_{1}\right)$ scattering.

The boundary conditions for each group can be independently specified and the flexibility of the specifications permit:

a. Perfect mirror reflection or symmetry.

b. Isotropic reflection (Lambert surface reflection).

c. Anisotropic diffuse sources by means of either a $P_{1}$ Legendre series or a short table of point values for the angular flux.

Independent specification of isotropic fixed volume sources for each group is also allowed.

As implied, both homogeneous and inhomogeneous problems are solved, and fissions can occur in either type of problem.

5. METHOD OF SOLUTION

TOPIC is an $S_{n}$ code which uses a combination of a direct method and an iterative method of solution of the Boltzmann transport equation. The direct method is used to solve for some of the 
angular flux points in each group and an inner iterative solution is used to solve for the others. The result is that most problems converge in as few outer iterations as diffusion theory solutions, and usually only one or two inner iterations need be performed.

The numerical approximation to the Boltzmann equation is a linear one with respect to variation in the space variable $r$ and one of the angular variables. Gauss quadrature is used to handle the second (polar) angular variable.

\section{RESTRICTIONS OR LIMITATIONS}

The TOPIC program is a package of four codes which allow different maximum numbers of intervals on the $\varphi$ halfspace with corresponding restrictions on the maximum number of mesh points allowed on the cylinder radius $r$. The number of mesh points allowed in the FORTRAN II and FORTRAN IV versions of TOPIC are listed below:

\begin{tabular}{|c|c|c|c|}
\hline \multirow[b]{2}{*}{ Code } & \multirow{2}{*}{$\begin{array}{l}\text { Maximum Number } \\
\text { of Intervals, } N \text {, on the } \\
\varphi \text { Halfspace }\end{array}$} & \multicolumn{2}{|c|}{$\begin{array}{l}\text { Maximum Number of } \\
\text { Mesh Points on the } \\
\text { Cylinder Radius } r\end{array}$} \\
\hline & & Fortran II & Fortran IV \\
\hline TOPIC 4 & 4 & 240 & 185 \\
\hline TOPIC 6 & 6 & 140 & 108 \\
\hline TOPIC 8 & 8 & 90 & 70 \\
\hline TOPIC 10 & 10 & 62 & 48 \\
\hline
\end{tabular}

Each code includes the capability of handling all lower numbers of angular intervals; for example, TOPIC 8 can handle 8, 6 , 4 , or 2 angular intervals.

The only version currently checked out by RSIC is TOPIC 4 in FORTRAN II. The sample problem for this version is included.

7. TYPICAL RUNNING TINE

An $S_{4}$ Problem with four groups of neutrons, 75 mesh points, and 3 Gauss quadrature points took 2.93 minutes on the IBM 7090 . 
8. COMPUIER HARDWARE REQUIREMENTS

The code may be run on the IBM 7040,7090 or 7094.

A 32,768 core memory and nine tape units are required.

9. COMPUTER SOFTWARE REQUIREMENTS

The code may be run as a four-link chain job on the IBM FORTRAN II Monitor System, or on the IBSYS Operating System in FORTRAN IV within the limitations set in item (6). The RSIC staff eliminated clock sampling and added an expanded IOU table to each chain link which assigns six tape units to A channel and three to B channel.

10. REFERENCE

G. E. Putnam, "Topic, A Fortran Program for Calculating Transport of Particles in Cylinders," DO-16968 (April 1964).

11. CONTENTS OF CODE PACKAGE

The package contains the following items:

a. the referenced document,

b. a reel of magnetic tape on which is written in five files: the source card decks for TOPIC-4 and new routines added ( 2 files); the binary card deck set up with control cards and input data for sample problem; the source cards to expand to TOPIC $-6,-8$, and -10 , and output from the sample problem.

12. HOW TO OBTAIN PACKAGE

Inquiries or requests for the code package may be mailed to CODES COORDINATOR

Radiation Shielding Information Center

Oak Ridge National Laboratory

P. O. Box X

Oak Ridge, Tennessee 37830

or telephoned to

Area Code 615; 483-8611, extension 3-6944, or to FIS $\mathrm{xx}-615-483-6944$. 
Persons requesting the package should send a reel of magnetic tape to the above address.

13. DATE OF ABSTRACT

January 1966. 


\section{RSIC CODE PACKAGE CCC-35}

1. NAME AND TITLE OF CODE

DIPSEA: Monte Carlo Dose Calculation - Isotropic Point Source in an Exponential Atmosphere.

2. CONTRIBUTORS

Technical Operations Research, Burlington, Massachusetts. MIT Lincoln Laboratory, Lexington, Massachusetts.

3. CODING LANGUAGE AND COMPUTER

FORTRAN and FAP; IBM 704, 709, 7070, and 7094.

4. NATURE OF PROBEEM SOLVED

DIPSEA was developed to determine the radiation dose resulting from a point isotropic gamma-ray source in an atmosphere of air whose density varies exponentially. The source may be monoenergetic or polyenergetic. A cylindrical geometry is assumed to describe the atmospheric region surrounding the point source. The assumed cylinder, divided into toroids, extends from $11 \mathrm{~km}$ to $100 \mathrm{~km}$ and has a variable radius that normally has a maximum limit imposed by statistical fluctuations inherent in Monte Carlo calculations. The code assumes the photon is lost after passing these boundaries.

The following are calculated: scattered, direct, and total dose $(\mathrm{KeV} / \mathrm{gm})$ in the center of toroidal cross section $(I, J)$; scattered, direct, and total dose (ion pairs $/ \mathrm{cm}^{3}$ ) at the same points; and the distance from point source to the center of the toroidal cross section $(I, J)$ in $\mathrm{km}$ and also in $\mathrm{gm} / \mathrm{cm}^{2}$.

\section{METHOD OF SOLUTION}

The code determines the contribution of the scattered dose at various positions from the gamma-ray source by the Monte Carlo method. The dose due to the unattenuated gamma rays is computed by the standard method: narrow beam attenuation divided by the square of the distance. 
The atmosphere is assumed to be divided into two zones; each zone has its own exponential expression for the density. The range of each zone is set equal to that altitude interval in which the gradient of the molecular-scale temperature is nearly constant.

Energies in the program are expressed in units of Compton wavelength. All interactions in the media are considered to be either Compton scattering or a pair production.

6. RESTRICTION OR LIMITATIONS

At this time there are no known restrictions or limitations implied by storage allocation.

7. TYPICAL RUNNING TIME

There are no statistics available to give a typical running time.

The sample problem (10,000 histories; $1.25 \mathrm{MeV}$ point source) ran for one hour on the IBM 7090 .

8. COMPUTER HARDWARE REQUIREMENTS

The code is designed for the IBM 704, 709, 7070, 7090 and 7094 computers with 32,768 core memory and three tape units.

9. COMPUTER SOFTWARE REQUIREMEITS

The code is operable in the IBM Fortran II Monitor System. Minor modifications would need to be made to run on other systems.

10. REFERENCE

Dominic J. Raso and Stanley Woolf, "Monte Carlo Program for Calculating Doses Resulting from an Isotropic Point Source in an Exponential Atmosphere," TO-B 64-12 (February 1964).

11. CONTENTS OF CODE PACKAGE

The package contains the following items:

a. the referenced document,

b. a reel of magnetic tape on which is written in three files: the source deck, the binary card deck set up with control cards and input data for a sample problem, and output from the sampie problem. 
12. HOW TO OBTAIN PACKAGE

Inquiries or requests for the code package may be mailed to CODES COORDINATOR

Radiation Shielding Information Center

Cak Ridge National Laboratory

P. O. BoX X

Oak Ridge, Tennessee 37830

or telephoned to

Area Code 615; 483-8611, extension 3-6944, or to

FTS $\mathrm{xx}-615-483-6944$.

Persons requesting the package should send a reel of magnetic

tape to the above address.

13. DATE OF ABSTRACT

January 1966. 


\section{RSIC CODE PACKAGE CCC-36}

1. NAME AND TITLE OF CODE

EMPIRE-2: Multi-Group Discrete Ordinate Transport Code Slab Geometry.

EMPIRE-2 has incorporated in it as modified segments the three RDR6 codes written by C. Dawson of the David Taylor Model Basin. Input preparation, output editing and slowing down segments were written at the contributing installation.

The original version of this code was written for the Philcc 2000 computer.

RSIC made necessary modifications to make it operable on the IBM 7090.

2. CONTRIBUTOR

Bettis Atomic Power Laboratory, Westinghouse Electric Corporation, Pittsburgh, Pennsylvania.

The code was placed in the RSIC collection through the services of TUG, the Philco Computer Users Group.

3. CODING LANGGUAGE AND COMPUTER

FORTRAN and TAC, Philco 2000

FORTRAN, IBM 7090.

The Philco 2000 version is available to domestic users from: TUG Executive Secretary, Philco Corporation, 3900 Welsh Road, Willow Grove, Pennsylvania.

4. NATURE OF PROBLEM SOLVED

EMPIRE-2 solves the multigroup neutron transport problem with slowing down in slab geometry via a discrete ordinate approximation. Its main function is to provide very accurate solutions to problems involving significant slowing down, absorption and leakage as standards against which approximate methods of wider applicability and lower cost may be compared. 


\section{METHOD OF SOLUTION}

The discrete ordinate method is used in this 7-segmented FORTRAN program. The cross sections, source and flux values are defined at lethargy points. A matrix formulation is used to establish pointwise scattering in sources which allow solution of the discrete ordinate approximation to the vector flux at that point.

\section{RESTRICTIONS OR LIMITATIONS}

EMPIRE limitations and features are:

1. Up to 200 lethargy groups (points) or up to 15 isotopes (see Logic Description for conditions).

2. Up to 12 compositions, 200 regions and 400 points.

3. Up to ten ordinates in the discrete ordinate approximation to the angular dependence of the vector flux.

4. Up to ten terms in the angular expansion of the differential scattering cross sections.

5. Reflecting or free boundaries only may be specified.

6. Arbitrary quadrature functions and weights may be input.

7. With the computed scattering-in and external sources to each group, the reaction rates are calculated correctly at that lethargy point. These rates are then assumed Iinear between groups in the EDIT segment for the integral over lethargy.

\section{ESTIMATED RUNNING TIME}

Estimated running time of sample problem: 12 minutes.

\section{COMPUTER IIARDWARE REQUIREMENTS}

A Philco 2000 or an IBM 7090 or 7094 may be used. A 32,768 core memory and 16 tape units are required.

\section{COMPUIER SOFIWARE REQUIREMENTS}

The code was designed for the BKS System for the Philco 2000 computer. The packaged version has been modified as follows:

Three library routines, LOADER, FIEXO, and IABIE, were eliminated; the TAC language was eliminated from the source or translated; the 7 -segment job was converted to a 7-link chain job; an expanded IOU 
table was included. The result is an IBM FORTRAN II Monitor System program, using 16 tape units, assigning 9 units to A channel and 7 to $\mathrm{B}$ channel. Input parameters control the number of chain links to be processed before problem termination.

10. REFERENCE

J. D. Butler, "Empire-1 and Empire-2: "Fortran Multigroup Discrete Ordinate Transport Codes to Solve Slab Geometries, "WAPDTM-436 (April 1964).

11. CONTENTS OF CODE PACKAGE

The package contains the following items:

a. the referenced document,

b. a reel of magnetic tape on which is written in four files: the source card decks, the binary card deck set up with control cards and input data for a sample problem, and output from the sample problem.

12. HOW TO OBTAIN PACKAGE

Inquiries or requests for the code package may be mailed to CODES CCORDINATOR Radiation Shielding Information Center Oak Ridge National Laboratory P. O. Box X Oak Ridge, Tennessee 37830

or telephoned to

Area code 615; 483-8611, extension 3-60.44, or to FTS xx-615-483-6944.

This code was developed at an installation sponsored by the Naval Reactors Division of the AEC, whose policy limits distribution to potential U. S. users. Foreign nationals interested in this code package should send their request through official government to government channels.

Persons requesting the package should send a reel of magnetic tape to the above address.

13. DATE OF ABSTRACT

January 1966. 


\section{RSIC CODE PACKAGE CCC-37}

1. NAME AND TITLE OF CODE

LIPRECAN I: Monte Carlo Two-Dimensional Neutron Penetration and Energy Deposition in Liquid Hydrogen.

This code is listed in the Argonne Code Center collection as Reactor Code Abstract 123.

2. CONTRIBUTOR

Advance Space Technology, Missile and Space Systems Division, Douglas Aircraft Company, Inc., Santa Monica, California.

3. CODIING LANGUAGE AND COMPUTER

FORTRAN and FAP, IBM 7090 and 7094.

4. NATURE OF PROBLEM SOLVED

LIPRECAN I computes the penetration and energy deposition of neutrons in liquid or gaseous hydrogen for use in nuclear rocket vehicle design. The code was designed to handle cylindrical and conical systems. A monodirectional point or beam source, parallel to the major axis of the system, may be used. Isotropic elastic scattering in the center-of-mass system is assumed and a hydrogen cross-section library is furnished.

Results given include the detailed distribution of both energy and neutron distribution as a function of axial penetration distance.

5. METHOD OF SOLUTION

Monte Carlo techniques are used to solve the neutron transport and heat deposition problem in two-dimensional geometry. The first collision distance may be selected from a uniform distribution or the standard exponential distribution. The other techniques used are standard. 


\section{RESTRICTIONS OR LIMITATIONS}

The following limits should be noted:

a. mesh sizes $50 \times 50$

b. incident spectrum 200 energy groups

c. energy range $14.0 \mathrm{MeV}$ to $.0001 \mathrm{eV}$; probably valid only to $.1 \mathrm{eV}$

d. library points 218 .

7. TYPICAL RUNNING TIME

Typical running times are on the order of .1 - .2 seconds per history depending on the initial particle energy and the cutoff energy.

8. COMPUTER HARDWARE REQUIREMENTS

The code was designed for the IBM 7090. A 32,768 core memory and four tape units are required.

9. COMPUTER SOFIWARE REQUIREMENTS

The code was designed to be compiled and executed in the IBM FORTRAIN II Monitor System. Standard input, output, system and auxout tape assignments are made. The auxout tape is used for binary information to be punched into cards for use in a possible restart. The restart procedure is controlled by an input parameter.

This is an all-FORTRAN code with the exception of three subroutines which are in FAP.

Input to LIPRECAN is accomplished through INPUT 1, the Douglas input package, which is coded in FORTRAN, and which is included in the package.

10. REFERENCE

R. II. Karcher, "The LIPRECAN I Code - A Monte Carlo Program for Two-Dimensional Neutron Penetration and Energy Deposition in Iicilid Hydrogen," SM 43594 (April 1963). 
11. CONTENTS OF CODE PACKAGE

The package contains the following items:

a. the referenced document,

b. a reel of magnetic tape on which is written in four files: the source card deck, the binary card deck set up with control cards and input data for a sample problem, binary data for restart of the sample problem, and output from the completed sample problem.

12. HOW TO OBTAIN PACKAGE

Inquiries or requests for the code package may be mailed to CODES COORDINATOR Radiation Shielding Information Center Cak Ridge National Iaboratory

P. O. Box X

Cak Ridge, Tennessee 37830

or telephoned to

Area Code 615; 483-8611, extension 3-6944, or to

FTS $\mathrm{xx}-615-483-6944$.

Persons requesting the code package should send a reel of magnetic tape to the above address.

13. DATE OF ABSTRACT

January 1966. 
RSIC CODE PACKAGE CCC-38

1. NAME AND TITLE OF CODE

TAEC: Spacecraft Trajectory and Environment Code.

\section{CONTRIBUTORS}

Nuclear and Space Physics, Aerospace Division, The Boeing Company, Seattle, Washington.

Bioastronautics Group, Biophysics Branch, Research and Technology Division, Air Force Weapons Laboratory, Kirtland Air Force Base, New Mexico.

TAEC was converted (1965) for the IBM 7044 by the DASA APOLIO Support Dept., General Electric Company, Daytona Beach, Florida. This version has also been made available to RSIC.

3. CODING IANGUAGE AND COMPUIER

FORTRAN, IBM 7044, 7094, and CDC 1604.

4. NATURE OF PROBLEM SOLVED

TAEC was designed to calculate proton and electron fluxes encountered by earth-orbiting satellites.

The program calculates the trajectory of the space vehicle and the characteristics of the radiation flux encountered. Trajectory points may be generated for circular, elliptic, or Hohmann transfer orbits.

The trajectory code may be used to select an orbit or trajectory incurring an acceptable radiation flux or flux rate; or a variety of B-L maps may be employed to determine the effect of the environmental model.

\section{METHOD OF SOLUTION}

The user supplies to the code description of a vehicle trajectory and radiation-environment data. The program calculates electron or proton flux rate and time-integrated flux along the trajectory. The general procedure is to give as input or calculate trajectory points and then compute radiation flux at these points. 
Given a description of the orbit and the point of injection, subject trajectory points are calculated as a function of time, using orbital flight equations. The trajectory points are converted to McIlwain's geomagnetic coordinates ( $B, L$, and $R, \lambda$ ).

Proton or electron flux at each point is determined by a table lookup and interpolation. Numerical integration (in conjunction with an interpolation scheme on $B$ and $L$ ) gives a timeintegrated flux for each point. A table lookup and interpolation on an array of spectral coefficients determines the spectral coefficients for the point. The flux at the point, dose-conversion factors, and the spectral coefficients are then used to determine dose rate and total dose at the point.

Angular distribution is determined for each trajectory point by solution of a pitch angle distribution function.

The code is designed so that new experimental data on the radiation environment and on the interaction of radiation with matter can be accepted.

The following general methods are followed:

1. calculation of the spacecraft trajectory in $B$, $L$, and $t$ coordinates,

2. devising a mathematical representation of the spaceradiation environment, including geomagnetically trapped radiation (Van Allen belts), solar particle event radiation, and galactic cosmic radiation;

3. determination of the radiation flux and energy spectra encountered in a given space mission.

\section{RESTRICIIONS OR LIMITATIONS}

There are no known restrictions implied by storage allocation.

7. TYPICAL RUNNING TIME

No statistics are available to determine typical running time. Estimated running time for the sample problem: 40 minutes. 
8. COMPUTER HARDWARE REQUTREMEITTS

The code was designed for the IBM 7094 and then made operable on the CDC 1604. A 32,768 core memory and 7 tape units are required.

Tapes are written in a form suitable for automatic graphing on a Universal Orthomat drafting machine (FORTRAN II version) and a Cal-Comp 570 digital incremental recorder (FORTRAN 63).

9. COMPUTER SOFTWARE REQUIREMEINTS

The packaged code has been checked out by RSIC on the CDC 1604 computer under the FORTRAN 63 CO-OP Monitor System. Four tape assignments, in addition to input, output and system tapes, are made. It can easily be made compatible with the IBM 7090 and 7094 computers, as it was originally written in FORTRAN II.

\section{REFERENCES}

John A Barton, B. W. Mar, G. L. Keister, W. R. Doherty, J. R. Benbrook, W. R. Sheldon, J. R. Thomas, K. Moriyasu and M. C. Wilkinson, "Computer Codes for Space Radiation Environment and Shielding," WL-TDR-64-71, Volume I and II (August 1964).

John A. Barton and G. I. Keister, "Symposium on Space Radiation Environment," D2-90684-1 (April 1965).

11. CONTENTS OF CODE PACKAGE

The package contains the following items:

a. the referenced documents,

b. a reel of magnetic tape on which is written in separate files: the BCD source card deck, the binary card deck, BCD input for a sample problem, and output from the sample problem.

12. HOW TO OBTAIN PACKAGE

Inquiries or requests for the code package may be mailed to CODES COORDINATOR Radiation Shielding Information Center Oak Ridge National Labcratory

P. O. Box X

Oak Ridge, Tennessee 37830 
or telephoned to

Area Code 615; 483-8611, extension 3-6944, or to

FTS $x x-615-483-6944$.

Persons requesting the code package should send a reel of magnetic tape to the above address.

13. DATE OF ABSTRACT

January 1966. 
RSIC CODE PACKAGE CCC-39

1. NAME AND TITLE OF CODE

PROP: Primary Proton Penetration Code

\section{CONIRIBUTOR}

Nuclear and Space Physics, Aerospace Division, The Boeing Company, Seattle, Washington.

Bioastronautics Group, Biophysics Branch, Research and Technology Division, Air Force Weapons Laboratory, Kirtland Air Force Base, New Mexico.

3. CODING IANGUAGE AND COMPUTER

FORIRAN; CDC 1604 and IBM 7094.

4. NATURE OF PROBLEM SOLVED

The primary proton penetration code was developed to predict radiation doses encountered in space missions. It may be used to determine the optimum vehicle structure and arrangement of internal equipment to provide maximum radiation shielding. It can determine the dose received by an astronaut at various body points when the vehicle is subjected to the incident radiations of the space environment.

The code calculates the absorbed radiation dose and energy spectmum resulting from protons that penetrate a shielding configuration. In addition, provisions are made to compute the LET spectra, local energy-loss dose, and semiconductor dislocation densities, all of which are defined in the referenced documents.

Doses and spectra may be calculated at points behind semiinfinite slab shields and at points totally surrounded by shielding. The doses are reported in units of tissue rads.

5. METHOD OF SOLUTION

The input data required by the program include the following: the incident proton-energy spectrum, the spectrum angular distribution, proton range-energy tables, a representation of the shielding 
configuration, the mean ionization potential of the tissue, lower bound of proton-output energy, and the tabulated response function to convert proton flux to defect densities. Using this information, calculations for semi-infinite slab shieldings and a vehicle analysis are performed.

In this code the primary protons are assumed to travel in a straight line and to continuously slow down. The equation describing the proton flux is reduced to quadrature and integrated directly. A geometry routine is included so that arbitrary particle geometry may be considered.

\section{RESTRICTIONS OR IIMITATIONS}

Assumptions made in the program include the following:

1. The dose $D$ absorbed by the receiver arises from the energy the incident proton flux loses by electron ionization. The energy losses from elastic and inelastic nuclear collisions are neglected.

2. The incident protons are assumed to maintain their original direction as they pass through the shield.

7. TYPICAL RUNNING TIME

No statistics are available to determine typical running time. Estimated running time for three sample problems: 1.5, 2.25 and 1.5 minutes respectively.

8. COMPUTER HARDWARE REQUIREMENTS

The code was designed for an IBM 7094 and then made operable on the CDC 1604. 20,098 core memory locations are used.

9. COMPUTER SOFTWARE REQUIREMENTS

The packaged code has been checked out by RSIC on the CDC 1604 computer under the FORTRAN 63 CO-OP Monitor System. The required 20,098 core memory is divided into 15,740 CCMMON storage locations and 4,358 locations for the instructions and other data storage. 
10. REFERENCES

John A. Barton, B. W. Mar, G. I. Keister, W. R. Doherty,

J. R. Benbrook, W. R. Sheldon, J. R. Thomas, K. Moriyasu and

M. C. Wilkinson, "Computer Codes for Space Radiation Environment

and Shielding," WL-TDR-64-71, Volume I and II. (August 1964).

John A. Barton and G. I. Keister, "Symposium on Space Radiation Environment," D2-90684-1 (April 1965).

11. CONTENTS OF CODE PACKAGE

The package contains the following items:

a. the referenced documents,

b. a reel of magnetic tape on which is written in separate

files: the BCD source card deck, the binary card deck, $B C D$ input for a sample problem, and output from the problem.

12. HOW TO OBTAIN PACKAGE

Inquiries or requests for the code package may be mailed to CODES COORDINATOR

Radiation Shielding Information Center

Oak Ridge National Laboratory

P. O. Box X

Oak Ridge, Tennessee 37830

or telephoned to

Area Code 615; 483-8611, extension 3-6944, or to

FTS $\mathrm{xx}-615-483-6944$.

Persons requesting the package should send a reel of magnetic tape to the above address.

13. DATE OF ABSTRACT

January 1966. 